\title{
The Role of Religion, Spirituality and Faith in the Processes of Significant Trauma and Recovery
}

\author{
By \\ Lynnette Hazel O’Brien
}

\begin{abstract}
A thesis
Submitted to the Victoria University of Wellington In fulfilment of the requirements for the degree of Master of Arts in Religious Studies
\end{abstract}

Victoria University of Wellington

2018 
Pag e | 2 


\section{Abstract}

For some people, religion, spirituality and faith (RSF) serves an important function, helping them deal with difficult everyday life challenges. This qualitative ethnographic study examines how and in what ways a group of Cantabrians engaged with RSF in dealing with diverse forms of significant trauma - from moments of crisis through to more extended processes of recovery. The research is located within the context of post-earthquake Christchurch, and is based on fieldwork undertaken in 2012-2013. It explores the experiences of respondents representing traditional Christian and nonorthodox, non-Christian faith paths. The thesis draws on data from participant stories to emphasise the subjective experience of RSF and trauma. It argues that in times of crisis, some people draw on RSF to help them address difficult life challenges. The study demonstrates the breadth, diversity and significance of such resourcing, as well as the sometimes surprising, unanticipated forms that this engagement with RSF may take. Contrary to theories that emphasise the marginalisation of religion during times of intense distress, the thesis shows that in varying moments of crisis, people for whom RSF is important, may draw on diverse forms of RSF as a matter of priority to help them.

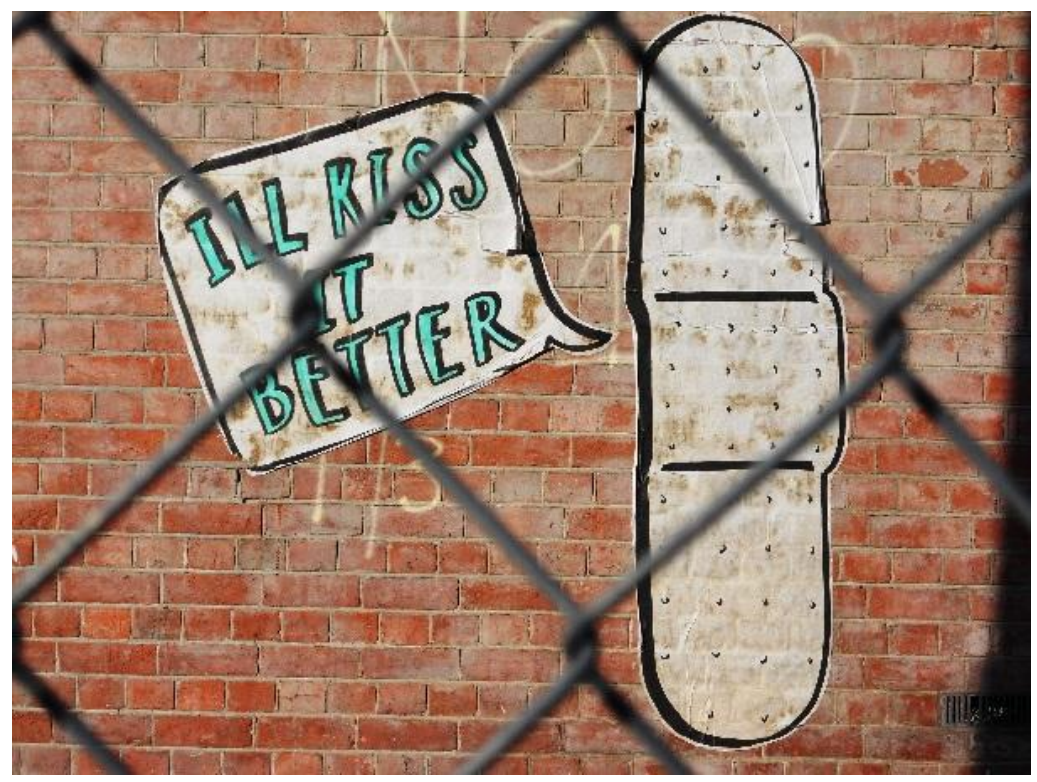

1.1 Painted exterior of Knox Presbyterian Church 


\section{Acknowledgments}

Thank you to my family; for your love, patience, support, and encouragement throughout my mature studies. Blessed Be!

A huge thank you also to my supervisor, Dr Geoff Troughton. Your wisdom and insight as I unravelled the many hours of field evidence, as well as your guidance of my thought processes and writing, is forever appreciated.

To all the respondents and unknown persons who shared their accounts with me, I thank you for your precious gifts of story. I carry them with me.

The Lord replied; My precious, precious child, I love you and would never leave you. During your times of trial and suffering, when you saw only one set of footprints ... that was when I carried you.

"Footprints in the sand" (unknown) 


\section{Contents}

Abstract 3

Acknowledgements $\quad 4$

Contents 5

Glossary $\quad 8$

Abbreviations $\quad 8$

Section 1: Introduction 9

1. Overview 11

1.1 Thesis Outline $\quad 11$

1.2 Key terms $\quad 12$

1.2.1 Religion, spirituality and faith (RSF) 12

1.2.2 Significant trauma 14

1.2.3 Recovery 16

1.3 Research context and background 16

1.4 Literature, theory and method 20

1.4.1 Maslow's hierarchy of needs 20

1.4.2 Key literature 22

1.4.3 Theoretical and methodological foundations 26

1.4.4 Insider-outsider researcher 28

2. Entering the field 31

2.1 Respondents 33

2.2 Respondent backgrounds and their Faith paths 35

2.2.1 Spiritualist Church 35

2.2.2 Paganism and Heathenism 38

2.2.3 Inclusive-Progressive Christianity 40

2.2.4 Hybrid Paths 43

2.3 Summary $\quad 46$ 
3. Prayer

3.1 Trauma and prayer studies $\quad 49$

3.2 Calling for help $\quad 50$

3.3 Meditation $\quad 54$

3.4 Not alone $\quad 57$

3.5 Listening, chatting and psychic experience 59

3.6 Prayer as Being-ness 63

3.7 Prayerful processing $\quad 64$

3.8 Conclusion $\quad 67$

4. Recovery through Ritual 69

4.1 Ritual studies and trauma 69

4.2 Fred's Inclusive-Progressive Presbyterian Church $\quad 71$

4.3 Eddy and Elspeth, Progressive Baptist Community $\quad 74$

4.4 Spontaneous ritual and contradictions 77

4.5 Ritual preparation and facilitation 80

4.6 Conclusion 82

5. Creative Exploration 85

5.1 Art and post-earthquake studies $\quad 85$

5.2 Creativity \& respondent faith paths 86

5.3185 White Chairs $\quad 87$

5.4 Art as renewal and recovery 90

5.5 Music \& poetry 92

5.6 Art and unresolved emotion 92

5.7 Conclusion $\quad 93$ 
6. Sense-making 95

6.1 Trauma and sense-making studies 95

6.2 Story and traumatic memory 96

6.3 Making sense through dreams and supernatural experience 98

6.4 RSF that hurts 100

6.5 Conclusion 101

7. Social support 103

7.1 Studies 103

7.2 Social support and hospitality 104

7.3 The absence of RSF social support 106

7.4 Pagan and New Age respondents 108

7.5 Support online 110

7.6 Challenge of support for solitaries 111

7.7 Spiritualist Church shuts its doors 113

7.8 Conclusion 117

8. Belonging and place 119

8.1 Studies 119

8.2 Inclusive-Progressive Church groups 120

8.3 Homelessness 121

8.4 Pagan and New Age respondents 122

8.5 A new whare $\quad 125$

8.6 A new land $\quad 126$

8.7 Conclusion 127

$\begin{array}{ll}\text { Section 3: Conclusion } & 129\end{array}$

$\begin{array}{ll}\text { Bibliography } & 133\end{array}$ 


\section{Glossary}

Magick: Used to differentiate between practitioners of religious magickal practise and magic as a media for entertainment

Progressive-Inclusive: Term adopted by some individuals and NZ parishes due to a debate over whether or not Progressive Christianity is truly "inclusive".

Reader: Person who "reads" divinatory tools (e.g. Tarot, Oracle cards, crystals) or gives a psychic or spiritual medium "reading".

Spirit: Can refer to Spiritual guides, dead loved ones, or other forms of perceived Spiritual/Supernatural support.

Spiritual Medium: Person who communicates with the dead. Often referred to as a "Medium."

The Craft: Umbrella term referencing diverse witchcraft traditions. Differentiates between those persons who self identify as Witches but whose religion is not Wicca. (Note: While all Wiccans are Witches, not all Witches are Wiccan e.g. Christian, ${ }^{2}$ Pagan or Eclectic Witch)

\section{Abbreviations}

RSF - Religion, Spirituality, and Faith

PTSD - Post Traumatic Stress Disorder

$\mathrm{NZ}$ - New Zealand
EQC - Earthquake Commission

PTG - Post Traumatic Growth

AUS - Australia

\footnotetext{
${ }^{1}$ Taussig, Hal, A New Spiritual Home: Progressive Christianity at the Grass Roots (Santa Rosa, California: Polebridge Press, 2006):133-4.

2 Rountree identifies NZ Christian Witches. Kathryn Rountree, Embracing the Witch and the Goddess: Feminist Ritualmakers in New Zealand, (London and New York: Routledge, 2004):40. Respondent “Unicorn" describes herself as an "eclectic".
} 


\section{Section 1: Introduction}

\section{Overview}

Anthropologist Clifford Geertz famously once said that 'the stories we tell ourselves about ourselves' reveal much about the way we interpret our collective and individual experiences of life. ${ }^{3}$ For some people religion, spirituality, and faith (RSF) plays a key role in helping 'ordinary people living ordinary lives', deal with what are sometimes 'extraordinary' collective and individual life experiences. ${ }^{4}$

One extraordinary life experience is significant trauma. Significant trauma can be understood as trauma that is ongoing, cumulative, and multifaceted. It can impact all aspects of an individual or group's social, economic, emotional, mental, physical, and spiritual worlds. ${ }^{5}$ In this thesis, I demonstrate that for some sectors of the community, RSF can be fundamental to the way people navigate significant trauma. The thesis examines trauma against the backdrop of post-earthquake Christchurch, in the period 2012-2013, focusing on the personal accounts of a group of Cantabrians from diverse faith paths. Their stories reveal a range of ways RSF is utilised during experiences of trauma and crisis. In the following analysis, RSF is demonstrated as a complex and multi-dimensional but nevertheless significant resource upon which my informants drew to address aspects of their experiences of significant trauma.

My own experience of significant trauma, and the pivotal role that RSF played during key moments in my life, is an important driver behind my initial interest in this project. Suffering from cumulative significant trauma, Post-Traumatic Stress Disorder (PTSD), delayed onset PTSD and limited social, economic, and personal agency; hybrid forms of traditional Christian and non-orthodox non-Christian faith paths were fundamental to the way I dealt with those experiences. Yet, despite widespread acceptance among mental health scholars that some people draw on aspects of

\footnotetext{
${ }^{3}$ Clifford Geertz, The Interpretation of Cultures (New York, NY: Basic Books, 1973): 448-450.

${ }^{4}$ M.D Stringer, Contemporary Western Ethnography and the Definition of Religion (London \& New York: Continuum International Publishing Group, 2008): 114.

${ }^{5}$ Kent Drescher and David W. Foy, "When Horror and Loss Intersect: Traumatic Experiences and Traumatic Bereavement," Pastoral Psychol, 59 (2010): 148, 154; J.L. Herman, Trauma and Recovery, Third Edition, (New York: Pandora Press, 2001): 51.
} 
religion to help them during difficult periods, I observed that scholars' assertions about the ways that RSF functions in such settings starkly contrasted my own experiences. The above disparity sparked a desire to explore other peoples' accounts of RSF and personal trauma.

This thesis adopts an ethnographic approach to analysing the subjective experience of RSF and significant trauma. I first began fieldwork in 2012-2013, but was forced to set the project aside for a period owing to heavy work demands. The present thesis draws upon the data gathered during that period and is therefore located within the context of post-earthquake Christchurch, despite its completion in 2018. The thesis is guided by a central question: how and in what ways do people for whom RSF is important draw on forms of RSF to help them mitigate the impact of significant trauma and deep distress?

The study is underpinned by two key suppositions. First, it is my contention that in times of crisis, some people draw upon RSF to help them address difficult life challenges such as significant trauma. This first supposition assumes that religion is a "lived" experience, entwined with everyday concerns. ${ }^{6}$

My second supposition is that RSF is employed in ways that are often overlooked in discussions on religion and trauma, both in academic and more popular literature. ${ }^{7}$ As an auxiliary aspect of this claim, I suggest that some people draw on both traditional Christian and non-orthodox non-Christian beliefs and practises to help them deal with difficult life challenges. That is, that the boundaries between traditional Christian and non-orthodox non-Christian belief and practice are more porous than is often recorded in studies of religion in New Zealand. ${ }^{8}$ Moreover, these porous boundaries are salient for analysing the ways RSF functions in 'everyday life', including in the context of trauma. For example, while scholars accept that it is

\footnotetext{
${ }^{6}$ I like Stringer's notion of religion-as-lived in terms of the way it functions for 'ordinary people living their ordinary lives and coping with all their troubles'. Stringer, Contemporary Western Ethnography, 114.

${ }^{7}$ McGuire, Marti and Stringer all argue a tendency among scholars to 'ignore' or disregard as 'folk 'religion, ways in which individuals draw on RSF in their everyday lives, that is less visible and therefore not so easily 'measured', or appears to deviate from traditional and/or accepted religiosities. Meredith B McGuire, Lived Religion: Faith and Practice in Everyday Life (Oxford, New York: Oxford University Press, 2008), 3-4, 12, 186; Gerardo Marti, "Present and Future Scholarship in the Sociology of Religion," Sociology of Religion 75 no.4 (2014):504-506, 508; Stringer, 110, 113-114.

${ }^{8}$ McGuire asserts that 'extensive religious blending and within-group heterogeneity are the norm, rather than the exception'. McGuire, Lived Religion, 187. Stringer similarly argues that as a 'coping strategy', the mutually drawing on traditional Christian and non-orthodox non-Christian beliefs and practises has been commonplace but less visible until more recently. Stringer, 110.
} 
commonplace for individuals and groups to draw on prayer and ritual as sources of strength during times of trial and consternation, it is only when exploring the more permeable beliefs and practises engaged in peoples' everyday lives that other forms of communication with deity/divine (or ritual expression) such as constant communication ("chatting"), spells, artistic outpourings of grief, and psychic experience; some of which are often omitted from discussions of the above, come to the fore. That is not to say that the practises are not known by scholars. Rather, they are not often included in current studies on religion and mental health, trauma, disaster, resilience, or religion in New Zealand.

\section{$1.1 \quad$ Thesis Outline}

The aim of this thesis is to examine the way in which respondents, following diverse faith paths, drew on forms of RSF - if at all - to assist them to address a broad range of trauma, deep grief and loss experiences. Trauma and grief ordeals were not clinically determined; some occurred prior to the events of the Canterbury earthquakes, and respondent narratives reflected a broad spectrum of trauma, from the significant to the significantly less so. This diverse representation was deliberate. Drawing on data from the field, I was able to clearly identify a strong correlation between the more intense the trauma experienced and the higher propensity that an individual or group was likely to engage RSF (in various forms) to help them during crisis events or as an integral aspect of their recovery process.

The thesis structure is divided into three distinct sections to differentiate between the introduction and fieldwork process, data and findings collected from my time in the field, and concluding thoughts and analysis. Throughout the thesis, images taken during my time in the field are included. A number indicate the extent of damage and effects - of the Canterbury earthquake on Christchurch RSF communities. Others relate directly to facets of the themes discussed in section two.

In section 1: Introduction; I clarify the central terms, significant trauma and RSF, and introduce the context of post-earthquake Christchurch. I discuss an encounter in the field that heavily influenced a redirection of my original research focus to those 
individuals dealing with (or recovering from) traumas and grief not directly related to the collective experience of the Canterbury disaster, yet occurring simultaneously to the earthquake events. I address the issue of traumatic experience as determined by the respondents, and consider the literature that informed my research, and the theory of postmodern interpretivism which underpins methodology and method. I highlight my position as an insider-outsider researcher. I outline the fieldwork undertaken, the respondents interviewed, and discuss the reasons for their inclusion in my study. I acquaint the faith-paths and background trauma stories of the research participants, accentuating the value of RSF in their lives.

Section Two: Analysis of Application of RSF Resources; follows the data collected and interpreted from my two visits to Christchurch in 2012 and 2013. Six key themes emerged inductively on reflection of fieldwork data. They are: Prayer, Recovery through Ritual, Creative Exploration, Sense-making, Social Support, and Belonging and Place. The themes highlight the ways RSF, in a variety of guises, functioned for respondents during pivotal periods in their trauma and recovery journeys. The beneficial impacts and challenges of the RSF tools and resources, from the perspective of the respondents, are scrutinised to consider occasions where RSF was employed more fervently or set aside in favour of more urgent concerns.

The final section: Conclusion; incorporates concluding comments and analysis.

\section{$1.2 \quad$ Key terms}

This thesis is underpinned by certain key terms and concepts that require clarification. They include notions of religion, spirituality and faith (RSF), and significant trauma.

\subsubsection{Religion, spirituality and faith (RSF)}

RSF (for religion, spirituality and faith) is a term I employ as a way of referring collectively to a broad range of religious phenomena and is not indicative of any specific community, or group that identifies itself by this terminology. Scholarly 
definitions for the individual terms "religion", "spirituality" and "faith" are diverse and contentious, even for some of my respondents. For the purposes of this study, I define "religion" as those behaviours, beliefs and activities that occur within the context of an organised spiritual community, such as a Church, Temple, or Grove. "Spirituality" refers to a personal experience and way of life that provides an individual with meaning and purpose of life. This may or may not exist within the context of an organised religious community. "Faith" is defined as a strong conviction or belief in something or someone that is held either by a group or an individual and relates to a belief pathway or tradition.

According to McGuire, the 'diverse', often contradictory, 'complex and ever-changing' religion-as-lived experience is modelled on the subjective, personal conceptualisation of the individual. ${ }^{9} \mathrm{Not}$, 'as little versions of the institutional model of religion'. ${ }^{10}$ My own construction of the term RSF is similarly modelled on respondent perspectives and assertions, and my observations in the field. Specifically, the acronym "RSF" is an attempt to address (and respect) a discomfort among my respondents for the term religion, preferring instead the terms spirituality and faith. Robbie and Barney explained:

One of the things that I found hit me amongst your material was constantly this word religion and I wanted to put Faith there. I very rarely use that word (Religion) now. (Robbie)

Yeah, it's like a naughty swear word really. It describes "institution" for me. (Barney)

... In the negative. (Robbie)

Like Robbie, I did not use the term religion to describe my faith path, until I entered university, suggesting a possible disconnect between the ways religion is understood by scholars of religion and the people they study - for whom RSF is a lived experience.

The terms traditional and non-orthodox also appear in this research, and are similarly problematic. In this study I use these terms purely for the purposes of

\footnotetext{
${ }^{9}$ McGuire, 185.

${ }^{10}$ Ibid.
} 
demarcation between organised Christianity on the one hand, and Spiritualist, Pagan, Heathen, Wiccan, The Craft, ${ }^{11}$ and New Age independent faith paths, on the other. The term hybrid identifies those participants who draw on a combination of beliefs and practises from both traditional and non-orthodox faith paths. ${ }^{12}$

\subsubsection{Significant trauma}

Mental health scholars 'conservatively' estimate a $50 \%$ chance of people experiencing some form of serious trauma or 'severe life stressor' in their lifetime. ${ }^{13}$ Significant trauma is my own working definition. It is used to distinguish from other forms of trauma, in that significant trauma is experienced repeatedly, over an extended period of time and encompasses a broad range of traumatic experience. People who experience this more prolonged and complex form of distress can suffer mentally, physically, socially, politically, economically, and spiritually. ${ }^{14}$ The effects are recurrent, can be overwhelming and cumulative. ${ }^{15}$ Recovery can be difficult for those affected, and sufferers are identified as at potential risk of developing posttraumatic stress disorder (PTSD). ${ }^{16}$

Importantly, there appears to be no agreed terminology or definition for significant trauma. Notwithstanding, the experience of significant trauma is most commonly the result of either:

1) A sudden, unexpected singular or series of events;

2) Expected but 'non-normative' trauma or prolonged abuse; ${ }^{17}$ or

3) Cumulative or recurrent situations involving 'intermittent shock trauma and ongoing strain'. ${ }^{18}$

\footnotetext{
${ }^{11}$ Umbrella term for diverse Witchcraft traditions. Includes men and women who self-identify as Witches but whose religion is not Wicca.

${ }^{12}$ McGuire prefers 'hybridity' to 'syncretism' to describe the 'social practise' of 'eclectically pasting together pre-existing bits and pieces of meaning and practise'... that 'may appear disparate to an outside observer but.. make sense and are effective in his or her world of meaning and experience'. McGuire, 195-200.

${ }^{13}$ Drescher and Foy, 147-8.

${ }_{14}^{14}$ Dresher and Foy, 148, 154; Herman, Trauma and Recovery, 51.

${ }^{15}$ Harold P. Blum, "Psychic Trauma \& Traumatic Object Loss", Journal of the American Psychoanalytic Association 51 (2003): 416.

${ }^{16}$ Drescher and Foy, 151-2.

${ }^{17}$ McCann and Pearlman refer to "expected but non-normative trauma events" as those events that are "expected by the individual, such as ongoing incest, but which, from the perspective of the larger society, are non-normative'. Lisa McCann and Laurie Anne Pearlman, Psychological Trauma and the Adult Survivor: Theory, Therapy and Transformation (London \& New York: Brunner-Routledge, 1990):10.

${ }^{18}$ Blum, "Psychic Trauma”, 416.
} 
Mental health studies assert that those affected by significant trauma can suffer serious adverse long term psychological, psychosocial, and physiological harm. ${ }^{19}$ Victims may report feelings of being overwhelmed, frightened and cognitively fragmented; a sense of loss of personal agency, or helplessness. ${ }^{20}$ Crisis situations can be felt as beyond one's ability to control, dangerous, or potentially life threatening. ${ }^{21}$ Additionally, prolonged and overwhelming trauma experiences can rupture an individual or group's sense of place and belonging, resulting in mental, physical, social and spiritual isolation. ${ }^{22}$

One complication is that significant trauma is not always instantly identifiable as trauma, potentially exacerbating the aforementioned senses of isolation, limited agency, and feelings of being overwhelmed. ${ }^{23}$ Indeed, new discoveries in mental health have deduced that 'many individuals who coped at the time of their traumatic exposure became unwell at a later date', developing symptoms of PTSD or 'delayed/late onset PTSD' that 'did not initially meet the diagnostic criteria for an acute distress disorder'. ${ }^{24}$ Moreover, recent studies identified that delayed onset PTSD in some cases developed into less readily recognisable physiological forms of trauma, such as 'fibro myalgia, irritable bowel, chronic fatigue', 'cardiovascular disease', or other seemingly unrelated symptoms of psychological trauma, making the condition difficult to diagnose or treat. ${ }^{25}$ Additionally, 'progressive escalations of distress[es]' have been found to emerge much more slowly than previously known, after a long post-trauma duration. ${ }^{26}$ Alternatively, old unresolved traumas are now understood to re-emerge, triggered by new, seemingly unrelated, 'adversities'. ${ }^{27}$ Either way, those affected can feel irrevocably changed post-experience. ${ }^{28}$

In the absence of an agreed term for this complex phenomenon, I define significant trauma as:

\footnotetext{
19 Herman, 34-5; Alexander C. McFarlane, "The Long-Term Costs of Traumatic Stress: Intertwined Physical and Pyschological Consequenes," World Psychiatry 9 (2010): 3-4.

${ }^{20}$ Herman, 33; Yuen, Angel. "Less Pain, More Gain: Explorations of Responses versus Effects when Working with the Consequences of Trauma." Explorations: An E-Journal of Narrative Practice 1 (2009): 8.

${ }^{21}$ Herman, 34.

${ }^{22}$ Ibid, 51

${ }^{23}$ Peres, Julio F.P, Alexander Moreira Almeida, Antonia Gladys Nasello, and Harold G. Keonig. "Spirituality and Resilience in Trauma Victims." Journal Religion and Health 46 (2007): 346.

${ }^{24}$ McFarlane, 3,8, 9.

${ }^{25}$ Ibid, 6 .

${ }^{26}$ Ibid, 3,6.

${ }^{27}$ Ibid 3,8.

${ }^{28}$ Ibid, 4 .
} 
Multifaceted, complex, aggregate trauma, stress and overwhelming grief resulting from either non-normative or prolonged abuse, or a series of sudden, unexpected, recurrent, or cumulative events involving intermittent shocks and/or ongoing strain.

\subsubsection{Recovery}

Clinical psychiatrist J.L. Herman asserts that 'trauma destroys the social systems of care, protection, and meaning that support human life'. ${ }^{29}$ Those same systems need to be reconstructed in the recovery process. ${ }^{30}$ Yet, the length of time and the way an individual recovers will be different for everyone ${ }^{31}$ As with trauma and grief, recovery is not therefore clinically diagnosed in this thesis. Rather, the term "recovery", is used in this thesis to stress the experience of movement from trauma, loss, grief, towards healing as a process during which RSF may be employed in a variety of ways, as part of that process, including during crisis events.

\subsection{Research Context and Background}

Post-earthquake Christchurch was chosen as an ideal research location because many Cantabrians - including my respondents - were dealing with the impacts of the 4 September 2010 and 22 February 2011 Canterbury earthquakes, as well as thousands of subsequent aftershocks. Initially, I wanted to know how people, for whom RSF was important, drew on RSF and in what way (if indeed they drew on RSF at all), during the earthquake events and in the immediate aftermath. The specific time period of 2012-2013 was chosen because participant memories would still be relatively fresh. Aftershocks were ongoing and the February 22 earthquake had happened only fifteen months prior to my visit.

\footnotetext{
29 Judith L Herman, “Recovery from Psychological Trauma”, Psychiatry and Clinical Neurosciences 52, no. S1 (1998) https://doi.org/10.1046/j.1440-1819.1998.0520s5S145.x

${ }_{30}$ Herman, "Recovery from Psychological Trauma".

${ }^{31}$ Ibid.
} 
On 4 September 2010, a magnitude 7.1 earthquake shook Canterbury at 4:35am. ${ }^{32}$ To the relief of many, and despite reported damage to homes and buildings, no Cantabrians were injured or killed. ${ }^{33}$ However, on Tuesday 22 February 2011 at $12.51 \mathrm{pm}$, central Christchurch was brought to its knees by a magnitude 6.3 earthquake. ${ }^{34}$ With the earthquake's epicentre near Lyttelton, on a shallow fault line just $10 \mathrm{~km}$ southeast of Christchurch's central business district, this time 185 people tragically lost their lives. ${ }^{35}$ Amid the devastation, 'several thousand' Cantabrians were badly injured, displaced from their homes, or were living in damaged, unsafe situations separated from loved ones, family, schools, churches, and communities. ${ }^{36}$ Some residents found themselves without an income or ability to return to work, and rapidly increasing debt. ${ }^{37}$ Others battled ongoing disputes with insurance companies and the government's Earthquake Commission (EQC) to have their homes rebuilt or repaired. ${ }^{38}$

In the aftermath of both earthquakes, aftershocks continued to plague Christchurch and the wider Canterbury region. By September 2012, GNS Science had recorded more than 11,200 aftershocks since the September 2010 earthquake, adding to peoples' already stressed nerves, strained relationships, and unstable property situations. ${ }^{39}$ Conterminous to the earthquake chaos, some Cantabrians were dealing with other difficult life challenges, some of which were completely unrelated to the earthquakes.

32 GeoNet, "M7.1, Darfield (Canterbury), 4 September 2010", EQC and GNS Science, http://info.geonet.org.nz/display/quake/M+7.1,+Darfield+(Canterbury),+4+September+2010 (accessed November 2016).

${ }^{33}$ Ibid; Rowney, Casey, Pantea Farvid, and Chris G.Sibley. "'I laugh and say I have 'Earthquake Brain!'": Resident responses to the September 2010 Christchurch Earthquake." NZ Journal of Psychology 43, No. 2 (2014): 4.

${ }^{34}$ New Zealand History, Nga korero a ipurangi o Aotearoa, "Christchurch earthquake kills 185". (Ministry for Culture and Heritage) http://www.nzhistory.net.nz/page/christchurch-earthquake-kills-185 (accessed October 2016).

${ }^{35}$ Ibid.

${ }^{36}$ New Zealand History; Potter et al determine injuries totalled 7171 people. S.H. Potter, J.S. Becker, D.M. Johnston, and K.P. Rossiter, "An overview of the impacts of the 2010-2011 Canterbury earthquakes", International Journal of Disaster Risk Reduction 14 (2015):10, 12.

${ }^{37}$ Potter et al. "An Overview", 12.

38 Bayer, Kurt "Cantabrians still struggling to cope with quake effects - research", New Zealand Herald, http://www.nzherald.co.nz/nz/news/article.cfm?c id=1\&objectid=11275709 (accessed October 2016)

New Zealand Herald, "Christchurch hit with more than 10,000 quakes since 2011", https://www.nzherald.co.nz/nz/news/article.cfm?c id=1\&objectid=11593554 (22 February 2016); Otago Daily Times, “11,000 Aftershocks since Christchurch Quake," https://www.odt.co.nz/news/national/11000-aftershocks-christchurchquake (4 September 2012). 
I travelled to Christchurch on two separate occasions. My first trip was for three days from Friday 11 May 2012 to Monday 14 May 2012. The duration of my second trip was two weeks, from Tuesday 2 July 2013 to Monday 15 July 2013. During my first visit to Christchurch in May 2012, a woman complained;

There are other things happening besides the earthquakes. I'm sick of talking about the earthquakes. People talk about the earthquakes like they talk about the weather. We still have to get on with our lives and deal with other things. ${ }^{40}$

The woman's comments really struck a chord with me. Over the course of my visits in 2012 and 2013 I began to notice just how many of my respondents were dealing with issues not directly related to the earthquakes. Some traumas were historical, ostensibly re-triggered by the earthquake events. Others appeared affected by multiple compounded stressors: social, economic and spiritual isolation, overwhelming grief, and ongoing strain. Meeting these people had a significant impact on the direction of my research.

In my investigation of the literature I noted that studies on disaster events tended to focus entirely on the disaster itself, and its impact on communities and individuals, with little to no attention on any parallel concerns that might be taking place at the same time. Articles on trauma and religion tended to reflect people suffering primarily at the extreme end of the trauma spectrum, rather than exploring multiple levels of trauma severity. Additionally, while emergent post-earthquake studies focussed on the "resilience" of Cantabrians, acknowledging that RSF was one factor among many coping and recovery mechanisms for Cantabrians, ${ }^{41}$ few articles considered how and in what ways RSF functioned to buffer trauma and facilitate recovery in practical everyday terms. More recently, the earthquake crisis has been identified as associated with the re-emergence of historical trauma concerns. ${ }^{42}$

\footnotetext{
${ }^{40}$ Conversation with dreaming workshop participant during teabreak 2012. Paraphrased as I wasn't able to write in my field note book at the time.

${ }^{41}$ Louise Thornley, Jude Ball, Louise Signal, Keri Lawson-Te Aho, Emma Rawson. "Building Community Resilience: Learning from the Canterbury earthquakes." Final Report to Health Research Council and Canterbury Medical Research Foundation. (2013): 38.

42 Olivia Carville, "Forgotten Victims: The Hidden Toll of the Christchurch Earthquakes," nzherald.co.nz (18 April 2016) http://www.nzherald.co.nz/nz/news/article.cfm?c id=1\&objectid=11622371
} 
Kotuku, a spiritual director I interviewed in 2012 similarly highlighted clients struggling with historical trauma and deep grief issues that had been triggered by the earthquakes. ${ }^{43}$ According to Kotuku, people were finding it difficult to understand what was happening to them and why. Unable to get the help they needed through traditional Christian RSF channels, some clients sought non-orthodox non-Christian RSF methods to help them. Despite this, no earlier studies examining aspects of the Canterbury quakes identified complex traumatic experience or the role of RSF (including minority, non-Christian, or non-orthodox forms) in helping people mitigate the all-encompassing effects.

It is important to point out that the communities, respondents and interviewees included in this study were not clinically diagnosed. The intensity of trauma is subjective to the experience of the respondent and therefore not classified on the basis of clinical, scientific analysis of criteria. Rather, my study is guided by the degree to which an individual (or group) felt traumatised, compromised, isolated, and unsupported in their experience, and drew on forms of RSF to help them. Moreover, for ethical, health and safety reasons, I also could not interview people presently suffering - or exhibiting symptoms of - extreme traumatic experience. Nonetheless, in order to pursue my study, a comparison of diverse distress was necessary. For this reason, respondent samples represent a spectrum of trauma causation and severity; including those respondents who were intimately involved in the significant traumas of others. In each case, the experience of trauma is "significant" according to the definition supplied above, though intensity varied, with some traumas independent of the direct impact of the Canterbury earthquakes. Those traumas occurred prior to, or ran concurrently with, the 2010-2011 earthquake events.

\footnotetext{
${ }^{43}$ Contracted to relationship services prior to the earthquakes, Kotuku works primarily with people "who have come to the end of [Christian] institutional life."
} 


\subsection{Literature, theory and method}

The following section outlines some of the theoretical underpinnings of my thesis, the literature it interacts with, and a basic description of my method.

\subsubsection{Maslow's hierarchy of needs}

In his influential article, 'A Theory of Human Motivation', Arthur Maslow argued that in moments of extremity, people seek food, shelter, water and safety, to the exclusion of all else, including religion. ${ }^{44}$ For Maslow, religion, along with love, community and respect, were 'fripperies' and 'unimportant' because 'they fail to fill the stomach'. ${ }^{45}$ I recognise that Maslow's argument centred on extreme human hunger and deprivation and this study does not attempt to equate the trauma experiences of my respondents with Maslow-type extreme hardship and deprivation. Moreover, the experiences of some of my respondents are sustained over an extended period of time; much longer than envisaged by Maslow. They are also representative of everyday extra-ordinary and stressful life challenges, quite different from Maslow's examples of acute human suffering. Nonetheless, Maslow's theory continues to influence works examining facets of trauma and mental health in the present day. Consequently, there is a risk that Maslow's position can be overgeneralised to encompass all situations of distress and cumulating crisis. There is a danger in that religion may be deemed irrelevant to people suffering a variety of traumatic situations and for whom RSF is central to their lives and well-being. Therefore, contra to Maslow and those scholars who apply his theory to the field of trauma, I contend that in varying moments of crisis, people for whom RSF is important, may draw on diverse forms of RSF as a matter of priority to help them address situations of urgency, and in ways that may be currently less understood. Compelling examples included in this study support my position, comparing other situations where RSF was set aside in favour of more urgent needs.

Hilary Abrahams' Rebuilding Lives after Domestic Violence: Understanding Longterm Outcomes' was an initial inspiration for exploring Maslow as a thesis argument. Abrahams points to Maslow's theory of needs as a useful tool for understanding 'the way in which domestic violence and abuse undermines every aspect of [a woman's

\footnotetext{
${ }^{44}$ Arthur H. Maslow, "A Theory of Human Motivation”, Psychological Review 50 (1943): 373.

${ }^{45}$ Maslow, "A Theory of Human Motivation", 374.
} 
life] and their determination to survive and reach out to others' ${ }^{46}$ Drawing on Maslow's structure as a guideline, Abrahams demonstrates how, as a result of domestic abuse, women lose not only a sense of 'personal identity, destruction of confidence and self-esteem, isolation from potential support systems, and the growth of fear and uncertainty', but also 'for some, even access to basic [physiological] needs for survival (e.g. food, water, clothing and shelter) had been controlled and denied'. ${ }^{47}$ Through a process of recovery, and shear 'determination to survive, to protect themselves and their children....and take positive action..to move forward in their lives', those needs of physiology, safety, belonging, and self-worth, as highlighted by Maslow, would need to be reclaimed and (slowly) rebuilt. ${ }^{48}$ It is important to note that Abrahams does not mention RSF at all as a potential resource in the survival stories of her women.

Like Abraham's women, my own experience of long term domestic abuse resulted in the loss of my home, sense of safety, power and control, connections to family and community, and systems of support. At times access to basic needs of shelter, and most especially food, were tenuous. Yet, throughout my ordeal, I drew heavily - and often instinctively - on forms of RSF, as my primary means of coping, sense-making, and accessing the aforementioned basic needs to survive. RSF played a fundamental role in my process of reclaiming and rebuilding my life. Maslow, it seemed to me, had overlooked a core criteria, pertinent to some victims of trauma. In effect, Maslow had secularised survival.

There can be a tendency to discount Maslow's theory as old, out of date or irrelevant and the intention of this thesis is not to test or challenge Maslow's theory. Acknowledging his continued influence in the present-day, my aim is to draw on Maslow's assertions as a benchmark for examining what role, if any, religion, spirituality and faith (RSF) have to play in addressing a broad range of everyday extra-ordinary experiences of trauma, loss, deep grief and recovery.

My premise is shaped by the idea that for some people, religion is a lived experience. The term "lived" experience (or, religion-as-lived) refers to the way

\footnotetext{
${ }^{46}$ Hilary Abrahams, Rebuilding Lives after Domestic Violence: Understanding Long-Term Outcomes, (USA: Jessica Kingsley Publishers, 2010): 22.

${ }^{47}$ Abrahams, Rebuilding Lives after Domestic Violence, 23

${ }^{48}$ Abrahams, 23-24.
} 
ordinary people practise, experience, and express their RSF in their everyday lives, dealing with everyday challenges, including significant trauma. ${ }^{49}$ Often traumatic situations and the role lived religion plays in grappling with them can involve long periods of isolation. ${ }^{50}$ It is the subjective experience of RSF in trauma recovery therefore, that underpins the epistemological approach of my project, and informs my methodology.

\subsubsection{Key literature}

In recent decades the role of religion in trauma recovery has begun to receive greater recognition by scholars and mental health clinicians. A turn from within the mental health arena in 'the last twenty years' has led to a notable increase in largescale quantitative inquiries seeking to incorporate RSF into clinical recovery practises. ${ }^{51}$ Yet small-scale, mental health and scholarly religion qualitative studies exploring the subjective experience of religion and trauma remain limited. ${ }^{52}$ Furthermore, as Tse et al. highlight, those studies that do exist have often taken place in the North American context, focusing on conservative Christian models of RSF that often bear little resemblance to New Zealand's socio-religious context. ${ }^{53}$

During my undergraduate study, I was inspired by M.D. Stringer's work, Contemporary Western Ethnography and the Definition of Religion. Stringer was an anthropologist working as a 'church-based community worker' for the Anglican Church in the United Kingdom, prior to his university appointment. ${ }^{54}$ Stringer witnessed [primarily] women from varied denominational parishes integrate contemporary non-Christian non-orthodox spiritual archetypes into everyday traditional Christian beliefs and practises; including reincarnation, visits to astrologers, attendance at Spiritualist Church meetings, use of 'local healers', and visits to loved one's grave sites to discuss personal concerns 'with a cigarette and a

\footnotetext{
${ }^{49}$ McGuire 12; Stringer, 114.

${ }^{50}$ Herman, 61-2.

${ }^{51}$ Donald F Walker, Christine A. Courtois and Jamie D. Aten, Spiritually Oriented Psychotherapy for Trauma (Washington D.C: American Psychological Association, 2015), 5.

52 Jamie D. Aten, and Donald F Walker. "Future Directions for the Study and Application of Religion, Spirituality and Trauma Research," Journal of Psychology and Theology 40, no. 4 (2012): 352; Robert Schweitzer, Jaimi H. Greenslade, and Ashraf Kagee, "Coping and Resilience in Refugees from the Sudan: A Narrative Account," Australian and New Zealand Journal of Psychiatry 41, no. 3 (2007): 283.

${ }^{53}$ Samson Tse, Chris Lloyd, Leon Petchkovsky and Wiremu Manaia, "Exploration of Australian and New Zealand Indigenous People's Spirituality and Mental Health," Australian Occupational Therapy Journal 52 (2005): 183.

${ }^{54}$ Stringer, 30-31.
} 
cup of tea'. ${ }^{55}$ Stringer argued that the way in which 'ordinary people living their ordinary lives' draw on hybrid forms of 'lived religion' to help them deal with 'practical problems' and 'cope with all their troubles', was nothing new. ${ }^{56}$ Yet, he argued, such practices are often overlooked, negated, or omitted from social science studies of religion. ${ }^{57}$ Stringer contends the above are 'elementary' forms of religion that are 'non-empirical' because they are 'unprovable' and cannot be measured'. ${ }^{58}$ What particularly inspires this enquiry is that Stringer did not promote his ethnographic study as a way of changing scholarly attitudes, but rather the way that religion is studied and analysed. ${ }^{59}$ Stringer calls it 'rethinking religion'. ${ }^{60}$ Likewise, I aim to "rethink" the way lesser known forms of traditional Christian, and non-orthodox nonChristian, faith paths are analysed, particularly with regard to everyday concerns like significant trauma.

Meredith McGuire's Lived Religion also informs my work. Asserting that hybrid expressions of lived religion may be more the 'norm, rather than the exception', 61 McGuire argues that individual and personal forms of RSF are often entwined with notions of wellbeing, health and healing, which 'need to be taken more seriously' by scholars 'than previously done'. ${ }^{62}$ According to McGuire, 'largely invisible', seldom recognised, often holistic, RSF healing practises can be integral to people's lived religion experience, providing a 'deep sense [of] healing' equal to 'what modern medicine has to offer'. ${ }^{63}$

Following Stringer and McGuire, I identified opportunities for research on groups that have been largely neglected within New Zealand scholarship, notably: Progressive Christianity, Spiritualism, New Age movements, Paganism and RSF hybridity, particularly as these function in the everyday. Where such movements have been assessed, they have usually been treated as traditions in conflict, distinct from one another. My study repudiates this oppositional approach, noting areas of mutual

\footnotetext{
${ }^{55}$ Ibid, 31, 59-60.

${ }^{56}$ Ibid, 113-114

${ }^{57}$ Referencing Robert Wuthnow's 'study of small groups in America', Stringer asserts that the author 'implies' that the religions of these groups "cannot be seen as "real religion" because it hardly ever leads to a dramatic change in the lives of the people concerned'. Stringer, 13.

${ }^{58}$ McGuire, 186; Stringer, 16, 68, 112-113.

${ }^{59}$ Stringer 3, 113.

60 lbid, 3

${ }^{61}$ McGuire, 4, 12-13, 187.

${ }^{62}$ McGuire, 120-1, 128-9.

${ }^{63}$ Ibid, 121,129.
} 
concern and overlapping practices. ${ }^{64}$ Vaccarino, Kavan and Gendall's call for more research on 'the New Zealand New Age movement [and] unstructured Christian groups', goes some way to supporting my position. ${ }^{65}$ Certainly, the authors point to 'evidence of a spiritual revolution' in Aotearoa, comprising of people who see themselves as 'less religious but not irreligious', as well as a rapid rise in indigenous spiritualities, and the high visibility of 'multiple spiritualities', whose presence date 'as far back as the early settlers'. ${ }^{66}$ By examining the above collectively and alongside one another this thesis isolates similarities, differences, and contradictions not previously identified, that further contribute to knowledge on RSF as a lived experience and a constituent in trauma recovery.

Finally, my research has also been influenced by a limited number of small-scale, qualitative projects covering a variety of topics incorporating the subjective experience and voice of participants. One study examining 'parents [in India] whose son or daughter had been murdered', paid particular attention to the personal narratives of the parents involved, told in their own words. ${ }^{67}$ According to the writers, 'most participants had a spirituality that was shaped by the religious traditions they follow', which helped them 'through their struggle [and] recover from their horrendous experience'. ${ }^{68}$ For some participants, RSF acted as a 'buffer' during particularly painful periods of 'disillusionment [and] rage'. 69

Washington et al.'s study of African American Homeless women in America similarly emphases the centrality of religion in coping with and recovering from the daily challenges of homelessness. However, primarily spotlighting church affiliation and related social groups, the authors acknowledge the negative impact this narrow focus had on one respondent (Ms Peters) who 'did not belong to a specific religion or spiritual community in the traditional sense', regarding instead her Alcoholics

\footnotetext{
${ }^{64}$ Ammerman's study of lived religious experience is among a limited number of enquiries examining disparate RSF groups collectively. Nancy Tatom Ammerman, "Sacred Stories, Spiritual Tribes: Finding Religion in Everyday Life," Oxford Scholarship online (2013).

${ }^{65}$ Franco Vaccarino, Heather Kavan and Philip Gendall, "Spirituality and Religion in the Lives of New Zealanders," The International Journal of Religion and Spirituality 1, no.2 (2011): 94.

${ }^{66}$ Ibid, 86, 87.

67 Jose Parappully, Robert Rosenbaum, Leland van den Daele and Esther Nzei, "Thriving after Trauma: The Experience of Parents of Murdered Children," Journal of Humanistic Psychology 42 (2002):33, 39.

68 Parappully et al, "Thriving after Trauma", 41, 50. Faith paths not specified but reference is made to participants attending 'church' following a long period of grief and anger. Ibid, 44.

${ }^{69}$ Parappully et al, 53.
} 
Anonymous (AA) group to be her 'spiritual group' ${ }^{70}$ Initially declining to participate in the study, ${ }^{71}$ Ms Peters' example drew my attention to the importance of studying forms of RSF that may fall outside current studies on religion, disaster, trauma, grief and recovery, yet are relevant to the New Zealand socio-spiritual context.

Schweitzer et al's studies on forced migrants fleeing from the Sudan to Australia, again involved primarily Christian and church-affiliated refugee communities. Notwithstanding, the authors also argue for 'more research that takes into account the beliefs, perspectives and values of the individuals', highlighting the way some respondents self-isolated from traditional RSF support when trauma experiences felt too overwhelming. ${ }^{72}$ By contrast, Elzbieta Gozdziak is an insider/outsider researcher examining the emic perspectives of Albanian Kosovar (Muslim) refugees. Gozdziak's study examines the role of human suffering as a spiritual experience that 'provides meaning to [an] otherwise meaningless experience'. ${ }^{73}$ Gozdziak highlights the way RSF functioned practically to assist her refugees cope with their adversities, noting that more needs to be understood so that service providers can be better informed. ${ }^{74}$

Lawson and Thomas' Older Black American Hurrican Katrina survivors are 'not necessarily church' affiliated but are nonetheless Christian, drawing on such tools as constant communication (and daily prayer) with God, belief in miracles, regular reading of inspirational spiritual material and finding ways to cope by helping others. ${ }^{75}$ Like Gozdziak, Lawson and Thomas would like to see future material that explores specifically how and in what ways people draw on RSF during traumatic experience and recovery. ${ }^{76}$ They also suggest examining the role of RSF tools beyond that of affiliation and prayer, such as 'speaking in tongues, visions, fasting,

\footnotetext{
${ }^{70}$ Washington, Olivia G. M, David P. Moxley, Lois Garriott, and Jennifer P. Weinberger, "Five Dimensions of Faith and Spiritually of Older African American Women Transitioning out of Homelessness," Journal of Religion and Health 48, no. 4 (2009):440.

71 Washington et al, "Five Dimensions of Faith", 440.

72 Rober Schweitzer, Jaimi H.Greenslade and Ashraf Kagee. "Coping and Resilience in Refugees from the Sudan: A Narrative Account." Australian and New Zealand Journal of Psychiatry 41, no. 3 (2007):7, 10, 11.

${ }^{73}$ Elzbieta M. Gozdziak, "Spiritual Emergency Room: The Role of Spirituality and Religion in the Resettlement of Kosovar Albanians, " Journal of Refugee Studies 15, no. 2 (2002):138, 140.

74 Gozdziak, "Spiritual Emergency Room", 143, 150.

${ }^{75}$ Erma J. Lawson and Cecelia Thomas, "Wading in the Waters: Spirituality and Older Black Katrina Survivors," Journal of Health Care for the Poor and Underserved 18 (2007): 345, 346.

${ }^{76}$ Lawson and Thomas, "Wading in the Waters", 350.
} 
prophecy', and music to determine their impact on mediating the effects of crisis situations. ${ }^{77}$ Some of the above are discussed in my respondent stories.

Most notable among the widespread material on religion, trauma, and mental health was a need for more studies examining specific 'nuances' of trauma and increased attention to diverse forms of RSF not currently represented in research. ${ }^{78}$ Others called for more NZ-specific inquiries where the researcher is connected to the people they study, ${ }^{79}$ or post-earthquake Christchurch research that explains actual processes supporting wellbeing. ${ }^{80}$ In particular was the appeal for future material that explores how and in what ways people draw on RSF during traumatic and stressful experience and recovery. ${ }^{81}$ This thesis responds to each of these challenges.

\subsubsection{Theoretical and methodological foundations}

The shape of my enquiry and my methods are underpinned by the theory of postmodernist interpretivism. Postmodernist interpretive approaches identify gaps in discourse between those voices and experiences that are less often heard (or documented), and institutional notions of "truth" as articulated in dominant discourses of power. ${ }^{82}$ Regarded by some scholars as 'controversial', contentious and contradictory, ${ }^{83}$ postmodern interpretivism places a strong emphasis on subjective experience - epistemologically and ontologically - as the primary source of

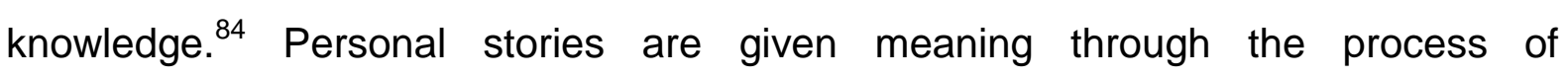
narrativization; and authorship and authoritative knowledge lie with the participant voice, which is included as a key aspect of the emic enquiry. ${ }^{85}$ Researcher reflexivity

\footnotetext{
${ }^{77} \mathrm{Ibid}, 350$.

${ }^{78}$ Aten, and Walker, "Future Directions," 352; Viccarino et al, 94.

${ }^{79}$ Kiwi Tamasese, Carmel Peteru, Charles Waldegrave, and Allister Bush. "Ole Taeao Afua, The New Morning: A Qualitative Investigation into Samoan Perspectives on Mental Heath and Culturally Appropriate Services." Australian and New Zealand Journal of Psychiatry 39 (2005): 307.

${ }^{80}$ Chris Sibley and J Bulbulia, "Faith after an Earthquake: A Longitudinal Study of Religion and Perceived Health before and after the 2011 Christchurch New Zealand Earthquake," PLoS ONE 7, no.12, (2012): 7.

${ }^{81}$ Gozdziak, 143; Lawson and Thomas, 350.

${ }^{82}$ R Jon McGee and Richard L. Warms, Anthropological Theory: An Introductory History, Fourth Edition (New York: McGraw Hill, 2008), 582, 533; Michael Oldani, "Postmodernism and Anthropology: Conflict or Cooperation?" Kroener Anthropological Society Papers 83 (1998): 87-88, 90.

${ }^{83}$ McGee and Warms, Anthropological Theory, 536; Michael Oldani, "Postmodernism and Anthropology," 85, 92.

${ }^{84}$ Gary Ferraro, Cultural Anthropology: An Applied Perspective (Belmont, CA: Thomson/Wadsworth, 2008), 88; Ann Gleig, "Researching New Religious Movements from the Inside Out and the Outside in: Methodological Reflections for Collaborative and Participatory Perspectives", Nova Religio: The Journal of Alternative and Emergent Religions 16, no. 1 (2012): 89-90; Jan H. Kroeze, "Postmodernism, Interpretivism and Formal Ontologies," In Research Methodologies, Innovations and Philosophies in Software Systems Engineering and Information Systems ed. Manuel Mora, Ovsei Gelman, Annette Steenkamp and Mahesh S. Raisingham. (USA: IGI Global, 2012):45, 47; Oldani, 87-88.

${ }^{85}$ Oldani, 87- 88.
} 
and personal connections between researchers and the communities they study are encouraged (studying "at home"); ${ }^{86}$ overarching religious meta-narratives are eschewed in favour of multiple RSF realities - including hybridity and syncretic forms depicting a 'bricolage of practises and beliefs'. ${ }^{87}$ Less visible, hard-to-measure, localised forms of RSF are favoured, which Marti stresses are essential for better understanding the shape of RSF in the contemporary world. ${ }^{88}$

In accordance with the above approach, participant accounts, the struggles they were facing, and the role of RSF during those periods, are recorded in the words, language, and perspective of the respondents. As a result, multiple realities are abundant throughout the respondent narratives. 'Less visible and hard to measure', ${ }^{89}$ the "bricolage" of participant practises, beliefs and RSF engagement are scattered throughout the respondent stories addressed in the themes in section two. Their accounts highlight a wide variance in the utilisation and type of RSF that people employed to help them. It is this subjective experience of trauma, RSF and recovery that serves as the primary source of knowledge for this research, shaping and informing how I analysed and interpreted the data. Conscious of the potential influence of my being connected to the wider communities of the people I studied in some way (see: Insider-outsider researcher 1.4.4); I contemplate my reaction to respondent stories, on a number of occasions in section two, and consider the impact that might have on my interpretation of the data.

My research methods are also informed by the postmodernist interpretivist approach, emphasising the centrality of participant subjective experience, presented in narrative form. These methods include: one-on-one interviews, group discussions, participant observation, audio recording, photography, and general field observation. During group discussions and individual interviews, I encouraged respondents to "tell their stories" rather than facilitate question-and-answer sessions. To ensure anonymity, no participants were photographed during my research, and respondents were referred to only by pseudonyms during recorded interviews, which respondents chose themselves. While some pseudonyms reflect respondent faith-paths, others

\footnotetext{
${ }^{86}$ Gleig argues a post-modernist interpretivist 'turn' to insider/outsider researchers who 'share political, cultural [religious] and social affinities' with the people they study, necessary for comprehensive studying of religion. Gleig, "Researching New Religious Movements", 89-90.

${ }^{87}$ Kroeze, 43, 45; McGuire, 195-200; Oldani, 86, 90, Viccarrino et al, 86-88.

${ }^{88}$ Marti, 508.

89 Ibid.
} 
speak to their humour, an often overlooked 'personal resilience factor' in trauma recovery. ${ }^{90}$

Respondents were sourced through a variety of methods - from searching the internet, to utilizing known RSF network contacts, contacting parish ministers, and sending posters (Image1.2) to religious leaders to share among parishioners they thought might be interested. The poster outlined the purpose of my study, and the sort of individuals or groups I hoped to speak to. I telephoned interviewees to introduce myself ahead of interviews so people could decide if they were happy to

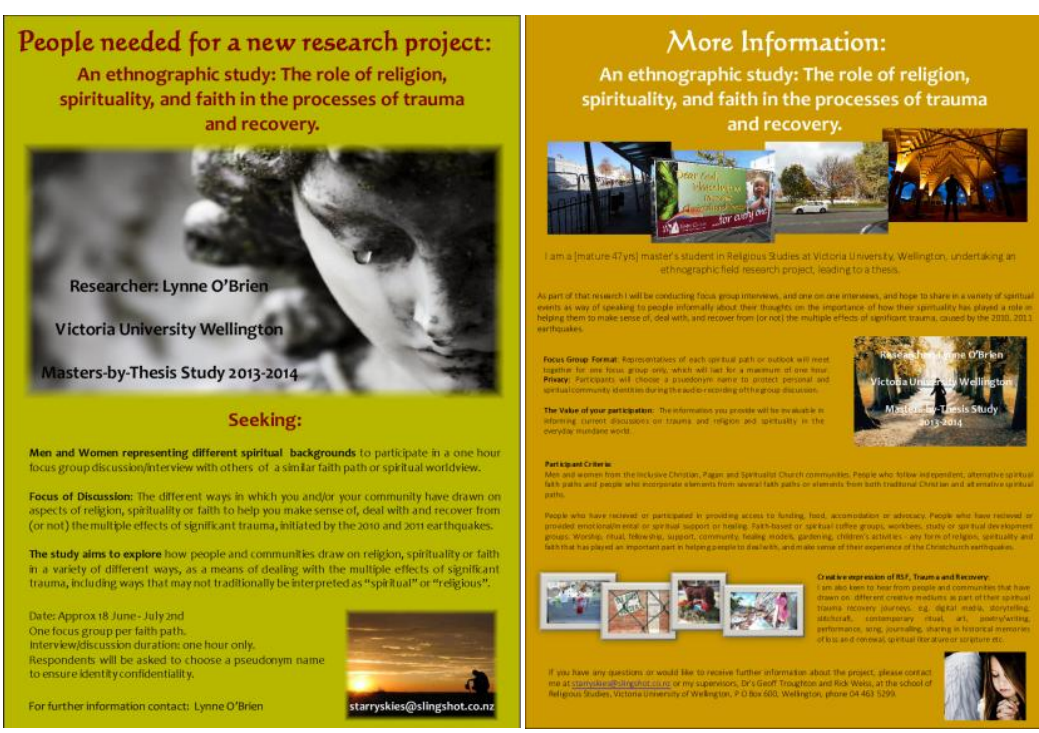

1.2: Call for research respondents poster 2013 continue.

Some respondents emerged from chance meetings during field exploration and impromptu visits. I spoke to people on the street, in public domains and on public transport. I was invited to attend and participate in a dreaming workshop but did not make an audio recording of that occasion.

\subsubsection{Insider-outsider researcher}

I identify as both insider and outsider in relation to the research undertaken. A member of the Inclusive-Progressive Christian, Pagan, and New Age/Spiritualist communities (pre-university studies), but not from Canterbury; I had privileged access. I am therefore an insider-outsider researcher. Tamasese et al. highlight the value of having shared (and local) knowledge and understanding of language, symbol, cultural practises and protocols, as well as social and religious hierarchies. ${ }^{91}$

\footnotetext{
${ }^{90}$ Nicholas A. Kuiper, "Humor and Resiliency: Towards a Process Model of Coping and Growth," Europe's Journal of Psychology 8, no. 3 (2012):477.

${ }^{91}$ Tamasese et al, 306-7.
} 
Breen similarly points to the 'advantages and disadvantages' of being 'one or the other' which can be balanced, and 'disadvantages reduced' by being both an insider and an outsider researcher. ${ }^{92}$

My insider-outsider position created opportunities, challenges and limitations. As an insider, I was able to interview RSF groups not always receptive to "outsiders" and in a way that Ellwood noted he could not. ${ }^{93}$ However, I did not always ask questions that a complete outsider might have probed more efficaciously. Notwithstanding, I endeavoured to question respondents carefully, concerned that as an insider I might make incorrect assumptions regarding meaning. This care proved helpful in identifying findings that ultimately surprised me.

In consideration of the aforementioned theories, methods and insider-outsider vantage points, my thesis aims to offer a fresh perspective on trauma, recovery, resilience and disaster. It is shaped by the postmodernist, interpretivist emphasis on contention, contradiction, and narrativization, and gives voice to the subjective experience of participants often omitted from existing RSF and trauma discussions. My project challenges Maslow's theory concerning the place of religion in the "hierarchy of needs" in times of crisis by arguing that, for those sectors of the community for whom RSF is generally important, RSF also plays a significant role in shaping responses to experiences of significant trauma. Such people draw upon RSF resources in a range of ways - some predictable, others unexpected and creative, and to variable effect.

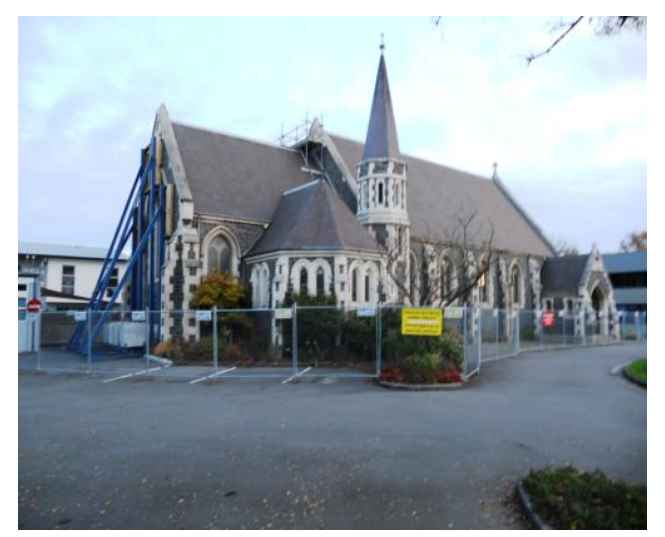

1.3: Damaged Church 2012

\footnotetext{
${ }^{92}$ Lauren J. Breen, "The Researcher 'In the Middle': Negotiating the Insider/Outsider Dichotomy". The Australian Community Psychologist. 19, no. 1 (2007): 163-164.

${ }^{93}$ Ellwood, Islands of the Dawn, 215. When I contacted Unicorn, she had heard of my interfaith work, distinct spiritual faith path and "name". I do not believe she would have been as open to my visit had my reputation not preceded me. In the same way, my attendence to an earlier FutureChurch conference, also attended by Fred, seemed to make a valuable difference to his willingness to engage.
} 


\section{Entering the Field}

In the following chapter, I introduce the fieldwork on which my thesis is based. I introduce the various respondents, their diverse faith paths and traumatic experiences.

On my initial trip to Christchurch in May 2012, I limited my study to the InclusiveProgressive Christian community only. I group interviewed three Presbyterian ministers representing three central city parishes with distinct socio-economic and demographic profiles and attended an Inclusive-Progressive Presbyterian Church service. I participant-observed a one-day dreaming workshop, attended by (primarily) liberal-thinking Catholics exploring Jungian and Christian symbolism to help make sense of recurrent nightmares experienced as a direct result of the earthquakes. I conducted a one-on-one interview with a spiritual director who worked with people following traditional Christian and hybrid spiritual faith paths, and explored aspects of the wider city, including the "red zone". ${ }^{94}$

An impromptu visit to a small church community situated close to the red-zoned areas of the eastern suburbs, introduced me to a theologically "mainstream", mostly elderly congregation of parishioners with limited financial and social agency and significant physical limitations. Their small church building had suffered extensive damage and, though not meeting the "inclusive-progressive/hybrid" criteria, I determined that my host parishioner felt suffering and the role RSF played for these people, provided important information for my study.
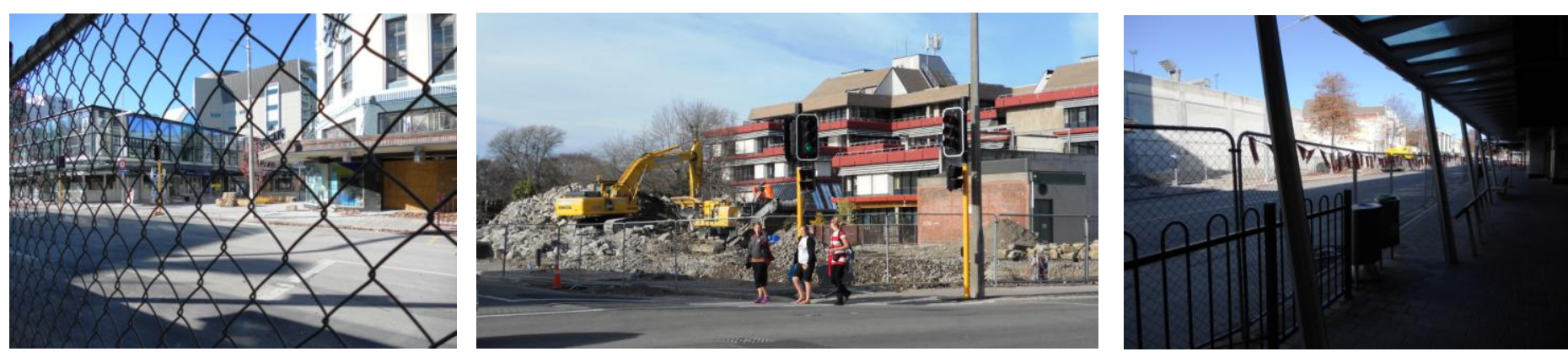

1.4: Red Zone 2012

In July 2013 I returned to Christchurch for two additional weeks. I recorded interviews, maintained a field-note diary, and took numerous photographs. This time

\footnotetext{
${ }^{94}$ Area in central city Christchurch most affected by the February 222011 earthquake, and cordoned off from the public.
} 
I expanded the research field to include representatives of the Spiritualist Church, Pagan, Craft, and Heathen communities, New Age, and hybrid faith paths. During group interviews, I added a method of writing respondent answers on an A1 sheet of paper taped to the wall, to prompt further discussion.

My original question of how and in what ways (if any) people drew on RSF to help them deal with trauma was expanded, to include more diverse forms of RSF, and traumas not directly related to the earthquakes. I revisited the Inclusive-Progressive and elderly (eastern suburbs) parishes. While I was unable to meet with the ministers in person for a second time, I spoke to "Robbie" via telephone and "Fred" via email.

On this trip I had a spur-of-the-moment conversation with a Catholic bus driver whose faith path was "hybrid". 95 Surprise interviews with an ex-conservative (now Progressive) evangelical Christian pastor and artists of the white chairs exhibition were particularly powerful, opening up fresh lines of analysis.

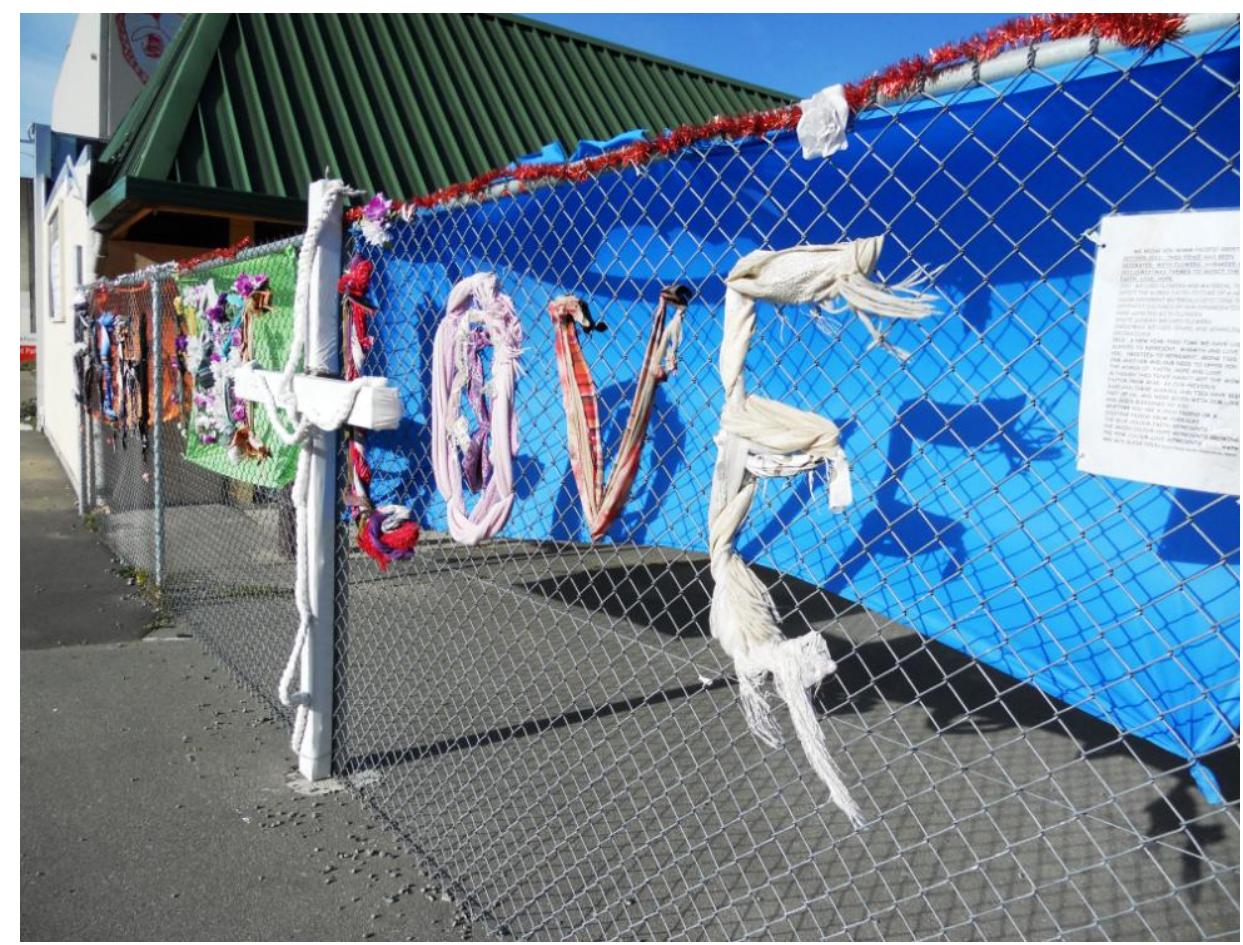

1.5: Trinity Pacific St Paul's Presbyterian Church 2013

\footnotetext{
${ }^{95}$ The bus driver offered her story whilst driving me to my next interview, and after a discussion about the project I was working on and my research aims.
} 


\subsection{The Respondents}

Respondents in this study include individuals and groups living in post-earthquake Christchurch and the wider region of Canterbury during the period 2012-2013. They represent a diverse social, demographic, age, gender and geographic spectrum.

I spoke to a total of twenty six people; seventeen females and nine males, and met with four of the eight faith communities chronicled in this study. Ages ranged from thirties to senior. Five respondents represented the Spiritualist Church tradition, six Pagan; seven Inclusive-Progressive Christian; one mainstream Christian and seven hybrid faith-paths. Respondents were mostly Pakeha embedded in predominantly Pakeha faith communities with an even spread of low to upper-middle socioeconomic representation. Two participants were Maori; four, new migrants. Twelve participants were married, one widowed, and six were single parents of young to adult children. One respondent was in a same-sex relationship. Another was openly gay. A further participant was married to an openly gay spouse. Most interviews or group discussions were one hour in duration, meeting in people's homes, churches, pubs, cafes and restaurants. I had email communication with Fred and spoke to Robbie by telephone.

Respondents were selected because they represent faith paths identified as absent from current discussions on religion and trauma, and nominally represented in enquiries on religion in New Zealand. It was important to the study that people told me how and in what ways they employed, or were challenged by, forms of RSF in crisis and recovery moments, uninhibited. Given the independent and porous nature of their theological traditions, respondent opinion was less likely to be dictated by RSF doctrine. As such, I hoped participants would speak frankly. An increased possibility of finding respondents following hybrid faith-paths that drew on elements of both of the above traditional Christian and non-orthodox non-Christian traditions, was likewise anticipated. This proved productive for highlighting similarities, differences and unexpected contradictions regarding the way people utilised RSF at key moments and in their trauma recovery. 


\subsection{Respondent backgrounds and their Faith Paths}

The following section introduces the respondents and the basic characteristics of their faith paths addressed in this study.

\subsubsection{Spiritualist church}

Cat, Annie-Bell, Castilian Blue, Catherine and Roselyn Billing are all Spiritualists. Cat, Annie-Bell, Castilian Blue, and Catherine attend a small Spiritualist church nestled in the heart of the eastern suburbs of Christchurch. They form a trauma support group, sharing their experiences and exploring forms of RSF. Rosalyn Billing is a friend of Catherine and her husband's, and

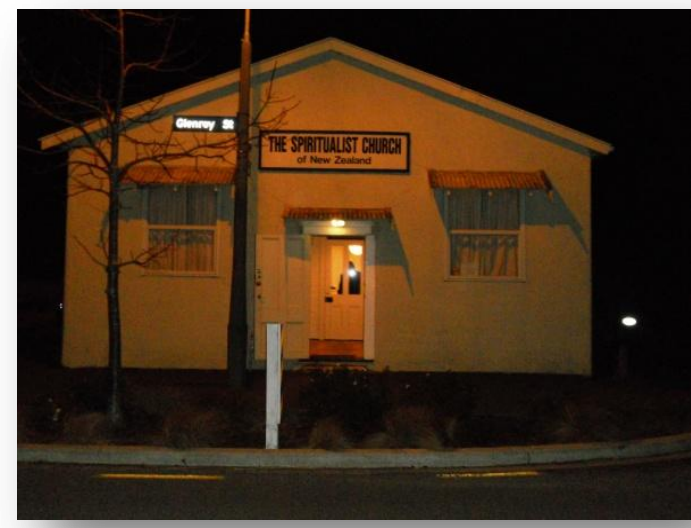

1.6: Spiritualist Church, Eastern suburbs attends a central city Spiritualist church community. She and Catherine belonged to the same Spiritualist church in South Africa, although they did not know each other in their home of origin.

Originating in the mid-nineteenth century, Spiritualism arrived in New Zealand as early as the 1850 s with the early pioneer setters. ${ }^{96}$ Spiritualism's central component involves communicating with the spirits of the dead, with the assistance of a Medium who 'channels' (receives from a spiritual source) messages to friends and loved ones. ${ }^{97}$ Originally a volunteer movement rather than a religious organisation, Spiritualism developed institutionally with the introduction of Sunday morning services during the twentieth century. ${ }^{98}$ Despite reflecting Christian symbolism and materiality, and often attracting people from Christian backgrounds, Spiritualist churches in New Zealand are no longer Christian-based, separating formally from their Christian counterparts in $1924 . .^{99}$

\footnotetext{
${ }^{96}$ Linda E. Hampton, Wise Women: New Zealand Women's Alternative Spirituality \& History. Leeston, Cant'y, NZ: Linda Hampton, 2013): 61.

${ }^{97}$ Rev Lyn Guest De Swarte, The Spiritualists' Handbook: A Concise and Extensive Guide to Spiritualism and All It's Practises, (USA: The New Spiritualist's Society: 2017), 40; Thomas Kingsley Brown "Religious Seekers and Finding a Spiritual Home: An Ethnographic study of conversion to Christian Spiritualist Churches in Southern California" Phd Dissertation, University of California, San Diego, 2000: 3.

98 John Gordon Melton Encyclopaedia Britannica https://www.britannica.com/topic/spiritualism-religion

${ }^{99}$ Hampton, Wise Women, 105-6.
} 
In her native South Africa, Catherine 'always walked a spiritual path', 'working with the Angels', and as an active member of the Liberal Catholic Church in which she married 'and had the blessing of children'.

But then my world shattered when I lost my son to leukaemia in 2009. I felt like I died inside.... It was like a big earthquake in my life. Everything was completely destroyed. It put a strain on my marriage .... I changed ... I needed answers.

Overwhelmed with grief, Catherine and her husband visited a Medium suggested by Catherine's son's teacher.

It was such a miraculous experience ... that started us on a completely different path. From then until now, Spirituality became my lifeline.

The couple joined a 'very welcoming' Spiritualist Church, and trained to become Mediums, before deciding to immigrate to New Zealand 'to start again'. Not realising the impact of the February 22 earthquake, Catherine and her husband arrived in New Zealand July 2011. Once in Christchurch, they joined the Spiritualist Church in the eastern suburbs. However, challenges in her workplace, postgraduate study pressures, and the realisation that Catherine was still grieving, took its toll.

It just [became] too much ... I thought well I need to take a bit of time out for myself to heal.

Catherine resigned from her job. Drawing on her counselling and mediumship skills, she set up the trauma group.

Spiritualism had been an integral part of Cat and his late wife's life for many years. Although Cat's trauma occurred at the same time as the Canterbury earthquakes, it was unrelated to the disaster. Following the loss of a baby daughter some years earlier, Cat's much loved wife passed away, after a short battle with illness.

4 September... That was the day we got the bad news, and I was just taking care of my darling.... She died the following year. So the earthquakes didn't really pay a big part in my life.

After [she] died and passed over, I went into a deep depression. Dug a big hole; didn't want to come out of it. I didn't want to live anymore.... Life didn't really have much going for it in my book. 
Cat told me he was so unhappy, he could have easily ended his life, were it not for the role of RSF - and Spirit - in his life.

It was like someone turned the lights on, you know.... Now I can't wait to get here!

Over a few short years, Annie-Bell's son was killed in a car accident, her mother died, her daughter died of cancer, and Annie-Bell's marriage ended. Forced to find somewhere else to live, suffering overwhelming grief and cumulative trauma, and with limited social and economic agency; Annie-Bell felt very isolated and alone.

In four and a half years ... I lost everything; I lost a family ... [it was] as though I had been living alone for years and yet I had this nucleus of family that literally shattered [overnight]. So I had to very firmly stay within my spiritual beliefs and know that I would be led by my guides, my angels and Spirit ... often all l've ever had, right through my life, basically.

At the time of the earthquakes, Castilian Blue was emerging from the traumatic effects of years of alcohol and substance abuse, as well as prolonged sexual abuse and physical violence. Maori but adopted into a Catholic Pakeha family as a child, Castilian's initial engagement with RSF as a resource for recovery was via the Alcoholics Anonymous twelve step programme.

It was a spiritual action programme but I was too sick at the time to realise [it could help me].

Drawing on the support of multiple organisations for herself and her daughters - one with special needs - Castilian Blue was introduced to Maori culture and spirituality via the Methodist Mission.

Every morning we would start off with the karakia, the waiata, and nga mihi (greeting or opening speech). I was really embracing my identity.

However, it was not until Castilian Blue joined the Spiritualist Church and Catherine's trauma group that she found the strength, support and acceptance she needed to recover and regain her children. Before we began recording Castilian Blue told me that for her, RSF is:

The thing you hold on to when there is nothing left to hold on to. 
Migrating from South Africa to New Zealand to join a male friend, Roselyn says she was 'not affected at all by the earthquakes'. For Roselyn, her sense of aloneness and isolation in a strange country, high stressors relating to work and finances, and feelings of being trapped in a controlling and unhappy relationship triggered unresolved trauma and deep depression from earlier years in South Africa when; married, pregnant, and with two very young children, Roselyn's husband had left her for another woman. Roselyn was left struggling financially and socially isolated and alone.

Newly arrived in New Zealand, Roselyn had nowhere to go.

Finding a job was well-nigh impossible and when I did find it, I had to work

like an absolute dog in order to keep it.... The boss I had was a bully.

When I met Roselyn Billing she was living in a small flat alone and relying heavily on her RSF to help her 'get through' her daily struggles.

\subsubsection{Paganism, Heathenism and The Craft}

Paganism is the umbrella term for a wide variety of nature-based religions. York describes Paganism as 'experiential and not a religion of creeds and faith affirmations'. ${ }^{100}$ Neo-Paganism, Druidism, Heathenism, The Craft, and the newly emerging Christopaganism, are just some of many spiritualities that fall under this category. Monotheistic, Polytheistic, pantheistic, and panentheistic, Pagan faith paths are highly eclectic in belief, practise, and form. ${ }^{101}$ However, central to all is a shared emphasis on sacred ecology, egalitarianism, and sacred sexuality. ${ }^{102}$

Prior to the earthquakes, Unicorn, John and Awen, Morningstar, and Blue regularly met at a local coffee shop with fellow Pagans. They also gathered in each other's homes for seasonal (Sabbat) gatherings.

Prior to the earthquakes we used to have regular coffee meets where anyone could come along to and anyone did. (Unicorn)

\footnotetext{
${ }^{100}$ Michael York, Pagan Theology: Paganism as a World Religion New York and London: New York University: 2003$): 12$.

101 Joanne Pearson, Belief Beyond Boundaries: Wicca, Celtic Spirituality and New Age (Burlington, USA: Ashgate Publishing Ltd, 2002); Dale Wallace, "Pagans at the Parliament." Agenda, No.61, Religion and Spirituality, 2004: 81

102 Lynne Hume, "Creating sacred space: Outer expressions of inner worlds in modern Wicca", Journal of Contemporary Religion 13 (3): 312; Adrian Harris, "Sacred Ecology." In Pagan Pathways: A Guide to the Ancient Earth Traditions, by Harvey Graham and Charlotte Hardman (London: Thorsons, 2000), 152; Graham Harvey and Charlotte Hardman, Pagan Pathways: A Guide to the Ancient earth Traditions (London: Thorsons, 1996):214, 216; Wallace, 82-83.
} 
Unicorn is a practising eclectic Pagan who previously lived in the eastern suburbs with her partner and their blended family. She co-ran the regular coffee group. When Unicorn's home was destroyed in the earthquakes, her family saw an opportunity for a fresh start and move to a rural location, about an hour's drive from the city.

John and Awen are migrants from the United Kingdom where the couple had run their own formal Pagan group. Overseas visiting family in the UK at the time of the September 2010 earthquake, John and Awen were in Christchurch 22 February 2011. With their home significantly damaged, the trained Samaritans did not suffer trauma themselves but were involved, first hand, in the significant traumas of others.

For Morningstar, Heathenism is her spiritual path, and her connection to ancestral cultural heritage, and identity. A single mother of two, Morningstar was separated from her severely autistic son for 'a number of hours' on 22 February 2011. Morningstar's state housing flat was destroyed in the quakes so she and her children spent several weeks in an emergency shelter on a Marae, before being reassigned a new place to live.

Blue, who lives alone, felt she was the RSF resource that helped others to deal with and make sense of their trauma experiences, during the earthquakes. The rest of the group agreed.

Silver Rain teaches Pagan classes in another part of Christchurch. A devout Pagan, Silver Rain has experienced successive losses, including the sudden death of her fifteen-year-old granddaughter - occurring just weeks before my visit - as well as the deaths of her father to a long-term illness, death of a grandson, illness of a son on whom the doctors had given up hope, and a daughter and her family who had moved into Silver Rain's backyard studio following the loss of their home in the February 22 earthquake.

I ask for more [spiritual] help everyday now; for myself, for healing, and more recently, for the healing of my Granddaughter's soul. 


\subsubsection{Inclusive-Progressive Christianity}
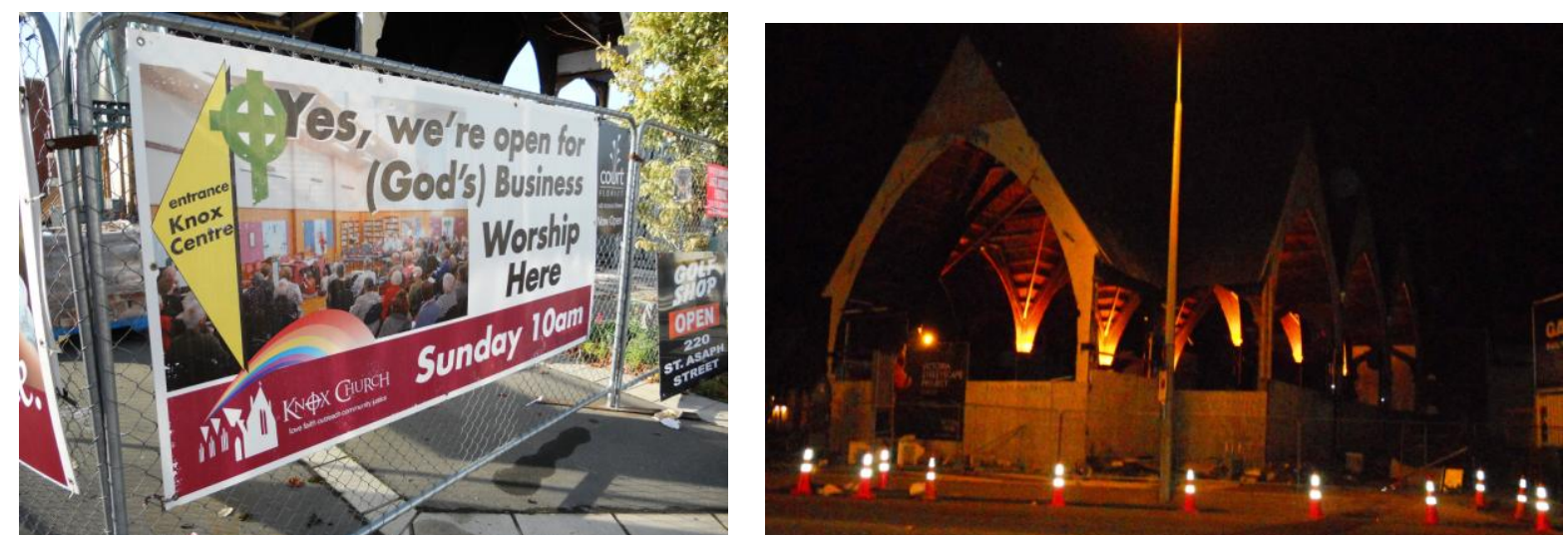

1.7: Knox Presbyterian Church, Christchurch. Destroyed in the earthquakes

Progressive Christianity emerged in the United States in the 1980s in reaction to the Christian Right. ${ }^{103}$ It remains little known or studied in New Zealand. Parishes in New Zealand who self-identify as Progressive are small in number and some, including the congregations and individuals in this study, distinguish themselves as 'InclusiveProgressive,104 Theologically variant in worship, belief, and form, Inclusive and Progressive Christians share emphases on areas such as a focus on the life and teachings of the historical Jesus, support for the Lesbian, Gay, Bisexual and Transgender (LGBT) communities, women's rights, social justice, environmental concerns, and religious pluralism. ${ }^{105}$

Pollyanna, Snow White, George, Pixie, and two of the three ministers I interviewed in 2012 self-identify as Inclusive-Progressive Christians. The parish I observed (and worshipped with) in 2012 and 2013 similarly categorise themselves as InclusiveProgressive. Eddy, Rufus, Elsbeth, and Peter Frazer are Evangelical Progressive Christians, another variation of Progressive Christianity. While the elderly parish in the eastern suburbs do not self-identify as Progressive or Inclusive, George and Pixie follow Progressive Christian hybrid paths, so are introduced under that category below.

\footnotetext{
${ }^{103}$ Delwin Brown, What Does a Progressive Christian Believe?: A Guide for the Searching, the Open, and the Curious (New York, New York: Seabury Books, 2008): xi, 1-3.

${ }^{104}$ St Andrew's on the Terrace Presbyterian Church, Wellington similarly describes its "theology is [both] progressive and inclusive". St Andrew's on the Terrace, "Celebrate with us; Where we come from". http://www.standrews.org.nz/celebrate-with-us/ (St Andrew's Centre)

105 Emphases vary between communities. Hal Taussig, A New Spiritual Home: Progressive Christianity at the Grass Roots (USA: Polebridge Press, 2006): 2, 4-5, 7.
} 
Pollyanna's spiritual life has always been important to her, especially during the tough times.

In all the hard times in my life I thought I could never have coped on my own. When my dad died, when I was sixteen ... I don't know how people get through things without any sort of faith; without God being right beside them.

Pollyanna's trauma occurred years before the Canterbury earthquakes, when she was living in the North Island and about to give birth to her second child. Battling post-natal depression, her husband announced he was gay. Spiralling downward, Pollyanna recalls one particularly difficult day:

On the worst day, I was sitting there and my dear wee boy who was about two at the time said "Mummy don't be sad. Jesus is just there behind you" and then trotted off.

And about that time, when things were really, really hard; I was standing out at the clothesline ... I heard God say "[Pollyanna], I love you just as you are". I was forty-two at the time and that was really profound.

Like Pollyanna, Snow White is also originally from the North Island and her significant trauma was not related to the earthquakes:

I was a born-again [Pentecostal] Christian; the whole thing ... speaking in tongues, casting out demons ... then I fell in love with a woman.

Snow White's girlfriend belonged to the same church. According to Snow White, she and her partner were 'shunned' and cast out by the church:

It was all very traumatic. A much worse trauma for me than the earthquakes.... I figured if I could get through that then I could get through anything. Really the earthquakes weren't half as bad for me!

Snow White's experience was so traumatising that she didn't know if she wanted to be Christian anymore. Despite this, her partner researched and found an Inclusive Presbyterian Church in the area where they were living.

They were just wonderful. 
At the time of our interview, Snow White said that her relationship with RSF was changing. She describes the process in her journey of recovery as 'not spirituality, it's soul-ual-ity'.

I'm leaning away from Christianity and more to.. I don't know what. A new journey. I think about myself, other people and my soul differently now. [Now] it's more of a "state of being".

Progressive Evangelical Christians, Eddy and Elspeth are artists who run an evening church group, 'which was born out of Alan Jamieson's A Churchless Faith - Faith Journeys beyond the Churches'. Jamieson's PhD in Sociology examines parishioners leaving Conservative Evangelical congregations. Eddy had been similarly questioning his own spiritual future.

I was feeling very disillusioned about church.... I liked Mark Pearson's idea of ancient-future-church. ${ }^{106}$

Rufus is also an artist, involved in the White Chair's art installation (see: Creative Exploration), and Eddy, Elspeth, and Rufus all self-identify as 'Fringe Baptist'. While I can find no written definition for the term, Pearson's successor once described the above as 'on the margins (fringes) of traditional Baptist Church'. When I asked Eddy and Elspeth how their community compared with Pearson's old parish they laughed: 'we're even more fringe than them!'

Peter Frazer was a Conservative Evangelical Pastor in an area of Christchurch that was struggling socially and economically, at the time of the February earthquakes. On the day the earthquakes hit, he rushed home to his family.

If you ask me what my spiritual resources are they are my wife and my politics.

Peter Frazer's post-earthquake trauma experience emerged out of a combination of feeling 'turned on' by his eastern suburbs parish and superiors, betrayal of trust from close friends and work colleagues, combined with an overwhelming sense of what he felt called to do in terms of advocating for the city's vulnerable. Peter wanted to help

\footnotetext{
${ }^{106}$ Pearson was Pastor at an Auckland (self-identified) fringe, Inclusive-Progressive Baptist Church in the early 2000's. His sermon Ancient-Future Church sparked a Progressive Christian conference of the same in 2005. Fred and I attended, along with Pearson's successor (a personal friend).
} 
people in his local community in crisis, to address basic needs of food, shelter and safety. By contrast, his community and RSF mentors viewed the earthquake chaos as an opportunity for evangelism and 'spreading God's word'. Angry, frustrated, and confused about what God wanted from him, Peter suffered a major personal faith crisis. At the time of our meeting, he had left the ministry and was working for local government finding homes for homeless teens in the eastern suburbs. Peter now self-identifies as a Progressive - no longer Conservative - Evangelical Christian.

\subsubsection{Hybrid Paths}

Several of my respondents practise a combination of traditional Christian and nonorthodox, non-Christian beliefs. For example, Mysar and Toast follow an eclectic RSF path of Spiritualism, Paganism, New Age beliefs, and Christianity. They own a New Age spiritual shop in one of the eastern suburbs hardest hit by the earthquakes. On February 22, the couple were in their original shop building with their adult daughter. During the event, both their shop and home were destroyed and Toast was admitted into hospital with a broken back. Forced to move into a tent and then garage, the couple eventually received emergency housing with the help of the Salvation Army. When I visited Toast and Mysar in their relocated shop in 2013, they were still battling EQC and insurance companies, and remained in emergency housing. Solitary practitioners, the couple do not belong to a larger Pagan or New Age group.

Mysar was raised Salvation Army but describes her parents as "very Paganism".

My passion is crystals, and herbs, [essential] oils, and [meditation].

She has continued the practises of her mother, specialising in crystals and herbs in the couple's spiritual shop and making remedies at home:

To Mum and Dad it was just the Bible ... it was normal.... That's how I was brought up!

My spirituality side of my life is my life. It's what I do ... it's my job and it doesn't stop here. I don't finish work for the day and go home and not do it. I'll probably go home tonight and sit at the table and play with my crystals.

Toast is a professional clairvoyant and Mysar's husband. Raised Assembly of God, Toast grew up in South Auckland with alcoholic parents, where internal spiritual resources emerged early in life: 
When you're in a situation where there's violence and stuff in your life, you can't really rely on external resources.

Toast says he began receiving psychic messages and visitations from Spirit at an early age:

When I was a child I [had a] visitation from [a spirit woman named] Marie that woke me up in the middle of the night ... the end of the bed was on fire so I had to get out.... With long dark hair she was standing over me.

At just 'eight years old', Toast was unsure whether he was dreaming or seeing 'Spirit'.

The bed was on fire which caught the house on fire and if she hadn't woken me, you see?

Marie continues to play a key role for Toast, in terms of spiritual guidance and as an RSF resource for helping others.

There are people out there that don't understand it but I see things. I'm a seer, if you like, and in the Bible there are seers but I don't tell people their futures. I tell people what I see through them [and] how they can resolve their problem internally, which is pretty good really.

George and Pixie are Inclusive-Progressive Christians who incorporate non-orthodox (Spiritualist) practises and beliefs into their traditional Christian faith. Pixie is a Presbyterian Church elder and Gestalt trained psychotherapist.

I use Tarot cards and Goddess [oracle] cards and things like that [for problem solving, prediction, and spiritual guidance.] It just makes sense to me.

George is openly gay and follows a blend of Inclusive-Progressive Christianity and Spiritualism.

The energy, the elements ... it gives me another understanding of God's creation. What I mean is I'm more environmentally aware that there are different.. there's not one set path, and all these different things make the whole person.... My best friend is a witch, and I think that is really cool! Don't you?! (giggle) 
[My spiritualism connects me] with the environment [and] with people who have passed and [I'm] a part of [that]. You are getting spiritual messages from inside. But my religious faith, like [this church] is tradition. I feel quite comfortable with tradition, [it] gives me like a safety barrier and context; structure [and] boundaries.

Attending church 'has always been a spiritual source' for George.

It is a place where traditionally it has given me an hour, an hour-and-a-half a week where I can actually sit back and think, and move forward.

Pingle is a single mum who attends the local Baptist church and regularly meets with her spiritual healer. Though Pingle keeps her two RSF affiliations separate, it is not something that bothers her. During the earthquakes Pingle was separated from her children. Following her trauma experience, Pingle embraced her RSF.

I felt like I was traumatized over what had happened being separated from both my children and my mother and the events [of that day]. [Later] ... at home ... late one evening, mum had gone [back to the UK] and the children were in bed. I remember going out to sit on the back doorstep with a cup of tea and a cigarette and I said "I'm ready. I want you to come into my life". I felt it, in every single bone in my body. Every single fibre of me felt it and it changed my life. l've never been in touch with these emotions [before]. It's something that I believe. Now I can feel it in everything I do. It's there.... [It's] who I am and part of me, and it's the most wonderful feeling in the world. The best thing that's ever happened to me.

[Before the earthquakes] I would just go through the motions. I just didn't feel it and I didn't believe it ... but I didn't ever question it. It was something intellectual, not something that I felt.

Since that moment on the back doorstep, Pingle has drawn on her RSF tools 'all the time'.

Everything [that has happened] since then l've drawn on that. Knowing that it'll be alright. 
The Catholic bus driver I interviewed can also be included in this group. According to the bus driver, returning to her Maori spiritual roots and incorporating them into her traditional Catholic beliefs and practises, was pivotal to her trauma recovery process, and from feelings of being abandoned by her local parish community, during the Christchurch earthquakes.

\subsection{Summary}

This thesis sought to address the question how and in what ways do people for whom RSF is important, draw on RSF in key moments of crisis and deep distress? It is shaped by calls from existing trauma and religion research to include; more RSF diversity, insider-outsider research, and participant subjective experience within a New Zealand context. Most importantly, my study responds to demands to practically identify how and in what ways people employ forms of RSF to help them mitigate traumatic experience. Located within post-earthquake Christchurch 2012-2013, my small-scale qualitative study was conducted over two years, involving numerous one-on-one interviews, group discussions and general field exploration. Through inductive data analysis, the following respondent narratives will demonstrate that, in varying moments of crisis, people for whom RSF is important may draw on diverse forms of RSF as a matter of priority to help them deal with and recover from experiences of trauma. The samples show that the extent to which people utilise RSF during stress periods strongly correlates to the intensity of trauma experienced, and the extent to which individuals feel compromised.

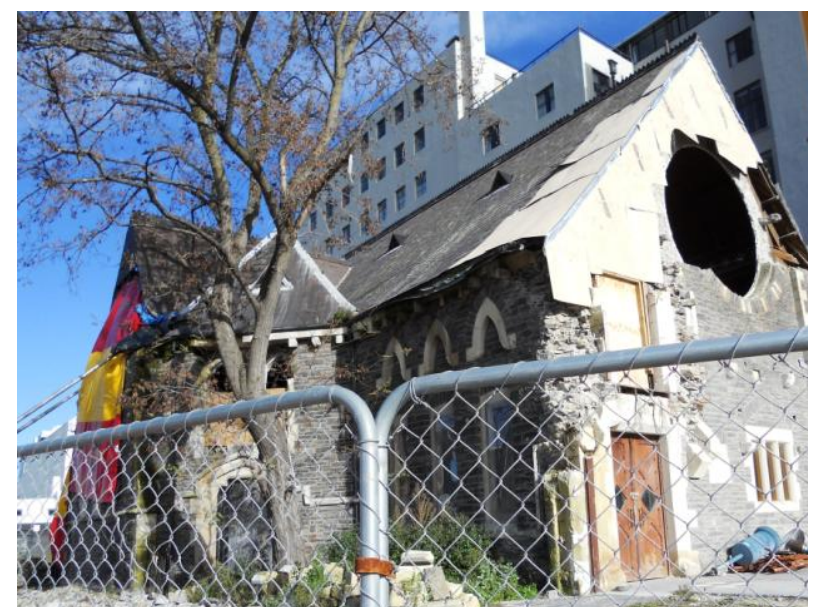

1.8: Destroyed Church in the red zone 2012 


\section{Section 2: Analysis of application of RSF resources}

The following section addresses the ways respondents appropriated RSF resources 2012-2013. After two field trips, data analysis identified six key themes: prayer, recovery through ritual, creative exploration, sense-making, social support, and belonging and place. I address each of these themes in the chapters that follow, highlighting practices that appeared particularly salient and pervasive. I begin with the application of prayer. 


\section{Prayer}

Prayer was the most commonly identified RSF resource among respondents, addressing a range of crisis concerns. This finding was not surprising, supporting existing literature that highlights people's attraction to prayer as a source of strength, empowerment, healing, or simply as a means of coping with high stress situations.

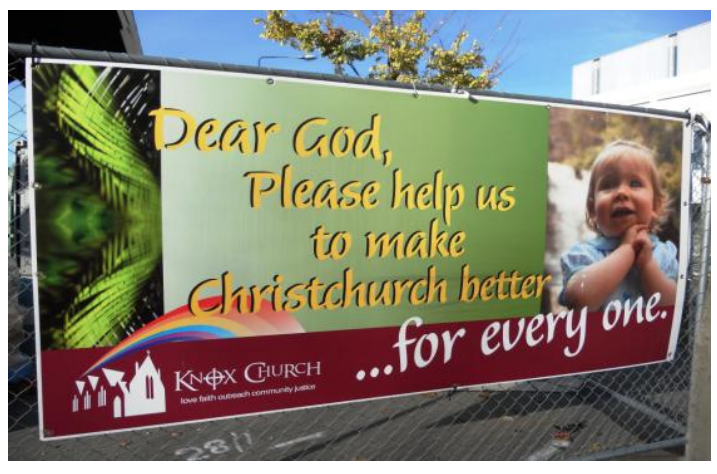

1.9: Knox Church 2013

It was the way my participants employed prayer that did not always conform to what might be conceptualised as traditional prayer. In this section, I examine the numerous ways respondents drew on prayer forms to help them address diverse significant trauma and deep distress, from calling for help, meditation, and intrinsic "knowing" one was not alone, to listening, "chatting" to God, and psychic experience. Other forms of prayer drawn on to help address difficult situations or facilitate recovery included prayer as a sense of Being-ness, or for processing feelings of confusion, abandonment, deep frustration and anger at one's deity.

\subsection{Trauma and prayer studies}

Literature on religion and trauma denotes prayer as a key factor in trauma recovery. How prayer actually functions in people's lives has been less readily addressed and findings are 'inconsistent' regarding the positive and negative effects of prayer on individuals' reported sense of well-being. ${ }^{107}$ What is agreed is that prayer 'fulfils diverse functions' in 'multiple ways'; 'effective at multiple levels' in helping practitioners deal with situations 'where people feel out of control' or overwhelmed. ${ }^{108}$

\footnotetext{
${ }^{107}$ Sarah Banziger, Jacques Janssen, and Peer Scheepers, "Praying in a Secularized Society: An Empirical Study of Praying Practices and Varieties," The International Journal for the Psychology of Religion 18 (2008): 257; Terry Lynn Gall, Claire Charbonneau, Neil Henry Clarke, Karen Grant, Anjali Joseph, and Lisa Shouldice, "Understanding the Nature and Role of Spirituality in Relation to Coping and Health: A Conceptual Framework," Canadian Psychology 46, no. 2 (2005): 93, 98; Linda Mayorga Miller, Terry Lynn Gall, and Lise Corbeil, "The Experience of Prayer with a Sacred Object Within the Context of Significant Life Stress," Journal of Spirituality in Mental Health 13 (2011): 249; Jerry T. Mitchell, "Prayer in Disaster: Case Study of Christian Clergy," Natural Hazards Review 4, No. 1 (2003): 20; Nava R. Silton, Kevin J. Flannelly, Kathleen Galek and David Fleenor, "Pray Tell: The Who, What, Why, and How of Prayer Across Multiple Faiths," Pastoral Psychol 62 (2013): 41.

${ }^{108}$ Banziger et al, "Praying in a Secularized Society", 264; Bronwyn Castel, Missing Pieces: Understanding the Influence of Client's Religious and Spiritual Beliefs within the Frame of Cognitive Case Conceptualisation, Massey University, "Study Explores Religion and Mental Health Care," http://massey.ac.nz/massey/about-massey/new/article (accessed February 11, 2013):40; Gal et al, 93; Neal Krause, "Lifetime Trauma, Prayer, and Psychological Distress in Late Life",
} 
Definitions are equally contradictory, and 'at times taken for granted'. ${ }^{109}$ Due to the broad spectrum of traditional and non-orthodox RSF representation in this enquiry, I define prayer as:

Diverse forms of religious or spiritual communication - or connection between an individual or group, and their Deity (Deities), Ancestors, Spirit guides, loved ones, the Supernatural, or perception of Ultimate Reality.

Prayer types conforming to this definition are manifold, and may include verbal and non-verbal prayer, forms of supplication (plea for help), intercessory (prayers for others), petitionary (prayers for oneself), discursive or contemplative prayers (meditation), or acts of praise. ${ }^{110}$ Intentional 'surrendering' of 'personal control' to deity, ancestors or the Supernatural, represents another form conducted by 'individuals under extreme stress' seeking relief, comfort or 'a sense of security' that the spirit world is now in charge of a difficult situation. ${ }^{111}$ Previous studies have highlighted a range of purposes for prayer in trauma situations, ${ }^{112}$ many of which were replicated for my respondents. By contrast, the range and combination of prayer forms respondents utilised was remarkably eclectic and diverse, and occasionally subject to change.

\subsection{Calling for help}

Morningstar utilised a combination of prayer types in communicating with Heathen Deity. Prior to her experience of trauma, Morningstar's prayer was formal and structured, often conducted at specific times of the day.

I was doing my daily devotions, lighting candles, burning incense to the Goddess and God and doing a daily Goddess reading. I had some Goddess cards and l'd pull a card and meditate and receive messages. I did that for a long time.

The International Journal for the Psychology of Religion 19, no.1 (2009): 57; Miller et al, 249; W.S.F Pickering, ed. Marcel Mauss On Prayer (New York, Oxford: Durkheim Press/Berghahn Books, 2003), 21.

${ }^{109}$ Banziger et al, 257.

${ }^{110}$ Banziger et al. 257; Rita M Holl, "What is Prayer?" Alternative Health Practitioner 4, No. 2 (1998): 110-111; Miller et al, "The Experience of Prayer With a Sacred Object", 249.

${ }^{111}$ Gal et al. 92.

112 Lawson and Thomas, 343. 
As stressful events cumulated, Morningstar's prayer engagement increased in frequency. The first event came the morning after the September 2010 earthquakes when Morningstar's children were 'at a sleepover at the top of the Cashmere Hills'. Separated from her children for several hours and with no cell phone or landline contact to confirm they were 'alright', an escort was eventually organised by the local council to retrieve Morningstar's children. While Morningstar did not draw on RSF on this occasion, she did five months later, on 22 February 2011.

Although her daughter's school was nearby, Morningstar's autistic son was 'at school on the other side of town'. With roads closed and bridges damaged, Morningstar and her daughter 'had no option but to go home' and wait.

And here was my son stuck on the other side of town and I couldn't get there.

Faring better, Morningstar's ex-husband received assistance from a policeman who took him to another school to meet a taxi delivering the boy, before returning father and son home.

But [they] never got home until 5.30pm that night and the earthquake was at $12.51 \mathrm{pm}$ in the afternoon. My daughter and I were just freaking out ... [but] I had to look calm for my daughter because I didn't want her to flip out.

Distraught phone calls from Australia and the North Island compounded Morningstar's stress.

There was a lot of asking Odin and Freya for help to keep me strong ... help me get through it ... [and] get my son home.

Morningstar said that praying to Odin and Freya helped to calm her down.

I suddenly felt, you know ... after I asked Odin for strength and calmness, I did become a little bit calmer ... and I didn't feel quite so fretful.

For the next three weeks, Morningstar and her children stayed in shelters. At her lowest ebb and exhausted, she travelled back and forth between the shelter, work, and home to feed cats, check on the house, and get ready for work. All respondents spoke of people's nerves being 'frazzled and on edge'. On one particularly tough day Morningstar had an altercation with an angry neighbour. Upset, Morningstar didn't go to work. 
I went back out to the marae and went to sleep ... yeah, the stress and just so tired more than anything else. Apart from asking [Odin and Freya] for strength to get me through it, with my brain still completely intact; I didn't really have time for anything else. [Other RSF practises]

Unfortunately, the worst was not over.

Six months after the earthquake, my son got hit by a car. He nearly died. So that just added to everything! The biggest thing for me was that I felt I didn't react [like I would have before]. Through my [Odinic] path ... instead of going nuts at his father, whose care he was in, I was more focussed on my son and what I could do to help him. My natural instinct was to give him healing while he was lying in the hospital. I could feel like one side of his head was burning and I was sitting there stroking his head and asking Freya to help with healing ... it was just natural. It was the first thing I did.... He had some bleeding on the brain ... [but] the bleeding stopped so that was a bonus; I was a lot calmer than I would have been.

Morningstar's story demonstrates that, as her trauma and stress compounded, she drew on her Heathen faith more fervently, replacing earlier established structured practises with more organic, instinctive procedures.

Instead of lighting candles, burning incense every day, and getting a card and seeing what message they (Odin and Freya) have for me, isn't as important to me now, as directly dealing with the issue and calling on them for aid and thanking them for the things they have done. I've gone back to grounding and centring myself; meditating, focussing, and journeying with them and stuff.

Maslow argues in traumatic situations, people abandon RSF in favour of practical considerations like food and shelter. ${ }^{113}$ Morningstar did the opposite. Her prayer increased as a means to help her access material needs such as food, shelter and community, as well as inner strength, resilience and mental health. Over time, Morningstar's RSF practises became more intrinsic and instinctive, belying Maslow's assertion that forms of RSF are 'mere fripperies ... [that] do not feed the belly. ${ }^{114}$

\footnotetext{
${ }^{113}$ Maslow, 373.

114 Ibid.
} 
Importantly, Morningstar's tendency toward the intrinsic in the wake of her trauma proved to be a recurrent pattern. Maltby and Day refer to intrinsic religion in terms of 'internalised understanding', in which people live 'their religious beliefs ... in every aspect of their life' rather than being directed by externalised frameworks or doctrine. ${ }^{115} \mathrm{~A}$ number of respondent stories from across the faiths included in this study reflect a similar disposition.

Like Morningstar, Silver Rain called on the Goddess to help her ill son when all traditional medical methods had been exhausted. Her method of supplication combined spell-work and use of crystals imbued with prayer.

[The event was] actually quite scary to be honest.... My youngest son is also very sick. He was going through a real bad time and the hospital had taken him off the drug programme that they had put him on because it was affecting his heart and his kidneys. I went and bought some crystals for him, specifically for the area that was needed. I did my own little consecration and blessed them and everything. I lit my candle and had [the crystals] sitting in my hand. Most of them were green. I stood there and shut my eyes and asked for the Goddess to send these crystals and the energy of them to him. As I opened my eyes, I saw this figure standing in the corner [of the dining room]. I just went all shivery and felt "oh my goodness!"

She crossed her arms, bowed her head - and she was cloaked - and said "It shall be done". The next minute it felt like the handful of crystals I had [in my hand] went whoosh like a great big flash of lightening to [my son's] house.

Do you know, in all the things I have seen and done, spiritually and psychically, I was gobsmacked ... but it was beautiful in its own right ... that belief was there for her to say "it shall be done". It was like [Goddess] turned the [crystals] into a big green ball and went whoosh!

\footnotetext{
115 John Maltby and Liza Day. "Religious Experience, Religious Orientation and Schizotypy", Mental Health, Religion and Culture 5, no.2. (2002):164; Gal et al, 92.
} 
Scholars debate whether spell-work, as a form of magick, ${ }^{116}$ can be legitimately conceptualised as a form of prayer. Some definitions distinguish magick as distinct from prayer, regarding magick as a manipulation of power, rather than a religious appeal for help. ${ }^{117}$ Others suggest that prayer is a form of magickal thinking 'located in a transcendent being or entity'. ${ }^{118}$ Conversely, popular literature considers spellwork as prayer communication with divine that works simultaneously with magick and ritual. ${ }^{119}$ Here, the ritual-maker is seen as seeking the assistance of Deity (through prayer) to direct the 'flow of energy from human to the Deities', providing a 'clear focus' in which magick is conducted, and sacred energies are drawn into daily life. $^{120}$

When Silver Rain told me about this event, she had been talking about meditation, daily prayer with a candle, teaching RSF classes to help 'keep her sane', and the numerous family losses she had suffered. This particular supplication appeared to be a response to cumulating stressors. Gal et al. insist that 'religious coping styles' utilised in situations of 'extreme anxiety' involve a 'collaborative relationship' with Deity 'to provide the individual with a sense of empowerment in the face of a difficult situation'. ${ }^{121}$ 'The burden' is thus shared with Deity in a process of prayer 'surrendering'. ${ }^{22}$ Silver Rain considered that prayer, in the form of ritual spell-work, relieved some of the weight of her distress whilst simultaneously providing her with a sense that she was doing something to help her son.

\subsection{Meditation}

Several respondents found meditation useful. Sometimes described as a 'principally secular, therapeutic, and an often individualistic pursuit' in the western world, ${ }^{123}$ spiritual meditation functioned for respondents as a means for connecting with Divine, and as a coping mechanism for processing deep distress.

\footnotetext{
${ }^{116}$ Spelling of magick is used to distinguish religious practise from magic as entertainment.

${ }^{117}$ Annemarie de Waal Malefijt, Religion and Culture: An Introduction to Anthropology of Religion. USA: Waveland Press Inc, 1968): 13, 197.

${ }^{118}$ Scott Cunningham, Living Wicca: A Further Guide for the Solitary Practitioner (USA: Llewellyn Publications, 1999), 57; Mitchell, 22; Christopher Partridge, The Re-Enchantment of the West: Volume 1: Alernative Spiritualities, Sacralization, Popular Culture and Occulture (London \& New York: T \& T Clerk International, 2004), 19; Kathryn Rountree, Embracing the Witch and the Goddess: Feminist Ritualmakers in New Zealand (London and New York: Routledge, 2004), 170.

${ }^{119}$ Cunningham, Living Wicca, 53, 57-58.

${ }^{120}$ Ibid.

${ }^{121}$ Gal et al. 92.

122 Ibid.

123 John P Bartowski, Gabriel A. Acevedo and Harriet Van Loggerenberg, "Prayer, Meditation and Anxiety: Durkheim Revisited," Religions 8, no. 191 (2017), 2, 4.
} 
Meditation helped Silver Rain to maintain balance in her life, to cope with her cumulative trauma.

I try to always keep a balance within my life, like meditation is - it's good for you, and I know that. Obviously there were weeks I didn't do it because of the situation but yes, I tried to keep that balance there.

Roselyn Billing on the other hand, struggled to communicate her need for space to meditate at home, to cope with her mounting stressors.

The house was full of stuff. It was just chocker everywhere. I said I wanted to make a room where I can just go and be on my own, light my candles, do my meditation. He was like ok, cleared a little space basically this size, stood a chair in the middle of it and said "there you go". That was his level of understanding of my needs; hence the relationship ended. [laughs]

Castel suggests that trying to communicate RSF needs to loved ones or clinicians, particularly during high stress, can be as challenging as dealing with the distress itself. ${ }^{124}$ Fortunately for Roselyn, a Medium at her church offered help.

[She] actually gave me a clue about how to cope and bury [my distress] until I had a safe place to let it out. I was very chuffed.

I can't remember the exact expression that she used. I haven't used it for a while but I used to say it every morning: "To the highest and the best you come to know". That was kind of the expression that I said all day.... It was the only thing that got me through. Seriously.

I used to sit and pray and meditate as best I could, all the way to work on the bus. Meditating on the bus was not easy but l'd put my headphones on and I used to say now this is my peaceful time.

Roselyn says meditating and praying on the bus to and from work helped to calm the panic she felt about how to deal with situations at work and home.

In here, panic in my stomach and a knot like you can't believe because I knew what I was going to [at] home [and] what I had been through [during]

${ }^{124}$ Castel, Missing Pieces, 177, 194. 
the day [at work]. I was in a state by the time I got home. All I wanted was a hug and a gentle hello. How are you? And I didn't get that. So, I battled through it [with meditation and prayer].

When I stepped on the bus, I cried every morning on my way to work saying [the mantra] to myself. Yeah, I used to do the Doreen Virtue meditations as well; ${ }^{125}$ the chakra clearing, the colours. Anything I possibly could!

Roselyn says that she no longer draws on those same mantras and prayers. Like Morningstar, the role prayer played for Roselyn Billing changed as her needs changed.

No, what I'm drawing on now is the fact that I know that I'm not alone and I know that I'm protected and I'm assisted all the way. I mean, I just know that they [Spirit $\left.{ }^{126}\right]$ are there all the time. If anything happens throughout the day, I think, thanks guys. Thanks for that. I just know that they're with me and that's brilliant.

However, not all respondents found meditation to be a positive and constructive coping and problem solving tool. When Unicorn drew on meditation during unexpected earthquake moments, it was quite unsettling.

On one occasion for meditation at night, I [visualised putting] my roots down into the earth, to connect with the centre of the earth, and the centre of my being; leading up to my crown [chakra]. There was an aftershock in the middle of that. When you get thrown out like that when you're half way through a meditation, its freaky.... It takes a couple of days to get your head clear after something like that; ... it's quite frightening.

I have not encountered accounts like Unicorns in existing literature on RSF, prayer and trauma. Her story nonetheless highlights the challenges and problems raised for practitioners of nature-based RSF in the context of crises where natural events (like meditation) occurring during nature events (earthquakes) are implicated in - or even central to - experiences of trauma and personal upheaval.

\footnotetext{
${ }^{125}$ Guided meditation tape.

${ }^{126}$ Term to describe Spiritual guides, dead loved one, or other forms of Spiritual/Supernatural support.
} 


\subsection{Not alone}

Respondents consistently reported a sense of not being alone in their traumatic circumstances. In this study, respondent "knowing" is a form of prayer and communicated insight, rather than simply passive belief. According to McGuire, lived religious experience blurs the boundaries between the sacred and profane to the extent that an individual's sense of [a constant] sacral presence' is accepted as similar to ongoing "chatting" with Deity or Spirits even though no words may be spoken. ${ }^{127}$

'Knowing' that she was not alone supported Pixie during difficult periods, especially at 12:51pm, 22 February 2011.

I was actually in hospital. I had just had surgery the day before and I was lying on the bed. I couldn't walk at that point. The nurse came in to check that I was alright and the next thing there was this terrible noise. Everything fell off the walls, the bed shook and [the nurse] lost it. She tried to get under my bed. She was shouting and saying "God! God! Where are you? God! We need you! Help us!" I was just sitting on the bed thinking "But .. God's here!" I wriggled my bottom to the end of the bed so I could get my arms around her and I said "It's alright. God's here with us. Relax. Relax and breathe." I knew in my heart l'd be fine. There was no need for all that and I also knew without a shadow of a doubt that we carry God with us. So God was there. Hello! Powerless to move or protect herself, Pixie appeared to draw strength from the knowledge she was not alone, enabling Pixie to keep calm and calm others in a state of panic.

George also drew strength and calm from knowing he was not alone; that he was protected and assisted at the moment the 22 February earthquake struck.

During the actual earthquakes themselves - suddenly the world stops and you become aware of everything; every moment, every breath. But I also felt peace. The strength was coming through from my spiritual side saying you're safe, you're ok. We're slowing things down. You've got to make decisions but the decisions (George clicked his fingers), they're [right] there. You [just] knew [what to do]. 
On February 22 George was at work, at the retirement home. The moment the earthquake struck, he looked at the roof to see if it was 'going to hold', and then at the elderly folk, wondering how he was going to help everyone.

[I was] aware, spiritually, that people had [already] died.... It was just a real knowing. [But] it's just part of the journey; just relax, breathe and we can get through this.

Part of it is having a belief in ourselves, as well as a belief in God, and the belief that God is protecting us; God is with us and that we're Ok. Yes, the unthinkable happens... (George and Pixie)

George and Pixie described their 'knowing' as more than merely a feeling of God's protection, but also a sense of God's active presence - that He was with them, 'and Spirit as well'.

Annie-Bell was another respondent who said Spirit kept her safe during the earthquakes.

I was in the house by myself when we got the big earthquake (February 22) ... once again I had to be within; resilient. It was basically my belief that Spirit would care and keep me safe because if I was injured I would not be able to be a support for my daughter.

Cat has had a similar sense of "knowing" of Spirit's presence or non-verbal communication all his adult life. After his wife died, Cat says it got him through the darkest times.

The ones that have helped me have been Spirit on the other side. They have really been there for me.

Cat said he had recently felt Spirit had given him 'permission to live again'. I just sort of had a feeling - like nothing in my head, like a word, which would be nice - but just a feeling [that] I have permission to live again. So ... I'm living again (he starts to smile). I'm finding things are opening up and every day is a little bit more happier than what it was before. 
For Cat, knowing that Spirit is constantly with him and encouraging him, combined with the support of the small Spiritualist Church Trauma group, delivered a sense of purpose for living.

I have a feeling; in myself I feel lighter in my stomach, in my head; clearer. I just feel like something's told me to live. Even though I don't feel like living, they tell me to live. No human being's told me that. It's coming from the other side.

A crucial point here is that Cat credits his RSF with providing a sense of purpose and a reason to live - something even more fundamental than food and shelter. Cat's account is similar to Schweitzer, Greenslade and Ashraf's study of Sudanese refugees who 'isolated themselves from the community', drawing instead on regular prayer with God to help deal with overwhelming feelings of unhappiness, isolation, and no one to talk to. ${ }^{128}$ In Cat's case, he credited his RSF with a significant improvement in mental health and general well-being. This sense of "knowing" and attribution of protection to Divine presence was widespread among respondents and across faiths.

\subsection{Listening, chatting and psychic experience}

Pollyanna's prayer, on the other hand, was more active, taking the form of informal "chatting" and "listening". Chatting can be understood as a 'regular line of communication' in intimate and ongoing relationship with Deity or the Supernatural. ${ }^{129}$ On 22 February Pollyanna says hearing God speak to her saved the lives of her and her friend.

Well, God saved my life. I was with my friend. We were in the Farmers parking building because we had to get to a meeting at one o'clock, at the Town Hall.

At ten minutes to $1 \mathrm{pm}$ the women reached the bottom of the parking building stairs.

My friend looked at me and said "Which way shall we go?" There was a rather creepyish [path]way and I said; "Now!"

\footnotetext{
${ }^{128}$ Schweitzer, Greenslade and Kagee, "Coping and Resilience in Refugees from the Sudan", 283.

${ }^{129}$ Cunningham, 53, 56-57.
} 
God took me by the shoulder and pushed me... I said "We go now! Out here now! Out fast!" We raced along the footpath and reached the corner and held on to the traffic pole. Then the earthquake came. In that one minute you see, so that was a one minute warning that saved our lives.

People were locked in the Farmers parking building [where we had just come from] ... for nine hours. Where we had walked along the pavement, that had all fallen down and the building on the corner we were on, didn't. So that's amazing. That's miraculous. We were holding on [tightly] to the traffic light pole and all the people were being jumped up and down; the people that came running out of Starbucks ... they were being thrown up in the air!

So I mean, God saved our lives. If I hadn't listened and thought "Oh, what the?? Why am I being made to go fast now?" I have learned over the years from a number of experiences, if God says something like that; if you don't listen - and people call it intuition, instinct, whatever - you absolutely must listen.

Pollyanna's report of psychic or intuitive communication with God is not uncommon. Luhrmann's study on prayer reported 'unusual sensory experience' among research participants including 'hearing voices' that were 'sometimes associated with a ... direct experience of God'. ${ }^{130}$ Such phenomena are recurrently labelled as 'criteria for psychoses'. ${ }^{131}$ Yet like Luhrmann I did not consider my respondent accounts to be evidence of psychosis.

Louise Child asserts that various 'states of waking, deep sleep, and dreaming' and 'visionary or dream figures' can be regarded as types of 'speech prayer'. ${ }^{132}$ Toast regarded speech prayer as integral to his life, livelihood and sense of wellbeing. However, during the earthquakes, Toast said he was receiving messages in his dreams that he was unsure about. With mounting stress, serious injury, and the loss

\footnotetext{
${ }^{130}$ T.M. Luhrmann, "Lord, Teach Us to Pray: Prayer Practice Affects Cognitive Processing." Journal of Cognition and Culture 13 (2013): 166.

${ }^{131}$ Ibid.

132 Louise Child, "Mantras and Spells: Durkheim and Mauss, Religious Speech and Tantric Buddhism". New Series, 9 (2003): 61-63.
} 
of their home and shop, Toast sought the advice of a local vicar. The meeting did not go well.

[At the beginning of the earthquakes] I went to a minister - he was Anglican I think and I told him my visions and what I was seeing and he told me they were demons.

Toast said that he felt sorry for the Vicar for thinking that way. He was worried about the message in the dream, and how he should help.

I had seen a child (young girl) asking me to tell her mother something and I kind of hoped [the Vicar] would've said "Well, other people come and say similar things and these things happen the way they do", but he was tunnel vision and it was really sad.

Toast told me that while 'it would have been weird' and 'a new experience' (had the Vicar been supportive), he would have felt more supported and 'reassured'. It would have been weird because my experiences and them understanding my experiences are a different thing.

Unfortunately, the Vicar wasn't supportive, so Toast sought advocacy 'elsewhere' in the form of an online international forum of clairvoyants 'training intuitives to seek missing children', where Toast also uncovered the mystery of the girl in his visions:

I learned she was a young girl in the [United] States who had been abducted by a neighbour...he had killed [and raped] her and dumped her body.

With details from Toast's dream, police in the United States were able to locate the girl and return her body home to her mother.

They found her [and] I was able to give a description of the killer's face [to the police].

Toast said that using his clairvoyance (speech prayer) to help others overseas gave him an outlet for unresolved frustrations closer to home, such as ongoing battles with insurance companies, EQC, and loss of the family home. Toast was fortunate to find a group that provided him with much-needed support and a sense of purpose. Castilian Blue on the other hand, was initially not so lucky. 
Castilian Blue began experiencing speech prayer prior to the earthquakes and as she recovered from her many years of trauma and abuse. Culbertson argues 'psychic opening [and] communication with Spirit guides is not far removed from certain types of intercessory prayers to the Saints and the Blessed Virgin; or from glossolalia (speaking in tongues), ${ }^{133}$ Unfortunately, Castilian had no prior knowledge of this type of prayer communication. Nor did she understand Maori spiritual practises and protocols.

I guess because of the experiences of psyche that I was experiencing... I didn't realise that you don't say those things amongst certain groups. People were bringing me photographs and all sorts of stuff, and they liked what I was doing right up until they didn't like hearing about things... and I didn't know at that time that you weren't to say that. So [it went] from "Wow you're.." this and "You're Matakite" (psychic abilities and future prophecy), to now you're crazy and all this. It went from one type of experience of feeling very embraced to being shunned and exodus from the community...[with] a mental illness. That then stripped away the embracing of the identity that I felt. I shunned [RSF] from that point.. again.

Around the time of the earthquakes, Castilian Blue joined the Spiritualist Church where she felt supported, part of a community, and empowered to continue to draw on her RSF (prayer) tools to overcome her challenges including the Alcoholics Anonymous' (AA) Twelve Steps programme. The programme involves regular prayerful communication with a 'Higher Power' for support, guidance and to 'restore sanity. ${ }^{134}$

This church has definitely been - certainly since I have done the steps and continued to redo the steps - my life. I know what it's been like without having spirituality of any kind ... from the beginning of my day to the end of my day ... it has absolutely changed my life, completely.

Both Castilian Blue and Toast's stories highlight the difference that recognition of individuals' RSF practices can make. Others' rejection of their speech prayer

\footnotetext{
133 Philip Culbertson,"The Shadow of the Transcendent: Valuing Spirituality in Psychotherapy," The Journal of the New Zealand Association of Psychotherapists, 4 (1998): 29.

${ }^{134}$ AddictionCenter: 12 Step Programs https://www.addictioncenter.com/treatment/12-step-programs/
} 
experiences led to frustration and confusion, or even distress and fear. In Castilian's case, rejection compounded her stress and trauma rather than alleviating it. Conversely, once she received positive assistance in her RSF practice, she flourished and began to recover.

Mysar's constant communication with Divine however, was mediated through her crystals.

I don't do [read] cards and I don't do clairvoyance like [Toast]. I do listen intuitively, whether it be to my guardian angels or whoever and I do sometimes hear voices. I'm not going mad [laughs] but you know ... sometimes I'm thinking "do I want this one or do I want that one?" and I will hear this voice saying "that one".

After the earthquakes, Mysar's use of her herbs, crystals and meditation increased. She viewed these as helping her feel safe and not alone, in the midst of instability and socio-economic isolation.

I've lost my home and a lot of my knick-knacks so now for me, the only thing that I have left is my spirituality; my crystals, you know my herbs and oils and stuff like that... I [also] use my gut feeling for most things. Women's intuition is pretty good.

As a long time tarot reader, I have always referred to forms of divination, like crystals, as "talking to Divine". Mysar's approach was similar, and reflects a sentiment shared by others in different contexts - for example, Kaldenberg in reference to Heathen runes. ${ }^{135}$

\subsection{Prayer as Being-ness}

Prior to Snow White's significant trauma events, constant prayer with God had been a big part of her everyday life. Later, however, her prayer activity diminished.

Snow White claimed that prior to her trauma:

Prayer, [speaking in tongues] and Bible study were important for me.

\footnotetext{
${ }^{135}$ Wyatt, Kaldenberg, Perceived Heathenism \& Odinic Prayer: A Book of Heathen Prayer and Direct Contact with Our Living Gods (USA, Wyatt Kaldenberg, 2011): 24, 101.
} 
At the time, glossolalia made her 'feel really close to God [and] part of something bigger than [her]self'. It provided a sense of safety, belonging, comfort, and 'rightness'.

I knew God's right behind you; I knew what to do and what not to do.

Prayer also functioned as a key problem solving tool.

All the time! [I remember] this guy I knew who was really big on prayer. He used to ask God how many sugars he should have in his coffee and that sort of thing. I was close but I never got that bad! [laughs]

Since her traumatic experience, Snow White no longer draws on glossolalia and traditional forms of prayer. During the earthquakes, she did not draw on prayer at all.

There's so much to do and think about and worry about. I guess that's the prime time when I should have been praying and I just couldn't do it.

Snow White's rejection of glossolalia or other traditionally understood forms of Christian prayer should not be understood simply as a displacement of irrelevant "frippery". In large part, it followed the deep distress generated by her Pentecostal Christian community. Like many other respondents following traumatic experience, Snow White's RSF practises shifted to forms of RSF that may be characterised as more organic and intrinsic. Although Snow White claimed to no longer pray as she had, she expressed a newfound experiential 'state of being-ness':

Occasionally there are like, perfect moments in life where everything just comes together. [For example], the other day - I'm a massage therapist. I'm massaging this guy.... We had some opera blaring on the [stereo] because he loves it loud and so do I. I looked out and saw my garden and felt that moment. You know? Once I would have put that in a God context but now ... it's more of a state of being.....

\subsection{Prayerful Processing}

For other respondents, prayer communication assisted with processing feelings of confusion. Unicorn felt that Goddess had abandoned her and was causing the natural disaster events. She wanted answers.

The earth is our foundation, our stability. It was a huge betrayal of trust [for me]. That's how I felt. I couldn't trust the earth to be my stability anymore ... it 
just wasn't. It was about a month later when the Japan [earthquake and Tsunami happened], I [asked Goddess]: "Is there some purpose to this or is this just growing pains, stretching, whatever?"

I was told it was a winnowing.... A winnowing is like clearing the wheat from the chaff; survival of the fittest type thing. I really struggled with that [but] it did give me the opportunity to take a step back and go ok I don't have to like it, but I understand it.

I was surprised by Unicorn's explanation of 'winnowing', in part because I had not heard of it as an aspect of Pagan belief. Traditionally, themes of 'threshing and winnowing or separating the grain' are accepted as Biblical references 'commonly used for judgement' on the 'fates of good and evil'; a theological concept of dualism generally not found in contemporary Paganism. ${ }^{136}$ However, as Mitchell points out, 'People often find themselves led toward the cosmological when trying to understand calamity'; 'find[ing] explanation and assign[ing] meaning', within the framework of their faith-tradition. ${ }^{137}$ Although Mitchell was referring to variations of traditional Christianity, Unicorn's comments suggest the above may apply to non-orthodox, non-Christian faith orientations as well.

The prayerful processing of clergy provides another significant dimension for enquiry. The role of religious professionals in assisting the recovery of trauma victims is widely understood. Less considered, are the personal, theological, and professional challenges for ministers during or following traumatic events.

Trying to understand what God wanted in the wake of distressing and inadequate support had a profound effect on Peter Frazer.

I remember, a few times, lying in bed ... I just felt so judged. I was asking why, why did I find myself in that situation? I asked God "Why are you leaving me alone to deal with this? ... God what are you doing? ... What do you want from me?!"

\footnotetext{
${ }^{136}$ Mt3:12, Lk 3:17; Harold W. Attridge, The Harper Collins Study Bible: New Revised Standard Version. USA: HarperOne, 1989): 1671, 1767-8; McGee, 10.

${ }^{137}$ Mitchell, 20.
} 
Frustrated and angry; Peter felt physically and spiritually 'very alone'. Rarely do studies examine prayer in the form of anger and frustration at Deity as part of the experience of trauma. Culbertson insists, however, that contrasting 'clinical perceptions' of RSF struggle as a 'breakdown'; spiritual agony may result in a 'breakthrough' to a new level of understanding. ${ }^{138}$ Soon, Peter began to look at his situation differently, making the decision to leave ministry and work for the vulnerable in another capacity.

Post-earthquake, the local challenges were huge. It made me look at mission differently.

I think the earthquakes brought to the fore what would have happened eventually anyway. It just made it happen quicker. I'm more fulfilled now working for a social service agency where I can advocate for people in need... l've become a lot more liberal.

According to Mattis, meaning-making and coping strategy is intricately interwoven with epistemology. ${ }^{139}$ Peter Frazer's tumultuous process of processing frustration and distress was entwined with how he understood God and his relationship with Divine. Like Mattis' respondents, Peter was able to 'interrogate and accept the reality of [his] circumstances', find 'emotional comfort and shield' himself from external pressures enough to formulate decisions that helped him to find a way forward. ${ }^{140}$ Prayerful struggle was a central means for doing this.

When I asked Peter Frazer what he would say to someone about spirituality and trauma he replied:

l'd want them to know that it might not feel like it at the time but God is there and God feels your heartbreak. Rather than judging you for your failure which is inevitable as humans - He's there and He's loving you. That weakness becomes part of your strength which helps shape your character. You'll be a happier, better person, if you let Him take hold of you through that.

\footnotetext{
${ }^{138}$ Culbertson 28-29.

139 Mattis asserts that her own respondents went through as similar prayer process of interrogation, acceptance and decision-making. Jacqueline, S Mattis, "Religion and Spirituality in the Meaning-Making and Coping Experiences of African American Women: A Qualitative Analysis", Psychology of Women Quarterly 26 (2002): 318.

${ }^{140}$ Mattis, "Religion and Spirituality in the Meaning-Making", 317.
} 


\subsection{Conclusion}

The most commonly utilised RSF feature, respondent prayer examples amassed a broad variation of communication types that did not always conform with traditional concepts of prayer. For some participants, prayer served as a vehicle for requesting assistance to heal a sick loved one; for protection, addressing overwhelming feelings of panic, distress, hopelessness and isolation. For others, it played a key role in sense-making, taking action on behalf of others and getting to safety. Yet, it did not always follow that participants found prayer helpful or sufficient in addressing their crisis situations. Indeed, while some prayer ordeals reinforced pre-existing beliefs; in others, the relationship with one's RSF (or Deity) deepened and evolved into more spontaneous, intuitive and intrinsic practises, on the one hand. On the other, sourcing suitable RSF prayer support, appropriate to the individual's specific needs proved to be a challenge for a few respondents.

Nonetheless, even in the midst of overwhelming grief, confusion or frustration, prayer as a coping or recovery mechanism was not abandoned in favour of more pressing needs. Across the traditions, both during and following traumatic experience, there was a general trend among respondents to replace formal, scripted prayer types for more organic and intrinsic forms of spiritual communication. This tendency was most notable among those respondents who experienced more intense forms of trauma, during or prior to the Canterbury earthquake events. Salient among participants were those respondents who utilised prayer to help them in ways that appeared distinct from their own faith-path traditions; a trait that appears again in the following chapter on ritual. A second recurrent theme was a strong sense of sacral presence among participants; that they were not alone in their struggles and trauma recovery processes.

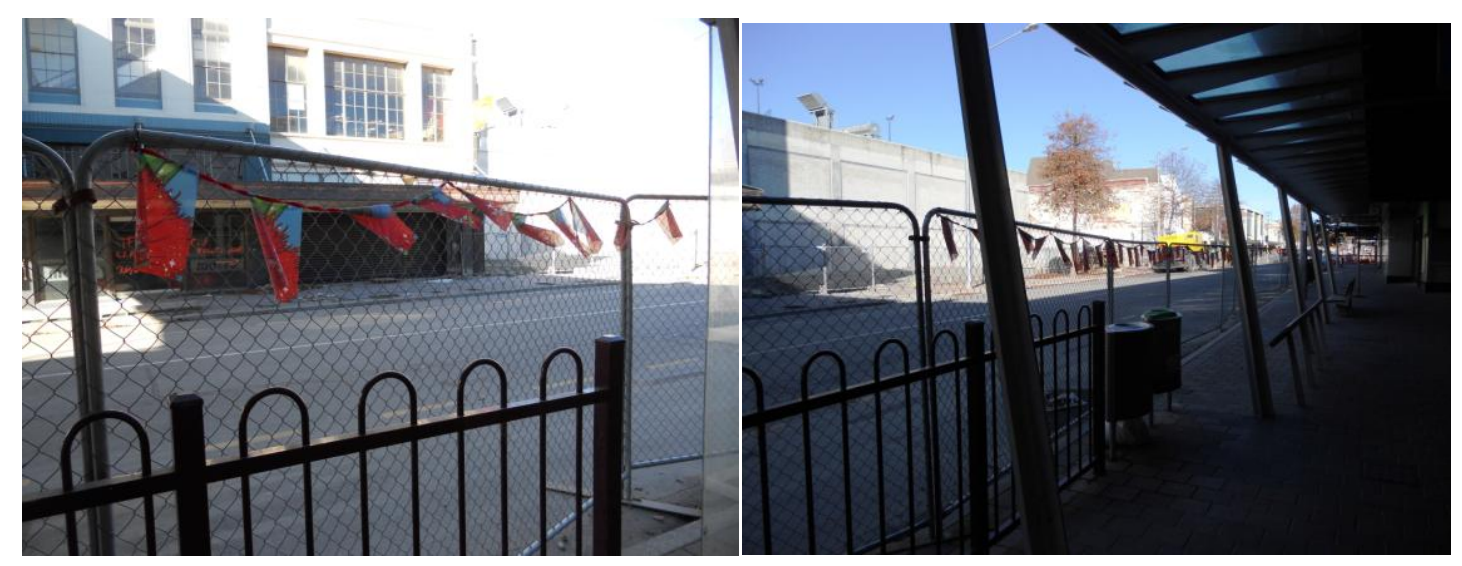

1.10: Flags on cordoned fences resemble Tibetan prayer flags, Red zone 2012 


\section{Recovery through Ritual}

Ritual is often identified as a central feature of religious activity, with ritual action asserted as inherently linked to a tradition's 'cosmological framework'. ${ }^{141}$ Evidence from the field challenged this assumption in the context of responses to significant trauma and recovery. Limited to just a few respondent groups, some participants did not draw on ritual at all, despite its centrality to their faith-path beliefs and practises. In this section I present evidence of respondents who utilised ritual to address trauma concerns did so for four main reasons; to express deep emotion; to distract from those same emotions; to facilitate personal empowerment; and to engender a sense of "moving forward" beyond feelings of loss, or personal and social limitation. I also demonstrate that prior RSF practise and belief involving ritual was not a predeterminant for the utilisation of ritual as a coping mechanism or recovery tool.

\subsection{Ritual Studies and Trauma}

Scholarly interest in religious ritual has been widespread since the late nineteenth century. ${ }^{142}$ Many studies have focussed on ritual's role within indigenous societies, with particular emphasis on rites for fertility, life passage and seasonal celebrations. ${ }^{143}$ Performative symbolic enactments, these rituals were generally accepted as functioning to reinforce specific belief systems and societal norms, as well as to maintain relationships with the Divine or the Supernatural. ${ }^{144}$ While there has been considerable recent interest in contemporary western religious and secular rituals and ceremony, ${ }^{145}$ exploration of non-traditional and hybrid spiritual ritual frameworks, of the kind examined in this thesis, have been slower to appear.

Definitions of ritual are wide-ranging. ${ }^{146}$ In this study, I employ McDonald, Zwissler, and Hurst's interpretations of ritual. McDonald likens ritual to a creative process of adaptability and 'ingestion of boundaries'. ${ }^{147}$ Zwissler considers ritual an expression

\footnotetext{
${ }^{141}$ Hollye Hurst, "A Narrative Study of Contemporary Ritual and the Revitalisation of the Spiritual Imagination," PhD diss., Institute of Integral Studies, San Francisco, California, (1995): 6; Julie McDonald, "Contemporary Ritual-makers: A Study of Indepent Celebrants in New Zealand," PhD, Massey University, 2011, 59; Rountree, 175.

${ }_{142}$ Catherine Bell, Ritual Theory, Ritual Practice, (New York: Oxford University Press, 1992): 16.

${ }^{143}$ Bell, Ritual Theory, 16.

${ }^{144}$ Malefit, 188-9, Rountree, The Witch and the Goddess, 174.

${ }^{145}$ McDonald, "Contemporary Ritual-makers," 58, 65.

${ }^{146}$ McDonald, 59.

147 Fiona Bowie, The Anthropology of Religion: An Introduction (Oxford, UK: Blackwell Publishing, 2006), 138; McDonald, 100.
} 
of 'internal thought and motivation'. ${ }^{148}$ Hurst, building on Goldenberg, sees ritual as shared by 'people coming together to support one another in the discovery of meaning'. ${ }^{149}$

In Victor Turner's classic formulation, ritual ceremonies are designed to move the participant through from one life stage or social condition to another, and to maintain a sense of social cohesion and equilibrium. ${ }^{150}$ The context of post-earthquake Christchurch 2012-2013 meant that Cantabrians were waking up to a "new kind of normal" where social cohesion and stability were somewhat elusive. A continuing state of fragility, unrest and even disarray persisted, even though rebuilding had already begun in earnest in some areas of the region. ${ }^{151}$ Two respondent rituals discussed below directly addressed the impact of the Canterbury earthquakes. The examples exhibit therapeutic qualities resembling contemporary (secular) psychotherapeutic ceremonies that confront composite distresses and concerns.

International psychotherapeutic exploration of ritual and traumatic life experience has become an innovative area of engagement. ${ }^{152}$ Mirroring the three phases of Van Gennep's rite of passage, such therapeutic forms aim to move individuals through a process of personal transformation, emphasising personal agency and control of personal 'boundaries', ahead of re-engagement with society. ${ }^{153}$ Harris argues the goal of 'reintegration' in ritual is important because a common characteristic of PTSD is the tendency toward self-isolation and withdrawal from society. ${ }^{154}$ Another common 'human neurological response to trauma' is the challenge to render traumatic experience into words. ${ }^{155}$ Accordingly, experimental therapeutic trauma recovery rituals are often constructed to 'offer a medium for difficult and potentially conflicted emotions associated with traumatic exposures'; to express and release

\footnotetext{
148 Laurel Zwissler, "Second Nature: Contemprary Pagan Ritual Borrowing in Progressive Christian Communities," Canadian Woman Studies 29 (1/2), 19.

149 Hurst, "A Narrative Study of Contemporary Ritual", 9-10.

${ }^{150}$ Victor Turner, The Ritual Process: Structure and Anti-Structure. Ithaca, New York: Cornell Paperbacks, Cornell University Press, 1991): 94-5.

${ }^{151}$ Bayer, https://www.nzherald.co.nz/nz/news/article.cfm?c id=1\&objectid=11593195

${ }^{152}$ David Alan Harris, "The Paradox of Expressing Speechless Terror: Ritual Liminality in the Creative Arts Therapies Treatment of Posttraumatic Distress," The Arts in Psychotherapy 36, No. 2 (2009): 95.

${ }^{153}$ Harris, "The Paradox of Expressing Speechless Terror," 99, 101, 105.

${ }^{154}$ Ibid. 105.

${ }^{155}$ Ibid. 97.
} 
within safely contained boundaries, where words may be inadequate or difficult to articulate. ${ }^{156}$

Contemporary RSF rituals can be equally 'innovative', expressive, and 'experimental', sometimes intentionally crossing - or blending - religious and cultural boundaries. ${ }^{157}$ However, in contrast to the above, the following rituals did not occur in controlled, scientific environments and participants were not guided through theoretically informed ritual processes to engage extreme traumatic concerns. The context of post-earthquake Canterbury was more chaotic than controlled and rituals developed in an instinctive, organic manner. Themes related to upheaval, grief and loss. Some participants were dealing with multiple traumas, including stressors not directly related to the earthquakes.

\subsection{Fred's Inclusive-Progressive Presbyterian Church}

Fred's parish employed a variety of creative, therapeutic rituals in the initial weeks directly following the September 2010 and February 2011 earthquakes. Progressive Christianity encourages artistically innovative and 'emotionally expressive' spiritual worship which includes explorative media like ritual. ${ }^{158}$ One such ritual, which I refer to as the "ritual of

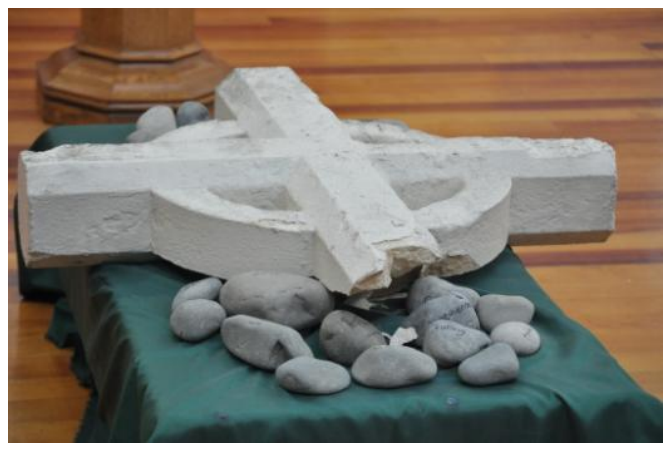

1.11: Stones depicting personal gains (2010) with steeple added in 2011. stones", was widely identified by the congregation as one they found especially helpful.

The ritual of stones was conducted the Sunday directly after the September 2010 earthquake. Individuals were invited to take a stone and write on it things people felt they had gained from the earthquake experience, rather than what they had lost. (Image 1.11)

That stones service that we had. That was sooo good; it was handled really beautifully. It was just really meaningful. (Snow White)

\footnotetext{
${ }^{156}$ Harris, 97, 99; Leslie E. Korn, Rhythms of Recovery: Trauma, Nature \& The Body (New York, Routledge, 2013 ), 171.

${ }^{157}$ Zwissler, "Second Nature," 17,19.

${ }^{158}$ Taussig, 17, 20-21.
} 


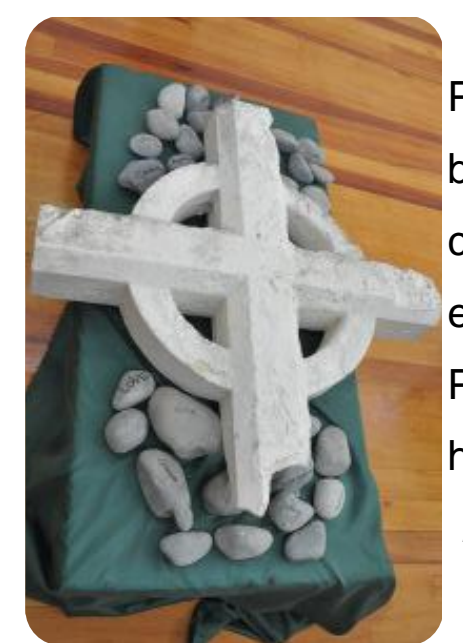

Parish members I spoke to suggested that focussing on the beneficial outcome, rather than loss, provided them with constructive ways to deal with the stress of the September earthquake by viewing the event from a different perspective. People told me the earthquake, which had happened late at night, had been a 'terrifying' experience.

It was the worst night you could imagine. (Pollyanna)

At the end of the ritual, the worded stones were placed in a prominent corner of the hall, where the congregation was then worshipping. In 2011, the church steeple, which broke off during the 22 February earthquake, was added to the display. According to Fred, the emphases of parish rituals between 2010 and 2011 were on the positive effects of the earthquake crises.

It was about the good stuff that had come out of [both] crises. (Fred)

Fred and Barney told me that a number of similar services were conducted in their two parishes during this period. Rituals incorporated a blend of creative exploration, symbolic enactment, and (sometimes) the sharing of personal stories, themes focussed on moving people beyond the trauma of the quakes. Parish members reported that they did not want to dwell on the emotional effects of the earthquakes.

Not a "ritual" in and of itself, a service held directly following the February 22 earthquake, illustrates the extent of parish emphasis on restoration and progression. Several members were invited to share their stories. These included: a young woman who had created a reproduction piece of art on the broken parish stained glass window and a double amputee who had lost his legs in the collapse of the PGC building.

[The man] who was a double amputee was furious that he didn't want to talk about February 22. He said "it's not that I mind", but for him, his wife, and his family, he actually wanted to talk about how they were progressing beyond it. (Fred)

So Fred changed the theme for the day from 'recovery' to 're-building,' to better reflect what members wanted to focus on. 
It's been quite noticeable. People haven't, I don't think, wanted to get stuck.

Most have wanted to get stuck in. (Fred)

Walsh points to the 'experience of powerlessness and [feelings of] being overwhelmed' that can be experienced as a result of trauma. ${ }^{159}$ The process of healing, according to Walsh, involves re-establishing feelings of 'safety and control, connection to others ... [and] a shared understanding of reality. ${ }^{160}$ In a situation that undoubtedly felt very out of control, the corporeal act of holding a stone and writing one's personal gains on it provided a tangible way to reclaim personal power and sense of moving forward. Zwissler's notion of ritual as an outward expression of internal feelings and motivations; ${ }^{161}$ is reinforced through personal stories by fellow congregation members, accentuating themes of rebuilding.

However, as Korn points out, the success of these types of therapeutic rituals depends on the intimate connection between participants, necessary for building trust. ${ }^{162}$ Ritual contexts of this kind require that participants feel safe. ${ }^{163}$ This need for intimacy was exemplified by what Fred described as extensive 'hugging ... [and behaviour] not normally associated with a Presbyterian gathering.' According to Snow White 'it was all about taking care of each other'.

Interestingly, ritual's value as a recovery tool post-earthquake quickly dissipated for Fred and Barney's churches. Highly valued in the immediate aftermath of the quakes, congregations subsequently moved on to engage more frequently with other forms of RSF.

As time has gone on rituals [like Fred's ritual of stones] haven't been needed. I haven't felt that it's been an ongoing thing. It's helpful to get some stuff out but actually, I think people - I think they want food for the continuation rather than to be held in the moment. (Barney)

\footnotetext{
159 M. Walsh, Violent Trauma, Culture, and Power. Palgrave Studies in Lived Religion and Societal Challenges (Cham: Palgrave Macmillian, 2017): 91.

160 lbid.

${ }^{161}$ Zwissler, 19.

${ }^{162}$ Korn, Rhythms of Recovery, 171.

${ }^{163}$ Ibid.
} 
As identified in the section on prayer, the pattern for engaging certain types of RSF at key stages, before moving on to other forms of RSF, continued in the deployment of ritual. Innovative rituals addressing trauma concerns resulting from the 2010 and 2011 earthquakes were particularly potent in the weeks, months, and early years following the Canterbury quakes. McDonald points to purpose-built rituals constructed according to the specific needs of an individual or group as customary in contemporary New Zealand. ${ }^{164}$ However, such ceremonies are often occasional or "one-offs," serving an important function for addressing immediate participant needs before moving on to other forms of RSF, as those needs change or develop. Similarly, Fred's stones ritual and consecutive activities encapsulating congregation member stories of trauma and recovery, are not commonplace within traditional Presbyterian Sunday morning church services. Consequently, creative RSF ritual held limited purpose in Fred's congregational liturgy, compared to other Progressive communities where worship innovation may have been more the norm, rather than the exception.

\subsection{Eddy and Elspeth, Progressive Baptist community ${ }^{165}$}

One ritual conducted by Eddy and Elspeth - among a number of creative ventures the couple led - took place in March 2011, just a few short weeks after the February 22 earthquake. Centred on the effects of the February quake, Eddy and Elspeth's ritual addressed a variety of historical and present-day traumas identified in the ritual as 'brokenness'.

After the February earthquake we did a memorial installation with rubble ... and broken china of our own. It wasn't hard to find broken stuff.... People wrote losses on the bricks. (Elspeth) (Image 1.12)

Then we built an altar out of the broken bricks and we served communion. (Eddy)(Image 1.13)

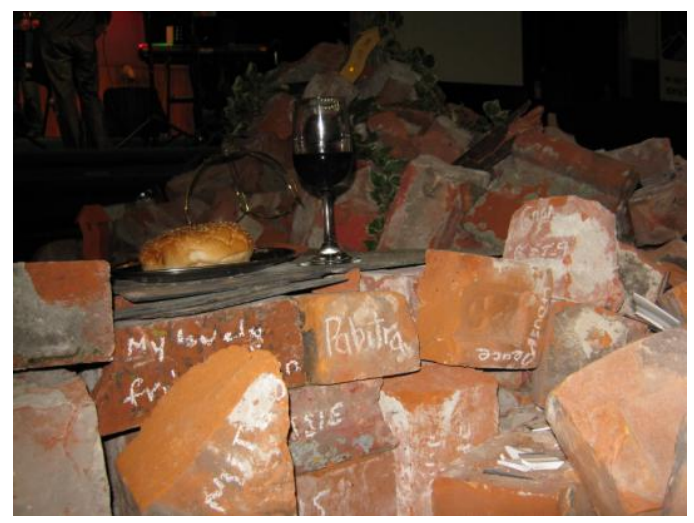

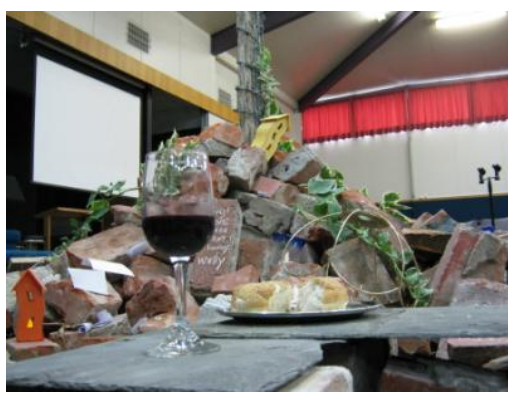

1.12: Above: words written on bricks. 1.13: Below: Barbed wire cross

\footnotetext{
164 McDonald, 66.

${ }^{165}$ Images provided with permission by Peter Majendie 23.7.18
} 
We said, you can write a name, a place, a date, a symbol that you feel you would just like to let go of. You could say it was your sin if you wanted, but for want of a better word, that you would feel if you could let this go, you would move toward being a bit more "whole".

So they wrote all sorts of things on these bricks and then we all got together and built one of those altars and put the communion on.

We said "Together we're bringing our brokenness and we're serving communion off that; this the communion) covers that (the brokenness). We're not getting rid of it and we're not saying it's not relevant or that you'll never ever return to it. We're saying it is part of you but it is, in some sense, dealt with.

We got emails from people saying "This is the first time l've ever done anything like this. This is the first time l've ever felt forgiven. I have been going to church for twenty years. I just sat there and listened.
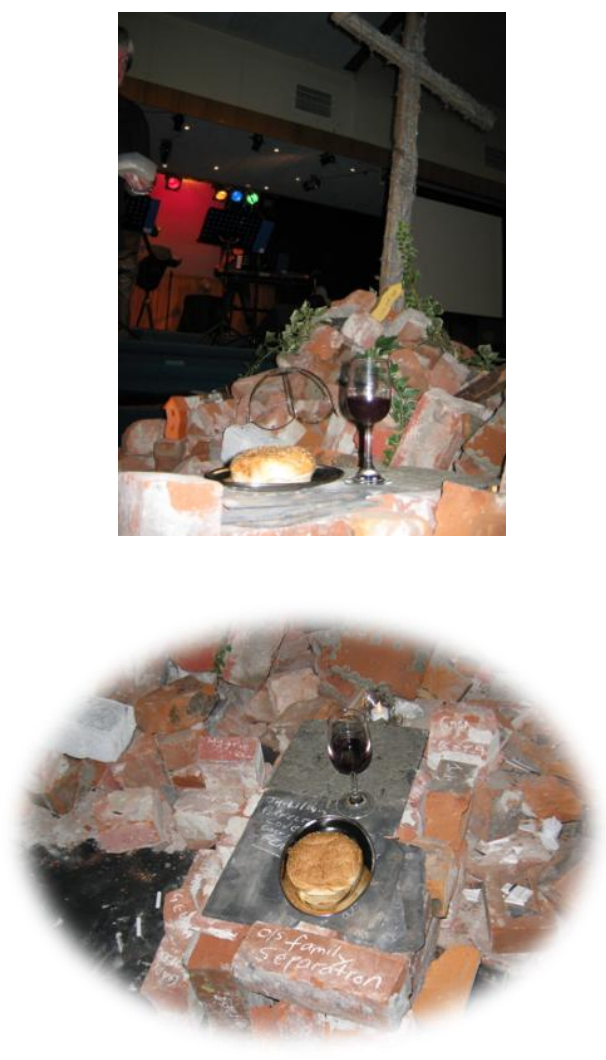

1.14: Communion served from broken bricks upon which participant grief issues are written in chalk But now I feel as if somehow, I have been forgiven."

Now that's just from some bricks and a piece of chalk! (Eddy)

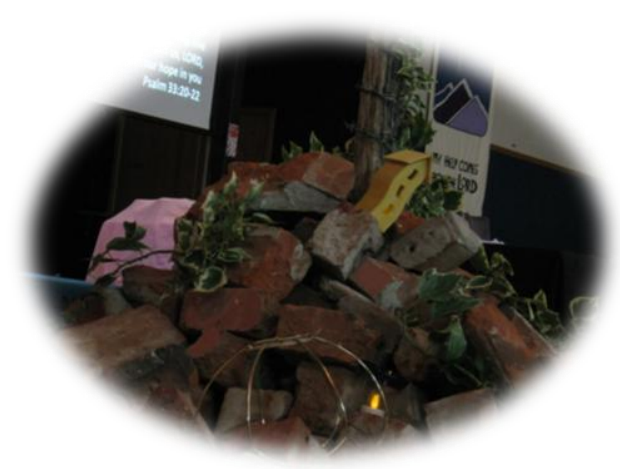

1.15: Data-screen and embroidery above bricks

Among the mound of broken bricks and household items, miniature crooked houses, small, folded, handwritten notes, and creeping plant life; people wrote words on the bricks in chalk to describe a broad spectrum of traumatic experience including 'family separation', 'fear', 'mum', 'three year old fear of being alone', 'Estelle', 'My lovely friend Diane', and 'Judy', among others (Images 1.12; 1.16). Elspeth told me a friend of theirs who also attended the ritual had 'lost six people in the earthquake'. Atop the pile of 'brokenness' stood a rough sawn wooden cross tightly bound in barbed wire and ivy plant (Image 1.16). On a data screen and embroidery above, hung the words: 
My help comes from the Lord....

Be With us, LORD, even as we put our hope in you. Psalm 33: 20-22 (Image 1.15)

Below, sat a glass of red wine and plate of bread on a makeshift corrugated iron tray from which the sacrament of Communion was served. (Image 1.16)
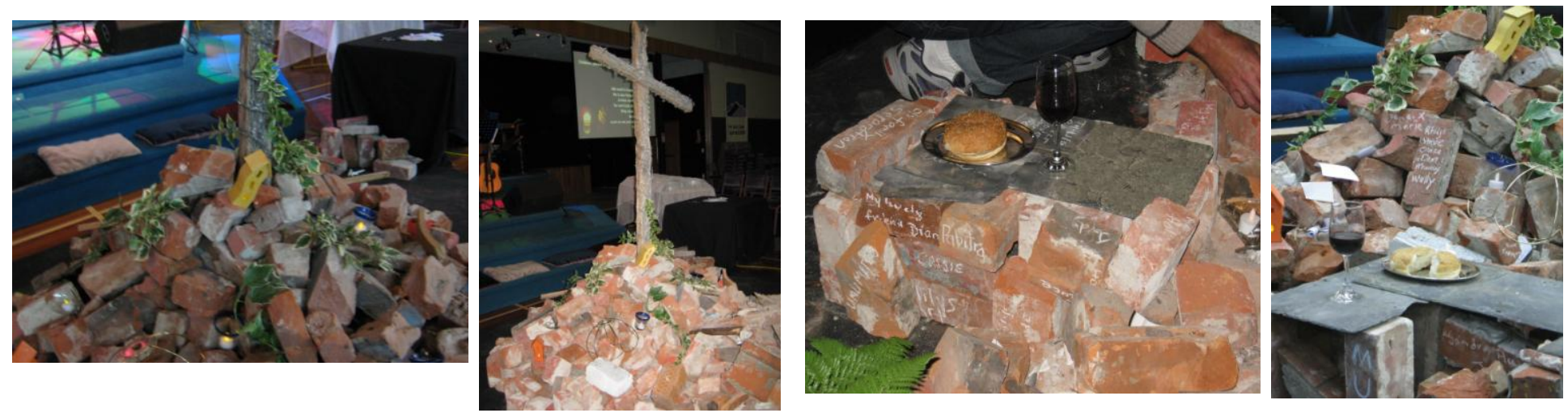

1.16: Lft to Rt: crooked houses and creeping vines beneath cross; barbed wire; words of grief on bricks, communion amidst handwritten notes and names of lost loved ones.

Symbolic representation to communicate religious beliefs and ideas is an important aspect of contemporary Protestant ritual. ${ }^{166} \mathrm{~A}$ common attribute of Progressive Christianity (and Fringe Baptist worship) is exploration of traditional theological ideas and boundaries using creative media. ${ }^{167}$ In this particular ritual, the idea of confronting painful life experience wrought with emotion and released to the power of the (Christian) Cross 'to be a bit more whole', is symbolically expressed through the life, death, and resurrection symbology of the broken bricks, green plant life, and wooden cross wrapped in barbed wire and ivy; symbolic of Jesus' crown of thorns, and personifying Christ's own pain and suffering. Eddy told me that initially, some participants grew angry. Yet Harris points to the benefit of these types of rituals for offering 'a medium for the expression and release of difficult and potentially conflicted emotions associated with traumatic exposure'. ${ }^{168}$ Bell supports this idea, highlighting the distinct nature of certain types of religious rituals involving symbol and symbolic action as 'cathartic responses to situations of anxiety or fear'. ${ }^{169}$

Indeed, anthropologists Clifford Geertz and Ritual studies scholar Catherine Bell assert that not all rituals aim to bring about some form of social or political

\footnotetext{
${ }^{166}$ McGuire, 34.

167 Taussig, 8.

${ }^{168}$ Harris, 99.

169 Bell, Ritual Theory, 71.
} 
equilibrium, or to move individuals from one life passage to another. ${ }^{170}$ Rather, the function of some rituals, they argue, is to 'render [the] ordinary everyday experience comprehensible'. ${ }^{171}$ The events that transpired following the 22 February 2011 earthquakes meant that, for many Cantabrians, there was little they could make sense of or "reintegrate" into some form of societal or political equilibrium. Therefore, rituals such as Eddy's communion in the rubble make space for creative exploration of traumatic experience where there is no explanation. As Wallace argues, Progressive Christian acts of communion fulfil an important function in 'legitimizing' 'the painful and joyful realities of life'. ${ }^{172}$ 'Through the sharing of' bread and wine, writes Wallace, 'love conquers the brokenness' of life. ${ }^{173}$

Like Fred, Eddy also asserted the above ritual was only possible because participants knew, trusted, and felt safe sharing their trauma experiences with each other.

It's easier to do things with the people that you know. I mean... I couldn't go and do this with some other Baptist church. I couldn't go on a Sunday and do what I do just anywhere. (Eddy)

It is worth pointing out that none of the respondents who engaged with ritual did so with strangers.

\subsection{Spontaneous ritual and contradictions}

One surprising feature of my analysis relates to the lack of ritual among some of my Pagan respondents. Although ritual expression and innovation is central to earthbased religious practise, members of Unicorn's Pagan group did not engage ritual at all in response to the earthquakes or other personal trauma and grief concerns. This is despite regularly meeting for solstice, equinox and other gatherings, prior to the 2010 and 2011 earthquakes.

Before the earthquakes we would regularly gather at someone's home to celebrate the festivals and the seasons and things like that. (Morningstar)

\footnotetext{
${ }^{170}$ Catherine Bell, Ritual: Perspectives and Dimensions (New York, Oxford University Press, ): 39; Geertz, 443.

${ }^{171}$ Bell, Ritual Perspectives, 67; Geertz, The Interpretation of Cultures, 443.

172 William L. Wallace, Progressive Christianity.Org: Spiritual Networking and Resources for an Evolving Faith. Worship Materials: Eucharistic Resources - From the Celebrating Mystery Collection (11 September 2015). https://progressivechristianity.org/resources/worship-materials-eucharistic-resources/ 
Ritual is regarded as at the heart of all Pagan, The Craft, Wiccan, and Heathenry spiritual practise. ${ }^{174}$ Personal and group rituals celebrate the seasons, moon phases, and a variety of rites of passage, often involving the re-enactment of mythical story. ${ }^{175}$ Planned or spontaneous, rituals are commonly created to address a wide range of personal, emotional and mental issues, including trauma. They function to maintain tradition, enhance spiritual or personal development, deepen a practitioner's relationship with Divine, and ensure the prosperity and development of the faith path. ${ }^{176}$ That the Pagan group did not draw on ritual at all, post-trauma, came as a complete surprise to me. When I asked why the group did not engage in ritual immediately following the earthquakes, Unicorn exclaimed: 'There was no time!'

We were just in complete survival. We didn't have water for about a month and no sewage.... Just things you don't think about ... taking a shower, washing your clothes, things were so much more of a mission ... just having to stay strong for my children; be ok for them and not have a meltdown. (Unicorn)

It is true that formal, organised ritual requires considerable planning, often involving extensive religious materiality as demonstrated in both of the above church rituals. However, much of Pagan ritual can be intuitive and spontaneous, drawing on one's immediate surroundings. ${ }^{177}$ Usually held outdoors or in the privacy of a practitioner's home, Pagan ritual can be created organically and unscripted, with little to no religious material artefacts, take as little as one to two minutes, rather than the standard one to two hours; and be entirely 'imaginal', relying on visualisation only. ${ }^{178}$ Ammerman's lived religion study similarly identified high levels of spontaneous Pagan ritual involving intuition. ${ }^{179}$ Yet it seems members of Unicorn's group did not instinctively regard ritual as critical in the immediate aftermath of the earthquakes.

On initial inspection, the above example upholds Maslow's theory that people set aside RSF for more urgent concerns during crisis periods. However, as identified in chapter three; Unicorn's group did not abandon RSF entirely, preferring instead,

\footnotetext{
${ }^{174}$ Sabina Magliocco, "Reclamation, Appropriation and the Ecstatic Imagination in Modern Pagan Ritual" In Handbook of Contemporary Paganism ed. Murphy Pizza and James R. Lewis (Leiden: Brill Academic, 2009):223.

${ }^{175}$ Magliocco, "Reclamation, Appropriation and the Ecstatic Imagination", 224, McGee, 17.

176 Selena Fox, "Pagan Rituals". Circle Sanctuary. https://www.circlesanctuary.org/index.php/circle-magazine/samplearticles/pagan-rituals

${ }^{177}$ Fox. https://www.circlesanctuary.org/index.php/circle-magazine/sample-articles/pagan-rituals; Cunningham, 74.

${ }^{178}$ Fox.

${ }^{179}$ Ammerman, 27,96.
} 
prayer, as a 'hazard adaptor'. ${ }^{180}$ Moreover, I noted a strong correlation between ritual-makers who employed creative ceremony for addressing traumatic experience and those respondents who demonstrated an interest in creativity in general. This may account for why members of Unicorn's Pagan group did not draw on creative ritual to the same extent they did prayer, despite ritual's centrality to Pagan RSF practise and belief. Equally, group members did not express any interest in artistic exploration as a way of dealing with issues of trauma and deep distress.

Conversely, George found spontaneous and intuitive ritual particularly helpful for addressing overwhelming feelings of loss related to the destruction of his church building.

One of the things during the earthquakes that I found difficult was the symbol of the earthquakes [in terms of] the damaged church. I found it very upsetting because [the church] was where I felt safe. It was tradition.

So, I prayed about it. The message came to me that I was to go and buy some flowers and throw them into the church to say goodbye to the old church.

Even though the church was 'just a building', George felt the loss and needed to 'mourn the old' in order to be able to welcome in the 'new' church.

Following a hybrid faith-path of Inclusive-Progressive Christianity and Spiritualism, spontaneous intuitive ritual is neither part of Progressive Christian practise (rituals are usually scripted) nor Spiritualist tradition and belief. ${ }^{181}$ While George received direction for his ritual schema in accordance with Spiritualist prayer practise, the method of his ceremony was more akin to an earth-based RSF property clearing and blessing. ${ }^{182}$ This accords with Zwissler's observation; that hybrid rituals often inspire 'innovation, spontaneity and experimentation' beyond the boundaries of one's faith tradition. ${ }^{183}$ Spontaneous, innovative ritual enabled George to privately express grief and feelings of loss of "safe" and tradition in a way that was personally, spiritually healing and appropriate to his RSF and grief needs.

\footnotetext{
${ }^{180}$ Term used by Mitchell, 20.

${ }^{181}$ De Swarte, The Spiritualists Handbook, 18.

${ }^{182}$ Fox https://www.circlesanctuary.org/index.php/circle-magazine/sample-articles/pagan-rituals

${ }^{183}$ Zwissler, 20.
} 
The contradictions of George and Unicorn's Pagan group are interesting. Neither group reflected the faith practises and beliefs of their own traditions suggesting that in times of great stress, people for whom RSF is important may move beyond the boundaries of one's own tradition in order to seek out the RSF resources that best meet the needs of the individual or group at any given time. Moreover, as George evinced, some people may employ several types of RSF at one time to address immediate needs, rather than drawing on resources separately or sequentially.

\subsection{Ritual preparation and facilitation}

For Silver Rain, the Catholic Bus driver, and Peter Frazer, ritual participation seemed less important than the process of ritual creation to redirect the ritual-maker's attention away from immediate life stressors.

Ritual was a fundamental aspect of Silver Rain's usual spiritual practises and teaching. She also used it to divert her attention from her ongoing life challenges and losses.

One of my members actually left because of the earthquakes and everything.

She couldn't cope with it and couldn't cope with focusing on the two different things. I remember her saying to me one day "I don't know how you do it [Silver Rain]. Do you need to have some time off?" And I said no, I couldn't because that's what keeps me going. Every month; knowing that I have that ritual to organize. No way could I just stop and say "I'm going on six months holiday". I couldn't do that.

A much needed coping mechanism, ritual preparation helped Silver Rain to find focus and a sense of calm amidst cumulating stressors, including the death of her father.

It was actually just before the earthquakes that I lost my dad as well. So the last two or three years for us have been horrendous, to say the least. Especially my dad dying. I chose to be there because I wanted to. But during that time of course, my own spirituality sort of took a slight little background. Once again, friends saying "you need to take a break [Silver Rain]" and I couldn't because focusing and organising ritual, or organising my class was my focus at the time to take my little piece of me away from the horror of losing my dad. 
While scholars like Ammerman have previously identified that RSF practices such as prayer and journaling can help people 'focus' spiritual attention and feel calmer, ${ }^{184}$ ritual preparation and facilitation has not featured. Yet, several respondents reported this effect, including Peter Frazer who commented how he found facilitating creative Christian ritual events 'nourishing' in the thick of other personal crises.

Silver Rain reported performing 'lots of healing rituals':

And that was a healing for us all - not only for me. Because each person affects other people in their life; whether or not you live with those people or it's your family, or the group situation. We all affect everybody because our friends feel our hurt. So we did a lot of big healing rituals and asking Spirit for healing. (Silver Rain)

Thus, for Silver Rain - and her Coven members - ritual functioned both as a healing resource and a much-needed distraction from distress.

Ritual preparation and facilitation likewise supported the Catholic Bus Driver to address post-earthquake isolation and reclaim a sense of personal power, spiritual agency and cultural identity. Feeling abandoned by her Church Community, the Bus Driver told me she had 'lost her faith'. Nevertheless, when her father-in-law - the only other Catholic in the family - passed away, the Bus Driver decided she would facilitate his funeral. Close to her father-in-law, she wanted to honour his recent passing.

When my father-in-law died, I actually took the service myself - the way I wanted it. I included Maori Tikanga. The priest actually thanked me for what he said was the best funeral in a long time [but] when he found out that most of the people attending weren't Catholic, he tried to rush it through. My daughter and I said "No." I am at peace now because I was able to farewell him properly, the way he wanted.

I asked the bus driver if she was at peace because she had 'some sense of control' over the ritual process.

Yes, definitely. I'm a much stronger person nowadays.

\footnotetext{
${ }^{184}$ Ammerman, 76, 253.
} 
McDonald's notion of ritual as one of adaptability and 'ingestion of boundaries' epitomises the Bus Driver's employment of hybrid traditional Catholicism, and traditional and contemporary Maori Spirituality. ${ }^{185}$ Simultaneously honouring her beloved father-in-law, the Bus Driver reclaimed a sense of personal, social, spiritual, and cultural agency and identity within a context she had felt marginalised and relatively powerless. According to McDonald, twenty-first century postmodernism has resulted in a 'blurring of boundaries', 'adaptation of spiritual and ritual practises', 'ritual invention', and incorporation of 'eclecticism' of religious and cultural practises that are mutually manifest within secular ceremony and Christian Church community. ${ }^{186}$ The Catholic Bus Driver example demonstrates how management of the above can engender empowerment for those involved.

\subsection{Conclusion}

While ritual is often identified as a central feature of RSF, this chapter has highlighted that in post-earthquake Christchurch, respondents' deployed ritual to varying degrees and for quite different purposes. For some, ritual provided a way to reclaim personal power and cultural, social identity. For others, ritual served a more pragmatic function, redirecting attention away from cumulating stress. Rituals centred on the effects of the Canterbury earthquakes were distinctive in that they were not designed to move people through to a new life stage or state of equilibrium. Rather, to express multivariate grief and loss beyond the limitations of the spoken word.

However, ritual as an RSF tool was not utilised by everyone. Some respondents did not employ ritual despite its centrality to belief and practise, whilst others appropriated intuitive spontaneous RSF ritual action notably distinct from their own faith traditions to address unresolved grief. A strong correlation was identified between respondents who employed creative RSF ritual to help them, and those persons who engaged creative activity in general, contrasting those participants who utilised RSF ritual for just a short period before moving to other formulations as needs evolved. The high variation and degree of innovation in ritual deployment demonstrated a striking tendency among respondents to move beyond the conventional boundaries of their RSF traditions. Most respondents were highly

\footnotetext{
185 McDonald, 100.

186 Ibid, 100-101.
} 
pragmatic in their attempts to address the needs generated by trauma at any given time.
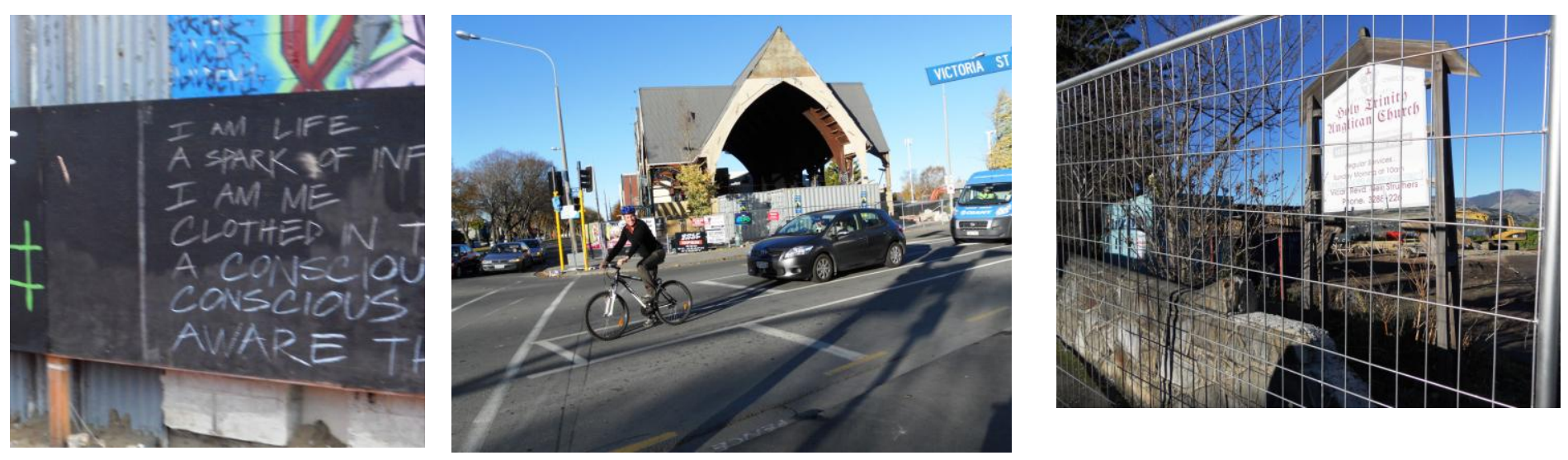

1.17: L to R: New Brighton, Central Christchurch, Lyttleton 


\section{Creative Exploration}

Contrasting the widespread exploration of religious ritual, enquiry into RSF art and creativity as a coping mechanism in trauma recovery has been less prolific. Recent scholarly appreciation of the value of creativity as a medium for expressing shared narratives of loss, grief, and resilience, focuses on the place of artistry in the recreation of 'a sense of continuity and permanence' for people negotiating complex trauma issues. ${ }^{187}$ Art and creativity is recognised as giving voice to the 'lived experience' of trauma, serving as 'powerful representation of community-unique perspectives' of disaster and other traumatic experiences. ${ }^{188}$ Researchers recommend increased exploration into how artistic installations represent recovery, empowerment, loss and devastation. ${ }^{189}$ In this section I demonstrate how, in the post-earthquake Christchurch context, RSF artistic enterprise facilitated spaces for members of the public to gather and grieve; individuals to take time out to process traumatic events, or to express feelings of recovery and renewal.

\subsection{Art and post-earthquake studies}

A select few post-earthquake Christchurch studies analysed the 'transformative qualities' of 'collective [and individual] crafting', noting the media's efficacy in assisting people to process 'all manner of thoughts and feelings'. ${ }^{190}$ They highlight the 'creative rebirth' of 'grassroots' public art that emerged 'in the immediate aftermath of the [earthquake] disaster', fulfilling a wide variety of local and social needs; including ways to remember loved ones lost in the quakes, create spaces of 'social connectedness' and 'place[s] to meet with peers, share stories, and process deep distress'. ${ }^{191}$ Scholars point to the way personal distress and growth often coexist simultaneously in an individual's recovery, which creativity may in turn reflect. ${ }^{192}$ While creative endeavour may be an outward reflection of the individual's inward journey of recovery and the place of RSF in that journey; field evidence suggested the way artistry is employed as an RSF resource, is not necessarily reflective of one's theological underpinnings.

\footnotetext{
${ }^{187}$ Raewyn Tudor, Jane Maidment, Ada Campbell, and Karen Whittaker, "Examining the Role of Craft in Post-Earthquake Recovery: Implications for Social Work Practise," British Journal of Social Work 45, no.1 (2015): 209-10, 213.

${ }^{188}$ Tudor et al, "Examining the Role of Craft", 216.

189 Ibid, 215-6, 218.

190 Ibid, 209-210.

191 Natural Hazards Centre, University of Colorado, Boulder, "A Creative Rebirth: Public Art and Community Recovery in Christchurch,"(2015)https://hazards.colorado.edu/article/a-creative-rebirth-public-art-and-community-recovery-in-

christchurch , 1, 4-5, Tudor et al, 206, 212.

192 Tudor et al, 208-9, 215.
} 


\subsection{Creativity and respondent faith paths}

RSF art and creativity is central to several of the respondent faith paths, in particular Progressive Christianity and Paganism, and to a lesser degree, Spiritualism. In Progressive Christianity, 'artistic expression' is 'pervasive' in worship -via multiple media - though less is mentioned of its place in lived RSF experience. ${ }^{193}$ By contrast, artisan handcrafting in multiple guises is central to Paganism, Heathenism, Wicca, and The Craft religious activity. Practises include making ones own religious artefacts and tools, decorative items or foods to celebrate the seasonal festivals; as an aspect of spell-craft, or general home-craft activities 'with a Wiccan [Pagan or Heathen] theme'. ${ }^{194}$ 'Psychic artistry', on the other hand, is a popular Spiritualist creative activity in which the Medium draws a figure from the spirit world using an array of colourful crayons or chalk, passing on a 'message' to the recipient. ${ }^{195}$ Not an aspect of Spiritualist lived experience; none of the Spiritualist respondents spoke of creativity as a way to help them address trauma situations. Similarly, among the Pagan respondents, only Silver Rain utilised creative endeavour as a mechanism for taking time out from her deluge of crises.

Silver Rain told me that art and creativity helped her to focus her attention away from 'the horror of losing [her] dad'.

And like, an ongoing thing... while looking after my dad, I used to sit and do craftwork. I make beaded hangings and dream-catchers and lots of things with beads and feathers and all sorts of things like that. That to me taps into that safe place within my heart. It gives that little bit of peace to the soul, while you're trying not to focus on the "yukky-ness", for want of a better word.

Tudor et al highlight a higher predominance of women who seek crafting, as a 'positive distraction from [the] day to day realities' of one's trauma situation, noting that a crucial 'benefit of craft[work]' in post-traumatic growth (PTG) is how the creative process allows 'individuals to spend a lot of time...[in]..deliberate, thoughtful reflection'. ${ }^{196}$ Taking time to 'think or ruminate' whilst crafting provides the individual with an opportunity to 'disengage from highly distressing emotions and thoughts, and

\footnotetext{
193 Taussig, 11-12.

194 Cunningham, 48, 182.

${ }^{195}$ De Swarte, 44; Partridge, Re-Enchantment of the West, 65.

${ }^{196}$ Tudor et al, 209, 212, 217. The Men's shed movement is noted as supporting male mental health.
} 
adapt to the current context'. ${ }^{197}$ Integral to the creative process, RSF was reflected in Silver Rain's creation of dream-catchers as art's gift of "peace to [her] soul".

Gift-giving as a creative activity has also been found to be fundamental to some survivors' sense of recovery by feeling they are contributing to those in greater need. ${ }^{198}$ A key aspect of Progressive Christian belief and practise, ${ }^{199}$ helping others helped Pixie to feel useful and productive at a time when she felt that her own sense of agency was limited.

Some people were saying, oh l'll take food and I'll do this and I'll do that. But I wanted to find a way that I could join in a group that was doing something. After the February earthquake I couldn't walk or do anything so I started knitting beanies for little children. I did quite a lot of those.

Thornley et al. found that helping others - a feature of resilience - boosted people's sense of well-being, empowerment, and feelings of belonging and social connection, in overcoming traumatic impacts like powerlessness, depression, isolation and upheaval. ${ }^{200}$ The active knitting of children's beanies, enabled Pixie's sense of empowerment; simultaneously reflecting faith desires to help others in need.

\subsection{White Chairs}

Creative activity to help others similarly underpinned Rufus' 185 White Chairs installation. With no public memorial space existing at the time, the 185 Chairs interactive sculpture became a place for people to deliberate and express all manner of emotions, anger and confusion related to the traumatic events of the 22 February 2011 earthquake. Inspired by Vincent Van Gogh's painting Jesus and Me (1888), ${ }^{201}$ and the idea that 'chairs have personalities of their own', each of Rufus' 185 White Chairs are individual, representing the diverse ages, gender, social, professional, and cultural backgrounds of the people who died in the earthquake. Sourcing chairs from various individual and group initiatives, ${ }^{202}$ the first chair was donated by a friend

\footnotetext{
197 Ibid, 209.

198 Ibid, 212.

199 John A. Buehrens and Rebecca Ann Parker, A House for Hope: The promise of Progressive Religion for the Twenty-First

Century (Boston: Beacon Press, 2010), 133.

${ }^{200}$ Thornley et al. 20-1.

${ }^{201}$ Peter Majendie, "Christchurch, 185 Chairs: In Remembrance."

http://www.sidedoor.org.nz/files/03 Christchurch-185Chairs-Draft R005.pdf: 1-11

202 Interview with Rufus and Elspeth 2013; Parsons, 180.
} 
in memory of his 'soon to be son-in-law' who died in the collapsed CTV building, just one week after completing journalism school.

It devastated the family. (Rufus)

Positioned on the site of Trinity Pacific St Paul's Presbyterian Church - also destroyed in the February quake - visitors to the installation were invited to sit in the chairs or wander among them. Among the numerous visitors to the site were family and friends who brought flowers on special days, as well as the anniversary of the February 22 earthquake.

People come a number of times. They'll come on certain dates. You'll find cards, flowers. One chair has jewellery left on it... soft toys.(Elspeth)(Image 1:18)

According to Rufus, even the process of painting the

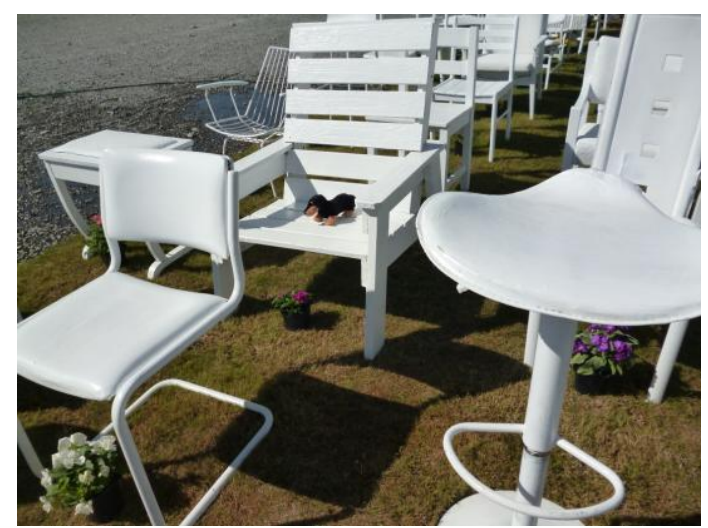

1.18: Small toy left on chair chairs was designed to engage people with the 185 who died. All painted by hand, Rufus said that 'some people took their chairs away' to paint and return later.

A lot of people either knew someone or knew someone who knew someone and so it wasn't hard to engage. People would say "well, I didn't know anyone but l'll see [the chair] as an individual". That was the idea.

Tudor et al. insist that the process of recovery from disaster (and trauma in general) is 'more of a journey of making meaning from experiences rather than a problem to be solved'. ${ }^{204}$ They argue that 'crafting facilitates people's passages of processing and making sense of' that experience' ${ }^{205}$ With few Cantabrians able to make sense of the earthquakes, Rufus' interactive art provided a way for people to process - and mourn - the tragic, inexplicable loss of the 185.

Mother's day was particularly tough.

There were a number of kids writing to Mum but there were also a number of mums and dads writing to their kids. (Rufus)

\footnotetext{
${ }^{203}$ Photograph by permission, P.Majendies.

${ }^{204}$ Tudor et al, 218.

${ }^{205}$ Ibid.
} 
Some chose chairs to represent lost loved ones. One mother chose a chair for every stage in her young son's life. Another chose two chairs to represent her son.

She said "we've chosen two chairs for our son. We chose the computer chair, and we chose the bean bag because he just lazed around at home." (Rufus)

But the bean bag had been stolen just a couple of nights prior.

It was like hitting her really.

"They have stolen his chair. They have stolen his bean bag". That's what she said. (Rufus)

Although Rufus was able to replace the bean bag, the incident highlighted the extent the 185 chairs served as a memorial for loved ones lost and mourned.

They also facilitated space to vent pent up anger and frustration.

People were very angry. They just came to the chairs..so angry.

Rufus says people were particularly angry after the first anniversary memorial service and again on second. Commissioned to unveil a second art installation not far from the official memorial service (Image 1.19), Rufus walked to the white chairs where 'hundreds of people' were waiting.

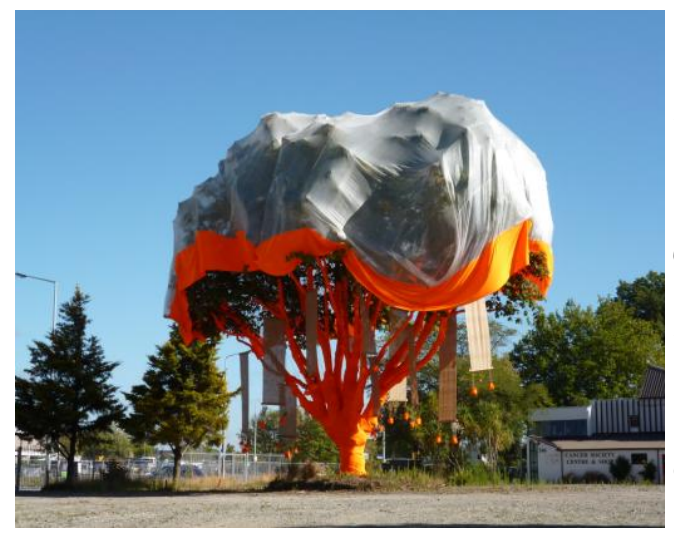

People just walked over to the chairs and there were no words at all. You could almost feel the connection and the communication.

.... I guess that was another one of those days where people, with the chairs, were just very engaged.

1.19: Second art installation created by Rufus not far from the official Feb 22 Memorial Service When I interviewed Rufus and Elspeth in 2013, the 185 white chairs display was intended as temporary, with chairs expected to be returned to families at its cessation. Five years on, the installation has become so 
important to locals and visitors alike Rufus is now fundraising for a permanent installation 'cast from aluminium'. ${ }^{206}$

\subsection{Art as renewal and recovery}

In contrast to the aforementioned roles of art as distraction or expression of difficult emotions, artistic endeavour can also represent 'resilience and regeneration. ${ }^{207}$ From a creatively 'gifted family', and two months after 'the September one which really affected me', Pingle began prolifically painting. Exhibiting a 'particular style and colours', and expressing inner feelings of renewal and recovery, Pingle had previously been 'too self-conscious' to explore her talents. Involving themes of 'views through windows' and 'flourishing' gardens; Pingle says her art exudes 'a confidence' not previously felt pre-earthquakes.

Everything grows and everything looks good.

Pingle says she feels an inner sense of 'self acceptance', post-trauma.

I don't have to prove anything to anyone - there's just this peace. The calm after the storm is the only way I can explain it.

Newfound self acceptance following traumatic experience was a sentiment echoed by several respondents suggesting an experience of RSF emotional-spiritual death and rebirth following intense traumatic encounter. With themes of rebirth as potent in Paganism, The Craft and New Age, as resurrection is in Christianity, Eddy's art similarly depicted concepts of renewal and re-emergence that he explored with his alt-worship group.

Through the year, after the very first earthquake, in September, we did some earthquake stuff because it was a very unsettling thing, I [did] some earthquake art and people responded with art.

Not offering whether the group talked about trauma experiences expressed in their paintings, Eddy showed me his own exploration of a mask made from maps and corrugated iron (Image 1.20) ${ }^{208}$.

\footnotetext{
${ }^{206}$ Jamie Small, "Artist calls for 185 white chairs to become permanent memorial to Canterbury earthquake," The Press, Stuff.co.nz https://www.stuff.co.nz/the-press/business/the-rebuild/88687177/call-for-185-white-chairs-to-becomepermanent-memorial-to-canterbury-earthquake

207 Thornley et al. 21.

${ }^{208}$ Permission P. Majendie
} 
Corrugated iron and brick dust was pretty common everywhere. The fractures [in the face] are really the fractures in the ground. I tried to get the face... it was like a new face emerging but some people didn't see it that way. They saw it as a death mask and found it quite moving. I don't mind. People interpret art how they see it and how they respond to it.

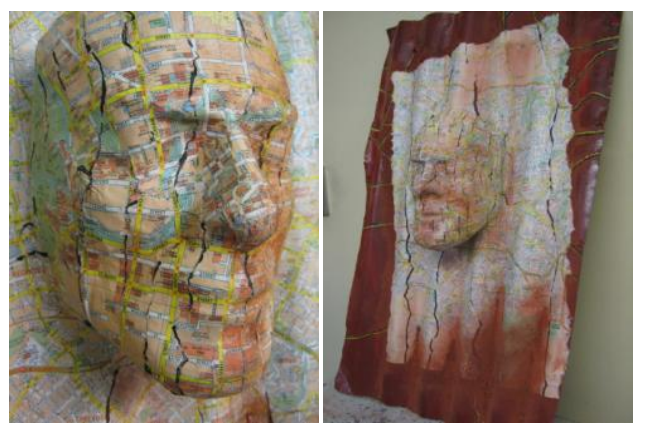

1.20: Mask made from maps and corrugated iron.
For Eddy, the mask represented the 'city of Christchurch', epitomising - like Pingle renewal and recovery. As with Eddy's earlier exploration in the rubble ritual of resurrection from devastation in Christ's love; the mask's symbolic message contrasted those who conceptualised the work as death, perhaps of historic (and fractured) Canterbury.

An important point is that RSF permeated every aspect of Eddy and Pingle's lives. Art could not be compartmentalised as "secular" from either their lived RSF, trauma experiences, or other everyday activities.

There is a tendency in academia to compartmentalise spirituality as if it is able to be lifted out and looked at [under a microscope]. It's in here, not parts of [us] in bits. It's just not like that. (Barney)

Not all respondents employed RSF craftwork to help them get through the toughest periods. Snow White said that prior to the Canterbury earthquakes she used to draw on creativity a lot as an RSF resource to 'nourish' her 'soul.'

Before the quakes I used to do handcraft hobbies. ... not a form of spirituality but spirituality in terms of feeding my soul. I found the creative act very nourishing.

After the February earthquakes, Snow White said that like many people, she was unable to focus on crafts, waiting until life felt calmer.

After some time had passed however, Snow White returned to her hobbies.

When I say I got back to my hobbies again, I had the headspace to focus on my mosaics. 
Snow White's setting aside RSF creativity activity can similarly be argued to support Maslow. Conversely, it may also reflect her aforementioned change in relationship with RSF in general.

Don't forget that, the whole earthquake and trauma and everything are a reflection of where we are on our own spiritual journey at the time. I don't think that they cause anything. I just think they are a reflection of where we already are. (Snow White)

\subsection{Music and Poetry}

Other post-trauma creative RSF examples included writing and poetry. Unicorn took up 'journaling and blogging', while Pollyanna pursued singing, and wrote poetry and verse about the earthquakes in the church newsletter. According to Fred, Pollyanna 'rallied the [church] choir together' and motivated the group to get singing to keep people's spirits up. Members of the public also told me that music had helped them cope with the earthquakes and process 'stuff'.

Like soul food, kind of thing (a Taxi driver)

Tudor et all argue invisible activities like craft, music, writing, movement, or gardening, are useful 'strategies [for addressing trauma] recovery and building social connectedness'. 209 They point to the role of craft as less realised valuable resources for recovery, integral to 'liv[ing] well'. ${ }^{210}$ Likewise, respondent examples demonstrate that craft as an aspect of lived RSF was as integral to some participant recovery processes as more traditional resources like prayer and ritual.

\subsection{Art and unresolved emotion}

Yet, not all experiences of RSF post-trauma art were positive. In 2012, a digital art picture of a stained glass window, destroyed in the February quake at Fred's church, was designed by a young graphic arts student. Aware of it through personal RSF connections, I discovered the digital image drew an unexpected upset.

Originally depicting 'the blue-braided rivers of Canterbury, ${ }^{211}$ the student - also a member of the congregation - asked if she could produce a digital version of the

\footnotetext{
${ }^{209}$ Tudor et al, 217.

${ }^{210}$ Ibid, 216.

${ }^{211}$ Knox Church, "History", Knox Church. Knox Presbyterian Church 2012-2014 Admin.
} 
original window, with an added third river (Image 1.21). ${ }^{212}$ To their surprise, when the revamped installation was presented to the congregation, people were upset and angry. It seems in an effort to focus on moving beyond the effects of the 2010, 2011 earthquakes; the revised stained glass window installation unintentionally unearthed feelings of fears of change and loss of control.

We actually have a veneer in Christchurch and its quite thin - Not new problems. All the things that had been there before [all] the issues that we have worked through over the years [in each of our lives], all came to the fore again. (Pollyanna)

It is difficult to know whether the resultant exposed sensitivities were simply too difficult to resolve. In 2013, the installation was not mentioned by respondents and on a recent visit I was advised the stained glass window was to be reinstated in the rebuilt church, with the upper two images only.

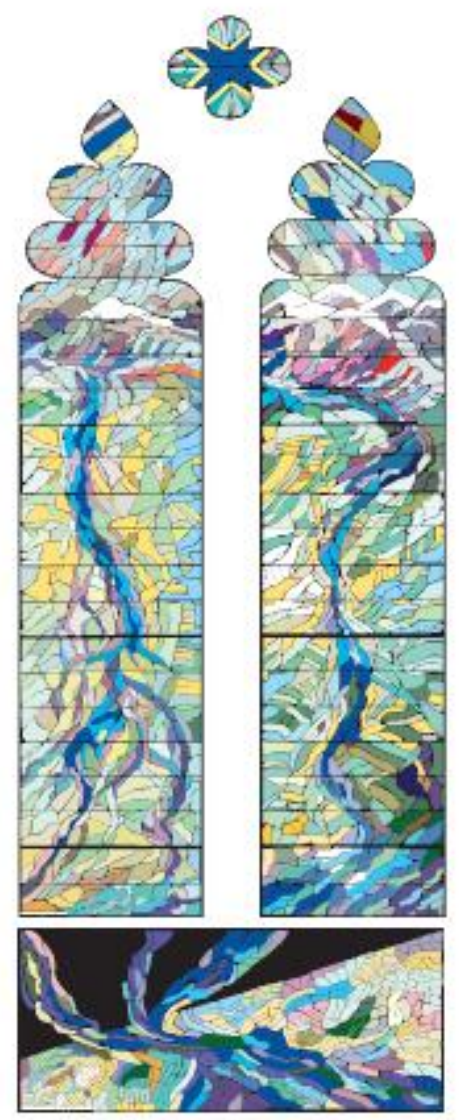

1.21 Digital Art installation of destroyed Stained Glass. Design by Renee Nankerville (lower panel), digitalisation of original upper two panels by Graham Stewart.

\subsection{Conclusion}

RSF art and creative exploration as a method for addressing trauma remains a limited area of inquiry, despite its prevalence in the immediate aftermath of the Canterbury earthquakes. Reflective of respondent relationships with RSF as a lived and all-encompassing experience, art and creativity functioned to help some respondents distract attention away from ongoing trauma or feel they were doing something to help others, despite their own sense of limitation. Interactive art created spaces for people to mourn and ruminate where other locales felt inadequate. Alternatively, art for some respondents functioned as an expression of recovery and renewal, while for others it inadvertently revealed unresolved grief and fears of change. Overwhelmingly, whatever the media, examples from the field demonstrate that for some people for whom RSF and creative activity are important, artistic endeavour is as indispensable in trauma recovery processes as more traditional RSF resources like prayer and ritual. Notwithstanding, while symbolic representation

\footnotetext{
${ }^{212}$ Interview with three ministers 2012.
} 
within the individual's creative work may be analogous with aspects of the theology of their faith tradition, the reason a person employs art and creativity is primarily determined by one's tendency toward the aforementioned, than a particular RSF framework per se.

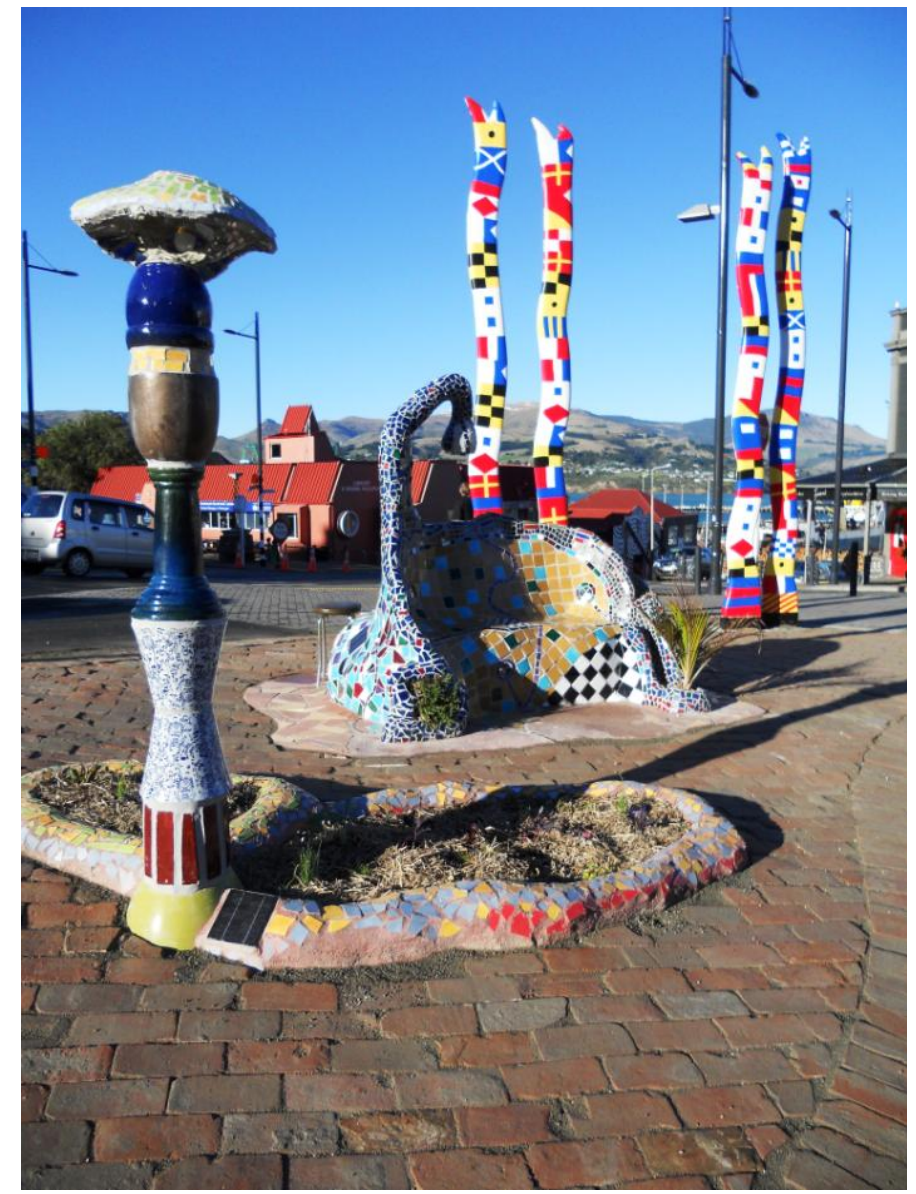

1.22: Art installations Lyttleton, Christchurch 2013

\section{Sense-making}

I know a number of people, that their lives will never ever be the same. And I think that they are, at this point, in a continual sad place. They stand at the 
[white] chairs and think well, it's totally impossible to understand. If it had been a drunk driver; if it had been somebody that I was angry at, or could get some justice for, but this is inexplicable.

We have had a bit of that stuff going on in Christchurch, you know, "where was God in it all" and I think that has been something that people have really struggled with. That they thought were doing pretty well, that they do live good lives; that they are nice people, and then inexplicably it all just turns to custard.

Sometimes I think its best just to shut up and say well, it is inexplicable and it is really hard, and that's all you can say. (Eddy)

The topic of "making sense" of religion and trauma is regarded by many scholars as synonymous with "meaning-making". As the above quote from Eddy eludes, the trauma recovery processes of some of my respondents involved accepting there were aspects of their trauma experience people would never make sense of. In this section, I demonstrate how respondents attempted to make sense of their experience or sought meaning in its absence in four key ways; through the use of storytelling, dream interpretation, supernatural experience, and analysing sensemaking's potential harm.

\subsection{Trauma and sense-making studies}

Scholars are divided regarding the relationship between finding meaning in traumatic memory, and making sense. Some argue that 'trauma survivors do not simply get over their experience, ${ }^{213}$ and need to find new ways of making sense of a life now shaped by the impact of trauma. ${ }^{214}$ Others view sense-making and meaning-making as entwined insisting sense-making is a pivotal resource for constructing meaning out of an otherwise meaningless experience, where people feel completely powerless and overwhelmed. ${ }^{215}$ Yet, one's ability to make sense of the senseless is considered largely dependent on one's capacity for articulating traumatic experience..$^{216}$ Indeed, the way people derive meaning or make sense of tragedy can

\footnotetext{
${ }^{213}$ Walsh, 90.

214 Ibid.

${ }^{215}$ Gall et al, 90; Gozdziak, 140.

${ }^{216}$ Harris, 96-97.
} 
be a resource in and of itself, empowering individuals to become proactive in their own recovery process. ${ }^{217}$ How a person makes sense or finds meaning is often enmeshed with 'causality', 'personal significance', or 'why an event occurred,' and is recognised as itself a 'lifelong process' of healing through which individuals and groups discover ways of understanding and talking about [the] complexity' and 'injustice' of their trauma situation or event, 'against the context of their religious beliefs'. ${ }^{218}$ As a result of that process people may make a 'radical break' from old ways of making sense, to form 'a new world of ongoing meaning-making' posttrauma. $^{219}$

\subsection{Story and traumatic memory}

The use of story as a resource for trauma recovery was a recurrent theme among the Christian groups, commonly used to teach or inspire listeners in a sermon or public address.

The biblical people told stories (Robbie)

By contrast, mythology and narrativization - important to Paganism and Wicca functions to explain ritual and seasonal celebrations, rather than to inspire action. Thus, narrative as a tool for trauma recovery was not employed by Pagan, Wiccan, Heathen, or Spiritualist respondents.

In Robbie's Inclusive Presbyterian Church, story in the form of elderly parishioner historical memory of the Blitz (and other events) of World War Two helped the congregation to grapple with the overwhelming impacts of the February 22 earthquake devastation.

Some of our people have found they've been able to contribute to the narrative in that we have a number of people who came here in the 1950's and 60's from England, and were part of the war scene in [Britain and] Europe. They have been able to talk about coming out of devastation and everything bombed around them, and finding something new. (Robbie)

\footnotetext{
${ }^{217}$ Parappully et al, 51.

218 Park and Folkman, "Meaning in the Context of Stress and Coping", 115; Maheshvari Naidu, "Displaced Sense: Displacement, Religion and Sense-making", Journal for the Study of Religion 29, No. 1 (2016): 107; Walsh, Violent Trauma, Culture and Power, 90.

${ }^{219}$ Wash, 90.
} 
According to Robbie, elderly folk had previously not felt they could 'contribute to the life of the church in a significant way'.

But suddenly, they've had an experience of the past they have actually been able to share.

Some members had previously never spoken about their experiences. Yet, by imparting personal stories of trauma, resilience, and finding meaning in recovery in an earlier period, parishioners empowered their own sense of belonging, value, and place in the community in a way that was ultimately beneficial to the congregation as a whole. Interestingly, a number of respondents equally referenced the earthquakes as 'like the Blitz' or a war zone.

I was doing the night shift [with the Red Cross in the CBD] - coming out to a city that was in total darkness, there were big holes and crumbling buildings and tanks and armed police and God knows what else everywhere. (Awen)

Sometimes, storytelling involves themes of hope, assumed to be integral to RSF trauma recovery. Not mentioned at all by my other respondents, it was debated by the three ministers. Barney's congregation explored biblical stories (like the Babylonian exile) and viewed hope as part of a larger 'meta-narrative' in which Christians are 'part of something bigger'. Conversely, members of Fred's congregation and close friends with limited social and economic agency, who suffered harshly post-earthquake, no longer had hope and found notions of a metanarrative unhelpful.

I have parishioners who have given up, who are stuck in a broken house with no hope [of recovery] in their lifetime - in their view...

...One guy, my own age, has lost his job, his home.... He has a young family....

What I find hard is maintaining my own sense of hope with all this, because I know the stories. The barriers seem so insurmountable..... I see the private lives of the parishioners and it's just a nightmare. That makes it very difficult in terms of the pastoral stuff which is bigger than all of us.

Robbie likewise struggled with concepts of hope in storytelling for struggling parishioners. 
What is hope in this situation? Often in the past, when l've been talking to people about the topic of hope, you tell stories. The biblical people told stories but this situation is so extraordinary. What are the stories?

Finding a story that one can relate to, to make sense of their experience and derive hope and meaning from, can be challenging for trauma victims. Godziack highlights how the trauma experience of her refugee respondents 'stripped away' feelings of hope, ${ }^{220}$ replacing instead with 'faith...for renewing and rebuilding'. ${ }^{221}$ This and the above respondent examples suggest that while stories of hope for sense-making were helpful to people suffering less serious traumatic experience, for those experiencing more intense and overwhelming trauma and limited agency, people turn to more intrinsic resources like faith or prayer. Unable to make sense of her traumas, Silver Rain turned to intrinsic RSF to plead with her guides to end her pain.

I just keep asking them please no more.. I'm not sure I can handle anymore.

\subsection{Making sense through dreams and supernatural experience}

Story for sense-making also manifested via the interpretation of dreams. The Catholic one day dreaming workshop explored Christian and Jungian symbolism to try and help their attendees explain the content of nightmares suffered as a result of the 2010 and 2011 earthquakes, and subsequent aftershocks. Symbols and phrases utilised included the Great Mother and being in the womb, Wisdom, Sophia, the Mystery, Jung and the unconscious mind; and crucifixion questions like why have you forsaken me? Leaders spoke of symbols of rebirth and recovery in 'the good news of the resurrection of Christ'. By contrast - and similar to Fred and Robbie's congregations - larger RSF meta-narratives appeared less useful to workshop participants attempting to make sense at a personal, spiritual level.

Unexpectedly, a small earthquake occurred during the workshop. I noted in my field diary that, in their panic, participants instantly leapt into explaining the event at a 'deeper' RSF level. Even more noticeable was that language took on a New Age style, distinct from earlier traditional Christian descriptions.

\footnotetext{
${ }^{220}$ Godziack, 144.

${ }^{221}$ Ibid.
} 
In that moment [the workshop leader - an ex-nun] spoke of tarot, Saturnreturns, visiting astrologers...[the language] was [distinctly] New Age!" [She said] "Everyone is moving into a new consciousness." (Field notes 2012)

It was my first empirical evidence of people instantaneously drawing on RSF at crisis moments and in the process, adopting less inhibited RSF formations to make sense of their experience that moved beyond the boundaries of traditional religiosities. Another example is Mysar's account of what happened to her and her family at 12.51pm 22 February 2011.

Toast, Mysar, and their adult daughter were in their New Age shop in the eastern suburbs when the February 22 earthquake struck. The front of the shop began to collapse around them. In the midst of the chaos, Mysar recalls seeing a 'large pair of hands' push her daughter back to safety.

Even though I couldn't see it, I could see with my third eye ... this big hand at the front of the shop. [My daughter had] run in to the hand and the hand had stopped her. But, at the same time, I was trying to get out the back door.

Mysar desperately tried to open the back door to get the three of them out of the collapsing building.

I couldn't get it open and the only thing holding it closed was a slip bolt. I had unbolted the bolt but the door would not open and I could literally see on the other side, these two big hands holding it closed. I remember screaming "for god's sake, let us out! We have to get out. Why are you holding us in here?!" and getting really angry, because these two hands were holding the door shut.

However, as Mysar continued to scream at the hands, without warning, a giant concrete beam fell from the building above and directly outside where Mysar had tried to exit.

I mean, we're talking maybe a metre wide and at least two metres high and goodness knows how many metres long.... If I had opened the door when I had undone that slip bolt, and stepped out, I would have been crushed - killed from the concrete beam. So these hands were keeping me in the building. I thought within the building was the most dangerous 
place, but these hands were [actually] keeping me there because they knew if I had got out, I would have been killed.

....I'm spiritual and l'm Paganism but l've also got these Christian beliefs from childhood so [to me] it was just the hand of God. .. that's all I could put it down to. Whoever the powers that be... that control my life from outside forces; it was their hands. Whether it was God or a guardian angel; whoever?

Gal et al. assert that unexplainable spiritual encounter and 'spiritual appraisal of crisis events' are commonplace but often reduced in literature to 'coping mechanisms'. 222 As frightening as the event was, Mysar was able to make sense of what happened to her, Toast and her daughter by reconciling that the 'hands' had protected her family from potential death. Pingle similarly reported a post-earthquake spirit encounter when she moved into a friend's house, which Pingle says, helped her to self-forgive for a past unresolved event. Mysar and Pingle's spiritual experiences repeat earliermentioned patterns of not feeling alone in their challenges, suggesting this, above all else, may be the most cogent RSF resource for people in crisis moments.

\subsection{RSF that Hurts}

People's need to make sense via RSF can sometimes cause distress and harm. Parsons records the 'unhelpful [RSF] conclusions' some individuals and groups 'trying to explain events' generated during the Canterbury earthquakes, 'caus[ing] further distress' ${ }^{223}$ An unexpected visitor to Barney's parish on the Sunday morning immediately following the February 22 earthquake was one of them.

A week after the February earthquake, we had a chappy turn up at church who was wearing what looked like an engineer's vest, and asked if he could say something.

Barney thought the man wanted to speak to the congregation in an official capacity. He actually turned out to be a self-proclaimed apostle from a church in Germany, coming to tell us that God is punishing us. I wanted to shut him

\footnotetext{
${ }^{222}$ Gal et al, 90.

${ }^{223}$ Parsons, 171.
} 
down. But then I thought, hang on a minute, is this congregation robust enough to see folly for what it is?

Barney decided to use the event as an opportunity for the parish to examine any unhelpful beliefs of their own.

Actually, there was a gem of truth in that attending to the better things in life is going to get us through this, and that some of the rhythms and changes in our lives, to make life normal, are going to be important, like prayer, stopping and listening, and things like that. So we embarked on [those ideas] as a response to [the man's hurtful comments]. Not because we believe in anything the guy said but actually, even for a quack like that, we need to be better equipped.

The idea of participants analysing unhealthy and potentially harmful RSF as a feature of trauma recovery demonstrates a willingness among some respondents to draw on positive forms of RSF to help address negative RSF attributes that have the potential to inflame latent trauma distress experienced by more vulnerable constituents. Responding to what was likely a very upsetting experience for parish members, the congregation sought to take a potentially harmful form of RSF sense-making and use it as an opportunity to empower and strengthen their own religious resources for addressing future challenges.

\subsection{Conclusion}

Sense-making and meaning-making are often assumed as interchangeable. However, as respondent scenarios demonstrate, many Cantabrians struggled to make sense of the devastation of the February 22 earthquake. While the use of biblical narrative and concepts of hope helped those less affected by the quakes to seek deeper meaning, these resources were less useful as traumatic experience intensified and one's own sense of agency significantly reduced. Notwithstanding, historical traumatic memory proved practically helpful, empowering storytellers with a renewed sense of value and place in their community, while interpretation of dreams and analysis of harmful forms of making sense assisted participants to explore new RSF resources not previously considered as practical tools for dealing with serious concern. Tendency toward reliance on intrinsic resources in response to escalated 
crisis, followed by a sense of not being alone in one's struggle, repeats a pattern identified in earlier sections.

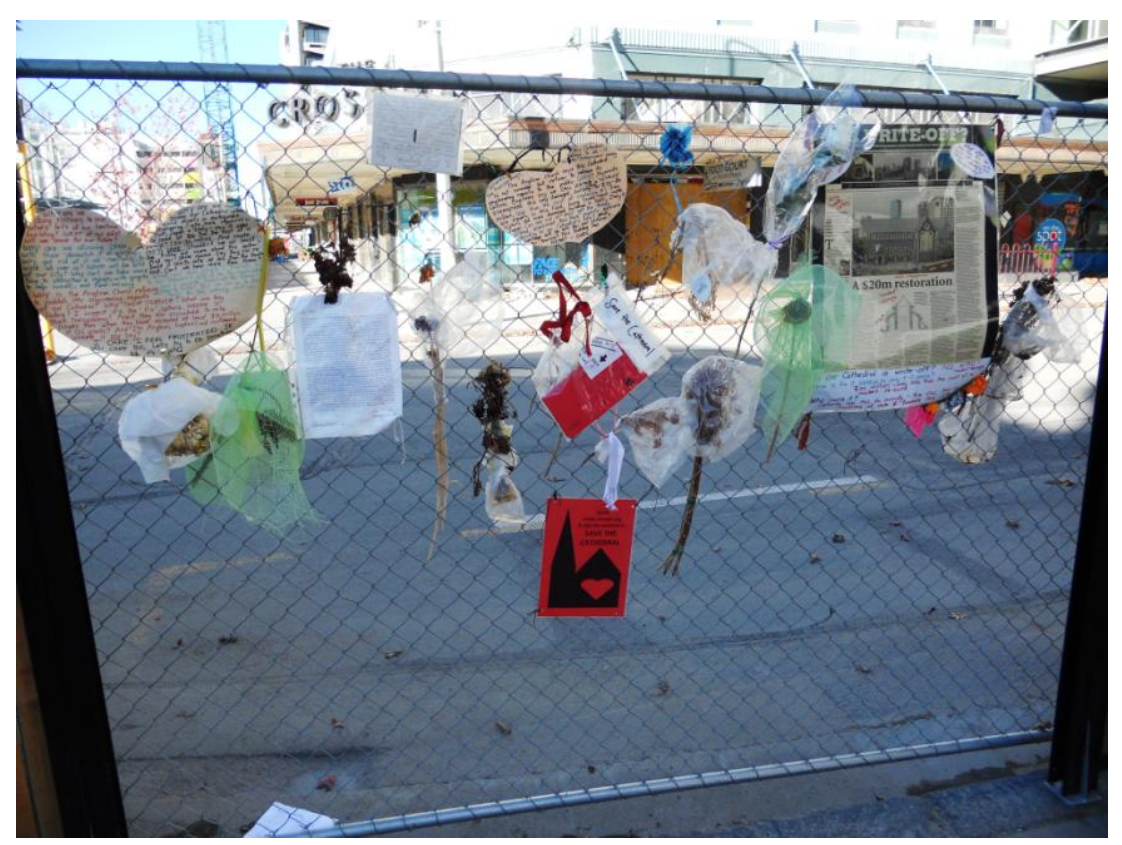

1.23: Prayers and expressions of distress, cordoned fences. Christchurch 2012 


\section{Social Support}

In trauma recovery literature, the role of RSF support is often framed according to traditional religious community, rather than for individuals who are on the margins or outside of orthodoxy. The challenge for some of my respondents was that some followed autonomous faith paths, independent of or only loosely tied to an RSF organisation. This sometimes resulted in social and emotional isolation and separation from much-needed practical or spiritual support. Whilst it might be assumed that RSF social support holds greater value for traditional religious groups where sociality is central to belief and practise, the below examples demonstrate that receiving social support was important to all respondents irrespective of whether or not helping others was integral to practise and belief. Types of RSF social support were highly varied with some assistance received - or sought - outside of the respondent's own faith path, particularly where social support within the individual's own RSF community was inadequate.

\subsection{Studies}

As a resource, social support is recognised in existing literature as one among a range of factors including prayer, RSF beliefs and finding meaning in suffering, that orient an individual to positively deal with diverse forms of high stress life experiences. ${ }^{224}$ Scholars have linked the benefits of RSF social support with positive impacts on resilience and 'well-being', such as the ability to 'buffer stressful life events, prevent emotional disorders and facilitate recovery'. ${ }^{225}$ Some research has found that religious involvement increases 'not only the amount of support, but also the quality of support and its impact on mental' wellbeing. ${ }^{226}$ Conversely, other studies on social support have pointed to the effects of social support as more of a hindrance than a help. ${ }^{227}$

A significant body of research on the topic highlights the role of church communities in providing financial assistance (or guidance), material items (clothing and housing

\footnotetext{
${ }^{224}$ Gal et al, 90; Julie T. Wilson and Joseph M. Boden, "The Effects of Personality, Social Support and Religiosity of Posttraumatic Growth." The Australasian Journal of Disaster and Trauma Studies 1 (2008) https://www.massey.ac.nz/ trauma/issues/2008-1/wilson.htm

${ }^{225}$ Harold G Koenig and David B. Larson, "Religion and Mental Health:Evidence for an Association," International Review of Psychiatry 13 (2001): 70, 72.

${ }^{226}$ Koenig and Larson, "Religion and Mental Health", 72.

227 Sally A. Shumaker and Arlene Brownell, "Toward a Theory of Social Support: Closing Conceptual Gaps," Journal of Social Issues 40, no. 4 (1984), 14.
} 
items), support networks, assistance into emergency or permanent housing or employment; general pastoral care and visiting to those in desperate need. An example of this is Melissa Parson's book Rubble to Resurrection which recounts numerous Canterbury Church communities that rallied to the needs of their immediate neighbours, following the September 2010 and February 2011 quakes. Their efforts mirror Shumaker and Brownell's definition for social support as an 'exchange of resources' between two or more actors, 'perceived by either the provider or the recipient as intended to enhance the wellbeing of the recipient'. ${ }^{228}$

\subsection{Social Support and Hospitality}

Hospitality - caring for others - is central to 'all three Abrahmic faiths,' including Progressive Christianity. ${ }^{229}$ 'Rightly practised' argues Buehrens and Parker, it can also be a 'powerful source of healing'. ${ }^{230}$ Post-earthquake, rather than leave the care and well-being of others to the minister, Fred's community viewed provision of support as a collective responsibility.

What we did immediately [following major earthquakes] was to look after our family and then we contacted the church circles to say that we are safe. We always checked with each other. How are you feeling? Whereas, before we were in our own little boxes. (George)

According to Pollyanna, Pixie, and Snow White, the congregation's collective care for one another, included taking time out at the beginning of Sunday services to check on members.

It's not just about "passing the peace" but "how are you? How's your house?" stuff like that. (Snow White)

By contrast, Pixie and George said the broader 'church systems' and governing (secular and RSF) 'bureaucracy were 'difficult'. George said the distressing effects meant people had to 'rely on [their] own sources of spirituality to protect [their] spirit and give [them] strength'.

\footnotetext{
${ }^{228}$ Shumaker and Brownell, "Theory of Social Support", 11-13.

${ }^{229}$ Buehrens and Parker, $A$ House for Hope, 40.

${ }^{230}$ Ibid.
} 
Angry that the system had let Fred down when he needed support most, members spoke highly of the social support Fred had tirelessly given of himself, including telephoning and visiting parish members by bicycle after the September and February earthquakes.

Even to the ladies who lived in the red zone in town. All sorts of things.

He was active Christianity in action, basically. There was no question of God has run away.. He was there boots and all. Really, a wonderful role model. It kept [us] going. He went off with the boys with their shovels... biking and shovelling....trying to help the army and everyone. (Pollyanna)

[But] he just got burnt out (Snow White)

Social support often involves a network of 'mutual obligations' and 'reciprocity. ${ }^{231}$ The above comments demonstrate that respondents perceived an imbalance in reciprocal support for Fred from governance, necessary for him to maintain his wellbeing and ministry.

One Inclusive-Progressive group who sought to offer support to their local community was Robbie's parish. Opening their church doors 'every day for the first six weeks' after the February 22 earthquake, Robbie's congregation offered a safe place for people to gather and share over a cup of tea. According to Robbie, in 2012, the church was one of the few buildings that remained standing. The congregation wanted to build on their own 'desire to meet together, be together' and 'quality of shared life' by offering hospitality and 'a cuppa and chat' to their wider local community. Progressive Christian concepts of radical hospitality draw inspiration from the scriptural quote Matthew 25:35 'I was a stranger and you welcomed me'. ${ }^{232}$ Displaced by the earthquakes, Robbie said that people in their local neighbourhood needed 'safe places to gather', find comfort and receive support. Paintner asserts that extending 'out-of-the-ordinary' hospitality to strangers allows God to be in 'all our experiences,' including 'the brokenness', pain and loss. ${ }^{233}$

\footnotetext{
${ }^{231}$ Shumaker and Brownell, 14.

232 Christine Valters Paintner, "Radical Hospitality and Holy Disruption," Patheos (September 30 2012) http://www.patheos.com/progressive-christian/radical-hospitality-christine-valters-paintner-10-02-2012 ; Marilyn Sewell, "Radical Hospitality," Unitarian Universalist Association (1996-2018) https://www.uua.org/worship/words/sermon/radicalhospitality ${ }^{233}$ Ibid.
} 


\subsection{The absence of RSF social support}

Negative experiences of RSF support were frequently reported by respondents. Although trauma scholars recognise a link between higher levels of social support and an increased potential for positive post-traumatic growth (PTG), they draw attention to growth's dependency on a range of factors including the size of the individual's social network, the extent of their embedded-ness in the network, or how satisfied one is with the social support they receive. ${ }^{234}$ The mainstream Presbyterian elderly parish, the Catholic Bus driver, and the Catholic dreaming workshop were not satisfied with what they felt was a lack of support from their wider RSF networks. All reported a negative impact the absence of RSF social support had on challenging situations until support could be sourced elsewhere. The elderly Presbyterian parish felt particularly isolated.

Reporting a loss of nearly $50 \%$ of their members to "relocation and death", ${ }^{235}$ the elderly Presbyterian parish's grief and sense of loss was further compounded by feelings of abandonment when their minister relocated to a Church in the north island, and questions were raised over the community's future. According to parishioners, regional (and national) governing bodies were considering closing the small parish and moving the church to one of the new post-earthquake satellite subdivisions where many young families (that could afford to) had relocated. Many of the elderly members had limited financial, social, and physical agency, often relying on others for transport to and from church. People were upset that they would not be able to attend the new church and would have nowhere else to go. They feared their small congregation was being rejected for the needs of younger and wealthier families.

The age of our members.... they won't/can't go....first we're told it's a rebuild, then its a half build then... we don't know where we are!

Thornley et al's post-earthquake Canterbury study found that elderly and Pacific people's were 'particularly reluctant to seek help', which 'negatively affected' their sense of wellbeing. ${ }^{236}$ Limited social, economic and physical agency, perpetuated by feelings of abandonment and rejection by the very actors the elderly congregation

\footnotetext{
${ }^{234}$ Shumaker and Brownell, 14, 16-17, 21; Wilson and Boden, https://www.massey.ac.nz/ trauma/issues/2008$1 /$ wilson.htm

${ }^{235}$ Field notes 2012

${ }^{236}$ Thornley et al. 17.
} 
relied upon for their external RSF support, likely exacerbated parishioner anxieties. The above example demonstrates a conflict between wider parish systems abandoning RSF in crisis periods - supporting Maslow's theory - in contrast to earlier examples of local and personal utilisation of RSF in key moments, as my thesis asserts.

The Bus Driver espoused a similar sense of abandonment by her local church, which she had relocated to be near after her divorce.

[At first] they were supportive and welcoming but then I wasn't as strong as I am now. I needed guidance.

Living outside the church's immediate suburban boundaries, the Bus Driver felt 'ignored, forgotten about'.

They looked after some, but not others. I felt abandoned. They never even called to see if I was ok. Since the earthquakes, I have turned away from my church. I have lost my faith.

After leaving the parish, the bus driver became involved in Boys Brigade leadership a Presbyterian faith-based youth programme for teen boys. A limited few articles examining individuals isolated from RSF and general community support found participants turned to internalised forms of RSF to help them in the absence of external assistance. ${ }^{237}$ Evidence suggests the Catholic Bus Driver lost faith in the lack of support from her RSF community, rather than her faith in God. By engaging RSF activity outside her traditional Catholic community, the Bus Driver found a supportive RSF community where she felt valued and belonged. A brief encounter; I was unable to ascertain whether the Bus Driver drew on internalised RSF resources, such as prayer. Had the bus ride been longer, I may have been able to find out more.

Attendees at the Catholic dreaming workshop echoed the sentiments of the Bus Driver, joining small cell groups in each other's homes to provide social and spiritual assistance to each other, in the absence of wider parish support systems. To try and get a balanced perspective, I spoke with a parish priest who also attended the workshop. To my surprise, the priest neither knew how his parishioners were coping, nor did he seem at all interested in finding out. It is important to point out there were

\footnotetext{
${ }^{237}$ Schweitzer, Greenslade and Kagee, 285; Washington et al, 439-441.
} 
no doubt other Catholic communities who did experience strong social and spiritual support. The above are the experiences of the people I encountered and therefore cannot be generalised to a wider group.

\subsection{Pagan and New Age respondents}

Many studies of RSF social support are located within mainstream American orthodox socio-religious faith paths where community is central to practise and belief. Conversely, many New Agers, Pagans, Heathens, Wiccans, and practising Witches, both here in New Zealand and overseas, often engage in solitary (non-orthodox) faith paths that are autonomous and therefore not attached to organised religious community groups. ${ }^{238}$ As McGee asserts, notions of 'community' for these groups, tend to be more commonly derived from familial and friendship social bonds even though - depending on the area - some may attend infrequent gatherings, camps and other events. ${ }^{239}$ McGee points to a need to include these groups in research to identify aspects of RSF social support that might be otherwise overlooked. ${ }^{240}$

Isolated by damaged roads and broken bridges, Mysar and Toast relied on each other and a few close friends who were of a similar RSF mindset for their spiritual social support.

We have been sharing our resources because of course we all have one strength that is stronger than the other. For example [Toast's] is clairvoyance and mine is my herbs and stuff. A good friend of ours does Indian head massages and another does flower essences. But, community-wise.... have felt abandoned by both, in the spiritual sense and also just in [terms of general] support.

Like the Catholic Bus driver, Mysar told me that no one from the Pagan or New Age communities had checked to see if Mysar and Toast were ok, or offer support. Oppositely, the Salvation Army was 'really supportive', offering Mysar counselling to address her 'nightmares and stuff'. Officers provided practical help with bedding, food, a heater, two washing machines (one was damaged in aftershocks), and emergency housing.

\footnotetext{
${ }^{238}$ La Dorna McGee, "Participation, Identity, and Social Support in a Spiritual Community," (Master of Arts, Sociology, University of Texas, Arlington, 2005): 8-9.

${ }^{239}$ McGee, "Participation, Identity and Social Support", 51.

240 McGee, 6.
} 
..But also just contact. We have a social worker and she comes in at least once a month to make sure that we are all ok.

Not involved with the Salvation Army since she was a child, Mysar walked some distance to collect water from a Salvation Army distribution outlet, after the February 22 earthquake. She was asked to fill out a questionnaire form.

As soon as I put that I was Salvation Army, the lady said to me "you're part of the family and we look after our family". I said to her "look I'm really sorry but I haven't been a part of the family for a good fifteen years" and she said "you're always family. You never get rid of family. Once you are ordained Salvation Army, that's it".

Mysar said the Salvation Army Officer's words made her feel 'really good!' I felt bad because I hadn't been going to church. She said "well look, you were brought up with Salvation Army faith and belief. I'm sure that fundamentally underneath you've been practising without coming to church on a regular basis.

At the Salvation Army counselling session, Mysar 'explained straight away my beliefs'. She was assured that this would not be an issue; that (Salvation Army Christian) religion would be 'kept out' of the counselling sessions. Mysar told the counsellor about her February 22 experience with the 'hands of God', and her and Toasts beliefs and practises. For Mysar it was important that these aspects of her life and wellbeing were included in the counselling sessions, and that she didn't feel judged or pathologized.

[I was] able to talk to her about [Toast's] clairvoyance and spirits and stuff and not feel she was judging me.... which was good because I did have my doubts. I didn't want to go and do it if it was going to be just all religion, and I wasn't able to say "well, yesterday I had a really bad day and so to get through it I had a head massage, or I made up a herbal tea or whatever; that's part of my life. .. ..just as much as the Salvation Army Christian belief is. I mean, that's what mum would have done. You know, as soon as the earthquake was on, Mum would have tried to make a fire and make a pot of tea. And not necessarily normal tea. It probably would have been a herbal 
tea. I mean, that's how I was brought up. I can't change that. I don't want to change that.

Mysar told me that if the counsellor had 'reacted differently' to what Mysar shared, that would have had a detrimental impact on Mysar's ability to cope with what was happening to her, her family, and home.

I probably wouldn't have gone. I probably would have stopped it. It would have made me feel uncomfortable.

Herman et al. highlight the need for clinicians to adequately support individuals affected by 'serious forms of adversity'. ${ }^{241}$ The writers note that 'personal resilience' is more likely to be acquired if the individual - in the absence of being able to avoid frequent and prolonged stress themselves - is 'buffered by supportive relationships' from different professional groups in the trauma victim's community, including complementary clinical care. ${ }^{242} \mathrm{~A}$ failure to do so, they warn 'could have severe consequences'. ${ }^{243}$ Because Mysar's counselling support made her feel spiritually "safe" and not judged to share her beliefs and experiences, it had a profoundly positive impact on Mysar's healing process. I should add that I encountered numerous reports of Salvation Army support irrespective of religious or irreligious background, including from Silver Rain, who received 'wonderful support' from the Salvation Army, despite her strong Pagan beliefs.

\subsection{Support online}

Online social support was an area identified across respondent groups, regardless of RSF background. Snow White and Unicorn were overwhelmed with domestic offerings of messages, goods, and safe places to stay in other parts of New Zealand.

I found facebook, oddly enough, great support. My friends aren't all in Christchurch so they couldn't come down and lend a shoulder so they did it virtual. I found that really supportive. And I met lots of people that I didn't know. (Snow White)

\footnotetext{
${ }^{241}$ Helen Herman, Donna E Stewart, Natalia Diaz-Grandos, Elena L Berger, Beth Jackson, and Tracey Yuen, "What is Resilience?", Canadian Journal of Psychiatry 56, no.5 (2011): 259.

242 Herman et al, "What is Resilience?" 263.

${ }^{243}$ Herman et al, 263.
} 
I had people I had never met, apart from online - and only talked to in a couple of online forums and facebook - offering me a bed in Mission Bay. Or, people I had met once at a (Pagan) gathering that said hey look we've got a bed here if you need it. (Unicorn)

Thornley et al's post-earthquake Canterbury study identified 'connectedness', 'participation in disaster response' and 'external support from organisations' as 'crucial' for post-disaster adaptation, 'building resilience', enhancing wellbeing and encouraging people's sense of belonging. ${ }^{244}$ Snow White, Unicorn's - and in Toast's earlier example in chapter three - online support systems demonstrate the extent to which RSF online communities may sanction similar sources of connectedness and wellbeing in the absence of localised (spiritual) support systems or where - in Toast's case -- redirecting attention away from the source of trauma may be a resource in and of itself.

\subsection{The challenge of support for solitaries}

Unicorn's group simialrly suffered an absence of local external RSF social support. I asked Unicorn if perhaps this was due to a mainly online community. The group assured that the local Pagan community was primarily face to face. They were upset when wider members moved away abruptly without word, not checking to see if others required assistance.

Bearing in mind that the Pagan group, pre-earthquake, used to meet in cafes or people's homes, and are made up of primarily solitary practitioners, perhaps it is more difficult to form organised cells of RSF social support to address member needs more effectively, in the same way the aforementioned Church's could. On the other hand, in the absence of a strong wider social network, Unicorn's group rallied around one another. Yet, while there was an apparent expectation of support from the wider community, the ladies all told me that Blue - who had been less affected by the quakes herself - was the sole primary support for struggling members in the group, often arriving with help and goods other members needed.

She made sure we were all ok. She'd turn up with something, just because she could.

\footnotetext{
${ }^{244}$ Thornley et al. 2.
} 
When I asked Blue where she drew her RSF strength from, to help nourish her in order to give to others, Blue said 'these guys are my family'.

Hospitality and servitude is not central to Wiccan or Pagan practise and belief. Therefore, faith expression is not shaped by a drive to help others, as in Progressive Christianity. Nonetheless, it was important to John and Awen that they were 'making a difference' by being involved in wider community responses.

I did a week's work after the February quake, with civil defence at the archives. With that experience you [get] a whole new perspective. I felt then that I was doing something that was positive. (Awen)

According to John, 'people were [also] coming into the office... everyday' to share stories of devastation and loss. Among them was a severely traumatized colleague. The colleague's daughter-in-law and grandchild had been badly injured in 'Cashel Mall when it collapsed'.

The little [grandchild] spent months and months in Starship; [the mother] in a separate hospital, and then eventually, at Burwood. [The daughter-in-law is] scarred; physically, emotionally, mentally. Because we were working with [our colleague] on a daily basis, all we could do to be there for [them], was just hold [our colleague].

Deeply distressed and angry, their colleague was fearful their daughter-in-law and grandchild 'were not going to survive'. John and Awen found the experience 'sobering'.

You don't walk away from it [unaffected].

I suppose because of our training with Samaritans, when [our co-worker] grew angry, we listened. When [they] cried, we held [them]. When [they were] afraid, we held [them]. Going through that with [our colleague], made us identify even more with [the earthquake experience].

As Shumaker and Brownell point out, the act of providing support and 'listening to a troubled individual' can be a cathartic experience for the trauma sufferer and 
enhance well-being and belonging for the giver. ${ }^{245}$ It can also be 'emotionally draining'. ${ }^{246}$ While John and Awen drew much strength from each other and their Samaritan training, they did not discuss RSF as a way to release potential pressures. This reinforces earlier patterns of respondents suffering escalated levels of distress and trauma, who drew more readily on RSF to help them, contrasting those who did not, to the same extent.

\section{7 $\quad$ Spiritualist Church shuts its doors}

A different scenario, Catherine's Spiritualist Church trauma group; in response to an absence of parish social support, affected a post-earthquake "rebirth" for the entire congregation.

Spiritualist Churches in the twenty-first century are often hampered by the challenges of a general New Age inclination toward spiritual and social independence from RSF community commitment. Contrasting active early settler (NZ) Spiritualist Church congregations,${ }^{247}$ the present-day emphasis on intense individualism can result in an absence of RSF sociality and support, particularly for isolated members during troubled periods. In the earthquake-torn eastern suburbs of Christchurch, Annie-Bell was especially impacted.

[The earthquakes] shut the church down for a while. I remember coming one night. My daughter was in hospital. I was really stuck and I needed a break so I thought it's Sunday night, thank goodness. I'll go to church. I got out there and they'd put - I actually stood out there with tears rolling down my cheeks; lonely old thing thinking no one wants me (laughs) - and there was a note on the church door "Closed due to suspected earthquake damage". Some windows were boarded up. I thought even the church had abandoned me. I was really down-hearted. (Annie-Bell)

Cat told me that 'everything was shut down'; the church had not moved to alternate premises and people were not contacted, including Annie-Bell.

\footnotetext{
${ }^{245}$ Shumaker and Brownell, 28. 
I wasn't informed. I had no one to ring. I didn't know how long [the church] was going to be shut. It was the time of my experience where I never needed to be anywhere else [but here]. I thought this is my sanctuary on Sunday. It's only an hour. Because I was up to here with everything happening... you go through the whole lot inside and you can't [carry it all], you feel everything. (Annie-Bell)

I just wanted to get back inside the door. It was my once a week, you know? (Cat)

Annie-Bell told me that she had previously tried to contact church leaders to advise them of her personal situation but she received no pastoral care or support.

He said "don't worry about it. Just come when you can." I didn't hear from anybody at the church.....they had my phone number....[but there was ] no community, no communication. I mean, my daughter was sick for a long time and I was a member of the church and I came [regularly] to church.

It was only when Catherine started the [trauma] group... [some time] after my daughter died..... thought oh well, I'll be brave enough to come. I need to do these things.

Living alone, suffering cumulative losses including the deaths of her son, daughter, mother, and marriage; Annie-Bell's experience mirrors many people who suffer trauma and grief in isolation - even when belonging to traditional church community disconnected from much-needed RSF social support, especially during crisis periods.

Meanwhile, Catherine set up the small Spiritualist Church trauma support group, as a way to provide spiritual and emotional support for members, including her. Emphasising the role of RSF in people's trauma recovery journey, the idea came to Catherine as she was working on her own spiritual development.

I thought there must be other people who can benefit from this as well. So that's when I started the group.

The aim of the group was to share with and support one another, whilst exploring various forms of RSF that might help them. 
Whether having a connection with our loved ones through meditation or through music, or synchronicity, we are all making those connections. So let's come together and share our experiences. That's when we created our own little community.

At the same time, the wider congregation were suffering in-house 'political struggles'. It was only when [people] were prepared to say "let's do some major soulsearching" ... we felt that the church had actually lost its Christianity from its soul and we had to make a complete turn around. (Catherine)

Catherine's comments are interesting in that historically, the 'non-Christian half' of the Spiritualist Church of New Zealand (est 1903) split with the Christian Spiritualist Church in $1924 .{ }^{248}$ As previously mentioned, present-day eclectic belief and practises are not underpinned by "Christian" ideology and practise in the same fashion as earlier periods in the Church's history. ${ }^{249}$ Although outside the scope of this enquiry, it would be interesting to know if the decline of "church-ianity", in favour of RSF individualism, has had a similar impact on declining NZ Spiritualist Church numbers and reduced social support.

Notwithstanding, Catherine and her husband set to work with others to try to recreate the 'wonderful experience' of the Spiritualist Church in South Africa. Whether as a result - or in spite of the internal fractioning - Catherine's trauma group evolved into a much-needed support dynamic for those involved.

People came and went over the months, but our core group remained...we've found that through sharing (and we listen to a meditation tape), we share about our week, our difficulties and our triumphs. We'll have tea together and then we share a bit more. We all come on Sunday and we chat with one another and so it becomes social as well. (Catherine)

Being part of the group 'really put [Cat] on a high'.

Some good things happened recently which l'm over the moon about [even though] I don't need verification about the spiritual thing; that the spirits are there, [but] I wanted answers. I wanted to talk. I didn't want a shoulder to cry

\footnotetext{
248 Hampton, 105-6.

249 Ibid, 146.
} 
on. I just wanted somebody to give me answers to my questions. I'm actually getting them slowly coming to this group with Catherine; looking at different things every week.

I asked Cat whether his questions were about life or why his wife had to die.

No, I know why she died because it was what she signed up to do. I understand that. It's just hard living a normal life you know. I mean I'm not asking.... well, I am asking... I've said a few times, what the hell am I doing here? I should be back home with her but that's going to come anyway. That sort of thing's going to happen when I go. I'm all happy [about that]. I've just gotta wait and live everyday life whilst it still pumps air into me each day.

Unlike Mysar and Toast, and the Pagan group, who sought support in the form of practical assistance like shelter, food, home goods, and counselling; the trauma group desired the comfort of fellowship and spiritual support with others of like minds. While there was an expectation of "church" as a haven of support and spiritual strength like their Christian counterparts, members sought spiritual guidance on how to live (and get through) day to day, rather than existential questions of why, for what purpose, or according to some kind of moral RSF guideline. Cat said that coming to the group makes him feel like he is part of a community; that he belonged.

I can't wait to get down on a Friday. I think that helps me spiritually.

When I visited the church for the Sunday evening service, parishioners excitedly told me that there had also been a dramatic change in community focus for the congregation as a whole. Learning lessons from the success of the trauma group, parishioners made efforts to keep in touch with others, to make sure they were ok. Regular social events were also being held, including a mid-winter dinner, planned for the following month.

There's been a kind of knock-on effect [from the trauma group]. What's happened is the spirit is starting to come back into the church. There have been various groups that have started up, this one being one of them, that has been a kind of example for our church...the other church members started seeing that; they see the joy and connection. (Catherine) 
Catherine told me that the complete change around of the congregation has also been a 'support for the minister'.

She felt completely on her own doing everything [including] all the pastoral care.

When I visited the small eastern suburbs Spiritualist Church community, I was not expecting to find anything like the post-earthquake rebirth story I encountered. Nor for that matter, did I expect to learn of the challenges that Cat, Castialian Blue, AnnieBell, and Catherine had faced that were completely unrelated to the earthquakes and yet occurring concurrently with the Canterbury quake events. Regardless, the 'knockon effect of the positive impacts of Catherine's group's social support on members' well-being, trauma recovery, and as a buffer against ongoing life challenges, ultimately filtered through to benefiting the well-being of the congregation in its entirety. Functioning as a coping resource for the smaller group, social support promoted the strengthening of social ties, and spiritual growth and development for the aggregate church community. It would be fruitful to find out whether that social bounty sustained over time.

\subsection{Conclusion}

Primarily associated with traditional RSF community contexts, RSF social support is generally considered as an exchange of resources to enhance the wellbeing of recipients. Differing greatly among groups, examples demonstrate the extent to which spiritual support can be as detrimental as it can advantageous. Where some respondents offered care to fellow community members or isolated individuals, inspiring their wider RSF community to do more, others facilitated safe space for their local neighbourhood, received practical help from RSF faith paths different to their own, or in the absence of adequate support, sought assistance elsewhere. Helpful sources included the internet, spiritual fellowship with like minds, pastoral care, and support that included respect of RSF belief, practise and experience. An interesting finding was that even where sociality was not at the heart of belief and practise there remained an expectation for social support.

Those for whom hospitality was central to belief appeared to offer support to others more than those for whom caring for others was not a key RSF component, 
contrasting wider church systems who did not provide sustenance when needed, despite grounded by the same theologies that prioritise hospitality as a central belief. Thus, evidence shows that RSF social support remained important to all respondent trauma recoveries, irrespective of whether or not it was adequately received or given. In those cases, participants turned to intrinsic RSF instead.

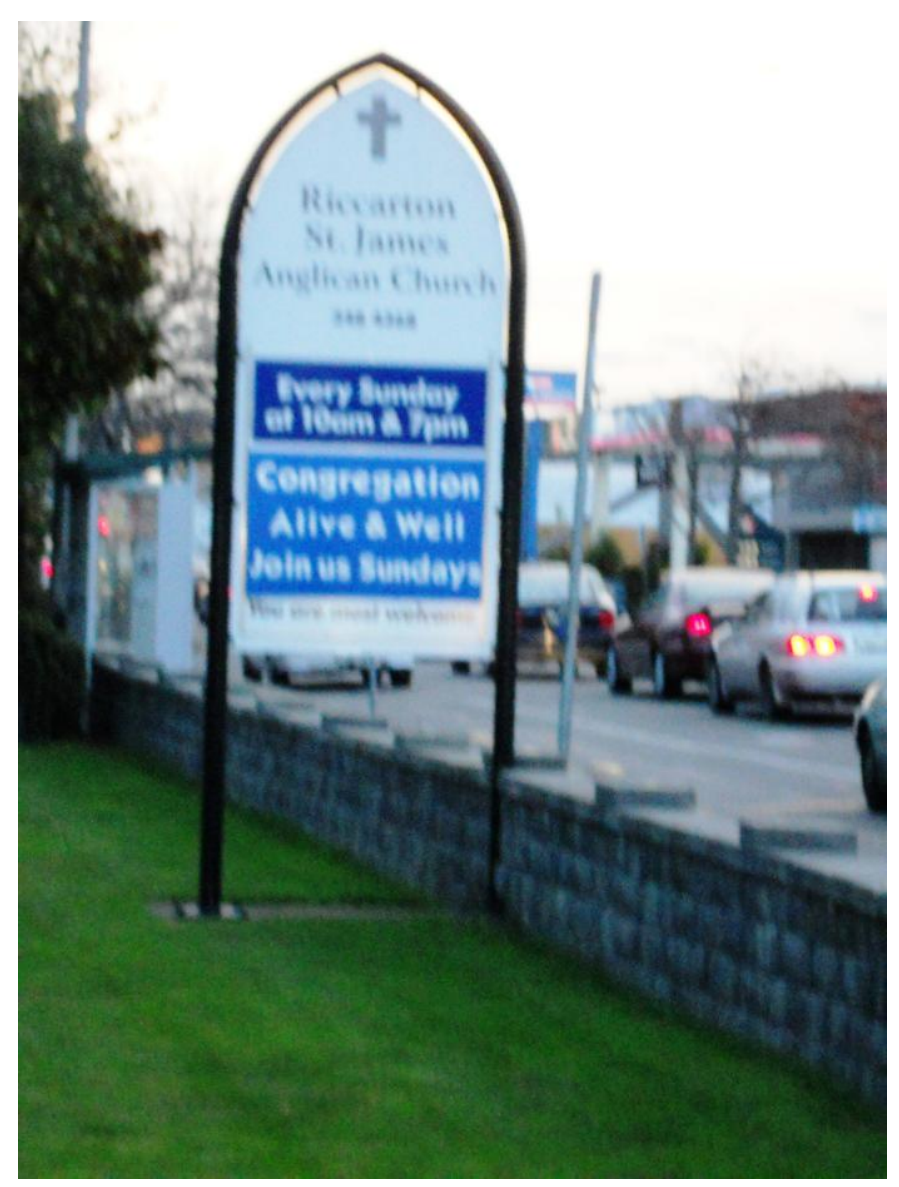

1.24: Church sign 2012 


\section{Belonging and Place}

The churches are falling down

(Catholic Dreaming Workshop respondent)

People keep saying that the Churches are falling down but we're still here! It is the buildings that are falling down. (Barney)

Belonging and Place is not a feature commonly

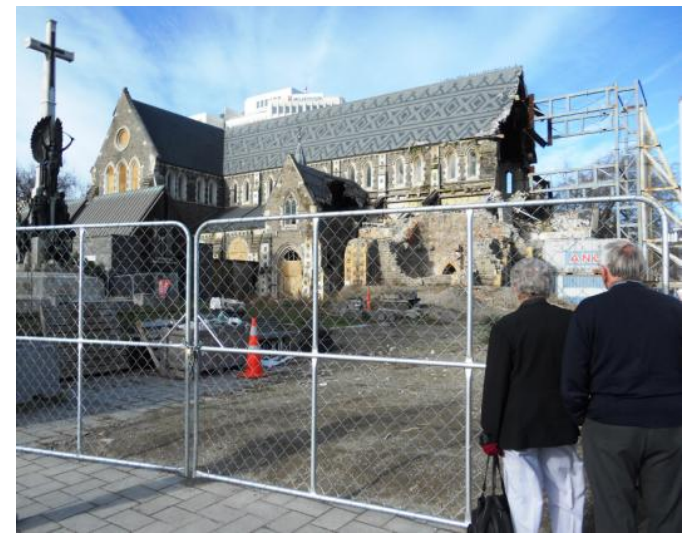

1.25: Canterbury Cathedral 2013 incorporated in RSF literature on recovery from traumatic event, yet was deeply entwined with the Canterbury earthquakes, symbolically immortalised in the nearfatal destruction of the Christchurch Cathedral. Contrasting the experiences of loss and displacement for traditional Church congregations, were respondents following autonomous faith paths not usually associated with specific buildings. In this section, I identify the confliction for some church-associated respondents between concepts of "church" as people versus buildings representing spiritual connection, intimate fellowship and feeling accepted. I reflect on challenges for Pagan and New Age respondents whose theology meant a precedence of connection to land rather than building, contradicting personal feelings of structures as spaces of support, being supportive to others, whanau, safe and continuity of spiritual practise. A further two examples highlight how without place may result in new definitions of belonging.

\subsection{Studies}

Notions of place and belonging are not just about buildings. They are places of memory, social networks, imagined histories, shared activities and 'felt value', as well as spaces of connection and support. ${ }^{250}$ According to Harrington, locations of place are 'structures of feeling inflected with closeness and familiarity', borne out of human agency, active social engagement, and relatedness within the context of people's everyday life worlds. ${ }^{251}$

\footnotetext{
250 Jane Therese Harrington, 'Being here': Heritage, Belonging and Place Making: A Study of Community and Identity Formation at Avebury (England), Magnetic Island (Australia) and Ayutthaya (Thailand), PhD Diss, James Cook University. (2004): 18; Lisa M. Vandermark, "Promoting the Sense of Self, Place, and Belonging in Displaced Persons: The Example of Homelessness. Archives of Psychiatric Nursing 21, no.5 (2007): 242, 245.

${ }^{251}$ Harrington, "Being Here", 307-8.
} 
A sense of place is intrinsically derived from how people feel and what they do and experience, as much as it is precipitated by the physical "thinginess" of place. $^{252}$

The physicality of place proved a challenge for the Inclusive-Progressive parishes of Robbie and Fred despite theological underpinnings of "Church" as people, rather than any building.

\subsection{Inclusive-Progressive Church groups}

Traditionally, Presbyterians place a stronger emphasis on "church" as the people, rather than the building, contrasting Catholicism, where buildings - as the 'outpost of Christianity' in a place of permanence - are traditionally consecrated and sacralised. ${ }^{253}$ For congregations of some of the Inclusive-Progressive Christchurch churches, loss of place represented disconnect from a sense of faith-familial intimacy, long-term memories and where one felt they were accepted and belonged.

Despite doing very well in 2012, in 2013 Robbie telephoned to say that circumstances had dramatically changed for her congregation. The church building and hall now both deemed unsafe, the parish had been forced to vacate their premises and amalgamate with another nearby Church for Sunday worship. Robbie was deeply concerned over the emotional, mental and spiritual impact, loss of the church premises had had on her community, and on herself. Robbie had tried unsuccessfully - to convince her members to talk to me, as a way to spark conversation with her people about how they were feeling post-move.

It is difficult just to talk to my people alone, so we can even begin a dialogue around this.

Harrington calls buildings 'structures of feeling' that reaffirm one's sense of belonging, not just because they are places of value but because it is the space where one feels accepted by others. ${ }^{254}$ As both Fred and Robbie's congregations self-identified as "Inclusive", contrasting many other Presbyterian Churches in

\footnotetext{
252 Ibid, 311.

253 Aaron M. Renn, "Erasing Distinctions: Eight Protestant Trends", The Institute for Sacred Architecture http://www.sacredarchitecture.org/articles/erasing distinctions

${ }^{254}$ Harrington, 384.
} 
Christchurch that did not, it is possible that a difference in worship style as well as theology proved a challenge.

Fred's congregation similarly struggled with the reality of permanently worshipping with another congregation for the first few weeks following the 22 February 2011 earthquake. Fred realised that while the experience of co-worship was 'nice', the situation was 'not going to be sustainable' long term, for his congregation. Parishioners told him 'We don't care where we worship, just as long as we are together'. The scriptural quote 'where two or three gather together in My name, there I am with them' (Matthew 18:20) can assume Christians will feel a sense of belonging wherever followers of the faith gather. Fred and Robbie's congregations mutually demonstrate that even within the same denomination, where one feels accepted and connected can be tricky. As Vandermark points out, creation or recreation of place and the associated sense of belongingness is a 'process' of recovery that develops slowly, over time and cannot be rushed. ${ }^{255}$

\subsection{Homelessness}

Forced disconnection from place appears to have had a positive, rather than deleterious effect on some respondent abilities to cope with and recover from traumatic experience. Pingle in particular said the experience enhanced, rather than diminished her faith. Contrasting other respondents relocated to new homes or shelters post-earthquake, Pingle and her young family were made homeless. A friend

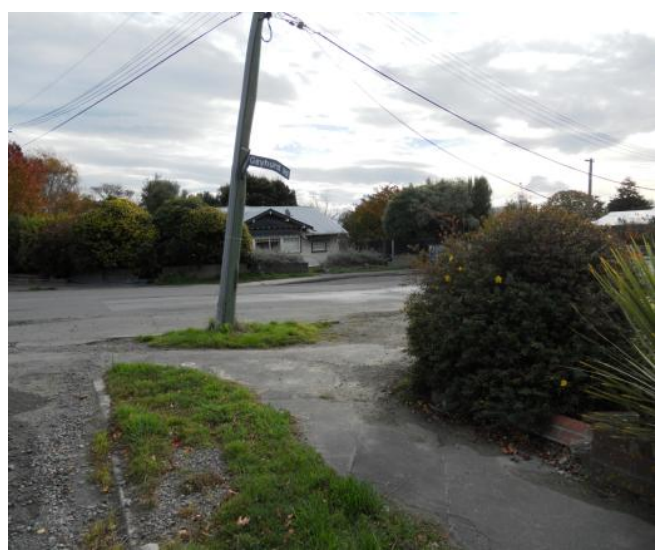

1.26: Sunken houses on the Eastern side of the Avon River (2012).
Pingle had known in the west coast, now living in Christchurch with his new partner, invited Pingle to stay with him. Vandermark notes that 'homelessness is not simply the absence of a physical domicile'. ${ }^{256}$ Rather, the absence or reduction of social connections, which can determine a reestablishment of one's sense of place and belonging - if only temporary - and perception of the world, shaped by one's personal experience. ${ }^{257}$ Seemingly unaffected structurally by the 2010 and 2011 earthquakes,

\footnotetext{
${ }^{255}$ Vandermark, 245.

${ }^{256}$ Vandemark, 243.

${ }^{257}$ Ibid.
} 
Pingle's Baptist church community were her mainstay for traditional RSF (Christian) support, and belief and practise, during what was a difficult time. On the other hand, the move to Pingle's friend's home - himself "alternative" spiritual - supported Pingle's equally important alternative spiritual beliefs and experiences.

Highlighted earlier, it is important that hybrid faith-path followers balance support of traditional and alternative RSF for health and wellbeing. McGuire highlights the complex nature of religious hybridity, resulting in a sense of belonging that can be 'multifaceted, messy' and often 'contradictory' at the level of the individual. ${ }^{258}$ 'Expressed and experienced' in everyday life, hybrid beliefs and practises may be informed by a variety of sources, and 'not limited to a single religious option'. ${ }^{259}$ As a result, religious commitment and a sense of belonging are likely shared among multiple groups, all of whom may be important to the person, for different reasons. ${ }^{260}$

\subsection{Pagan and New Age respondents}

Mysar and Unicorn's RSF faith path does not tie them to any building or specific place. Rather, central to Paganism and The Craft is connection to land. Yet, disconnection and relocation affected each woman very differently. Meanwhile, Toast viewed "place" as his responsibility to create for others in need.

Toast told me that he and Mysar had tried to keep their New Age shop open to provide a location for people to gather and share their troubles in the same way Robbie's church had offered "cuppa and chat."

Part of why we are here is because people need places like this, just to come and be. These places hold space.

In New Age circles the turn of phrase 'these places hold space' refers to the recognition that people of like minds often like to gather in New Age shops to connect with others, read books, or just to "be" in a place where they feel accepted and belong; not necessarily to purchase items as one would expect in a traditional retail store.

\footnotetext{
${ }^{258}$ McGuire, 208.

259 Ibid, 208-9.

260 lbid, 209.
} 
On my first visit to Mysar and Toast's shop in 2013, the couple told me of a recent incident where a woman had come into the shop, talking on her cellphone. The call was from EQC and she was arguing.

She had a complete breakdown. She'd had enough. I sat her down and gave her a cuddle and told her it was ok. (Mysar)

The woman started to apologise for her behaviour but I told her it could have been any one of us. We're all going through it. She said she felt so much better just knowing that. She lived alone with her daughter and grandson, I think. (Toast)

While the New Age store was a place of support for Toast and Myser's local RSF community, home as a building was Mysar's spiritual nexus that she struggled with losing when it was destroyed in the February 22 earthquake. Central to Pagan practise and belief is the connection to land, linking present day sacrality of life and the natural world with historical (and imagined) past, ancestors, and notions of belonging and community that extend beyond the living and the physical, empirical world. ${ }^{261}$ Therefore, one might have expected a connection to land, rather than building, to be more important to Mysar. This was not the case. For Mysar, the idea of moving into emergency housing meant being separated from her spiritual home.

To me, my land is my land. I mean that in a physical sense. Like to me my home is ... where I did all my Paganism. My altar and stuff was all there. Not outside. Now I'm in emergency housing I have to try and make do with what I've got. It's really hard... because the Pagan side of me is telling me that it doesn't matter; its land and its trees, but the Cancerian (astrological sign of Cancer) side of me is telling me well, really, I just wanna go back [home]! So, I'm getting conflicted and I'm having to just constantly tell myself to be patient, to just relax and its ok, and l've got all that I need. I've got the trees, l've got the air and l've got the sky....

Mysar told me that for her, she could not just 'pop up an altar and create sacred space anywhere' as some Pagans do. She needed to be at home. In many ways, Mysar's confliction with the theology of her faith-path mirrors that of the

\footnotetext{
${ }^{261}$ Jenny Butler, "Remembrance of the Ancestors in Contemporary Paganism: Lineage, Identity, and Cultural Belonging in the Irish Context," Journal of the Irish Society for the Academic Study of Religions 1, no.2 (2015): 95.
} 
aforementioned Inclusive-Progressive Presbyterian respondents. While theology may have argued for church as the people, as opposed to the building or site in which the people gather; members struggled emotionally and spiritually when faced with the reality of permanently vacating their place of worship. Pagan theology similarly dictates the land as deeply spiritual. However, for Mysar, home was a place of safe and ongoing spiritual practise.

On the other hand, Unicorn found her forced move from her urban eastern suburbs home to a new rural property, some distance from Christchurch city, spiritually beneficial.

It's been a huge thing for me; a huge spiritual shift. When I lived in town, in the suburbs, I used to hear people say Pagans can't really be Pagans in the city; they're too removed from nature. I would get really offended because I wasn't that removed from nature - I thought. But now I'm out here, I get it. I don't think [Pagans are] so much removed from nature as insulated. In town, to prepare for winter, you turn the heat-pumps on and put an extra blanket on the bed. Out here, we've got several months of preparation for winter. It makes you aware of, not just the cycle of the year, but also how that is reflected in your own body as well; your own natural cycle is more raw and exposed to the elements.

Unicorn said that moving to the new rural property, resulted in a new relationship with RSF that was more about 'being' rather than 'doing' spirituality. Similar to Morningstar and Snow White, Unicorn set aside earlier spiritual activity such as formalised ritual for more interiorised, organic RSF.

I love being out here and I love that spiritually, I don't feel like I need to be "doing". It's like I stopped doing "stuff". Spiritually, I just need to be. I actually have an altar for the first time in years. The most l've done with it is, l've actually dusted it (group laughs) - and ok, I'm not good with dusting at any point in time, but I haven't filled it with clutter, which is quite unusual for me. I have this [special] space that I have kept tidy. ...for me, that is quite huge.

For Unicorn, relocation to a new place meant RSF reconnection and a renewed sense of belonging rather than dislocation and loss. 


\subsection{A new whare}

Relocation and change meant new spaces of support, acceptance, belonging, and spiritual home for Castilian Blue. Reconnecting with her cultural and Maori spiritual heritage had been paramount to Castilian's process of healing and recovery from long term addiction and abuse, underpinning her sense of identity and place in the world. Yet, it was not until Castilian left her familial home on the rural coast, and moved to urban life in the eastern suburbs of Christchurch, that she found a new spiritual home in the form of the Spiritualist church and Catherine's trauma group. Here, Castilian found a place replete with much-needed friendship, fellowship, and belonging. The support Castilian Blue gained from the Spiritualist Church operated alongside the practical and secular support she received from counsellors, doctors, Otautahi Maori women's refuge and assistance for her special needs daughter.

So I drew upon a lot of support.

Consequently, Castilian began to 'reconnect' with life.

The Maori model of health, Te Whare Tapa Wha is based on the notion of the four walls of the whare, representing the spiritual, mental and emotional, physical, and familial aspects of self for personal and social wellbeing. ${ }^{262}$ 'Interdependence with whanau rather than independence from whanau' is argued as central to the individual's recovery journey to health and wellbeing. ${ }^{263}$ For Castilian Blue however, it was her new spiritual home and RSF "whanau" that were as equally integral to her social, mental, physical, spiritual, and familial success, as were traditional notions of family and wairua (spirituality). In this context, the Church is both "place" as a building and site of the people who gathered there, as well as a place where Castilian felt "held and safe."

It is possible that Castilian's adoption as an infant into a Pakeha family may have played a role in Castilian Blue's sense of belonging and place in a Pakeha-dominated Spiritualist RSF environment. Mutually, Castilian's aforementioned experience of rejection - noted in chapter three - from a Maori-dominated RSF context, due to her lack of knowledge regarding Maori spiritual protocol, may likewise have impacted heavily on Castilian's feelings of belonging, acceptance and fellowship in a group

\footnotetext{
${ }^{262}$ Central PHO (Central Primary Health Organisation). "Hauora Maori: Maori Model of Health: Te Whare Tapa Wha." (2010). http://www.centralpho.org.nz/hauora-maori ${ }^{263}$ lbid.
} 
where others had similarly experienced social, emotional, mental, and spiritual marginalisation and struggle in their own recovery processes.

\subsection{A new land}

Loss and new "home" was a common theme for several respondents. However, John and Awen's aforementioned active involvement with post-earthquake victims helped them to feel 'much more part of the community' and that they 'belonged'. The couple say the defining moment was the February 22 memorial service.

I think for the first time since we have been in New Zealand, we both turned to each other and said "we're kiwis". We forgot about being British. ...Because we had shared this experience [of the Canterbury earthquakes], we were New Zealanders. That was a huge thing for us and it actually made us decide to go for citizenship. Not turning our back on what we had gained from being British, but looking at this as our home now. This is where we will die. Where our ashes will remain or whatever. (Awen)

Bennett insists that the need to belong is still important to people. ${ }^{264}$ However, the idea of belonging is 'not one sided', she argues. ${ }^{265}$ 'In order to belong to anything, one has to be accepted, and become part of the "we" group'. ${ }^{266}$ Devout Pagans who had led their own Grove in the UK; severing links with their birth home would have meant disconnection with their spiritual home as well. Interestingly, John and Awen told me that they felt a deep 'spiritual loss' at the destruction of the Canterbury Cathedral in Christchurch. Not a part of the congregation, the couple attended midnight mass every Christmas. According to Harrington, personal experience of local stories connects people to places, including those for who place may be relatively recent, such as for new migrants. ${ }^{267}$ Place and belonging it seems, is important to many people, including those for whom RSF is important, even though how "place" manifests itself may not be tied to a building or specific land, or even one's cultural or spiritual origin.

\footnotetext{
264 Julia Margaret Bennett, "Doing Belonging: a sociological study of belonging in place as the outcome of social practices," PhD. Diss.. (University of Manchester, 2012): 38.

${ }^{265}$ Bennett, "Doing Belonging", 40.

${ }^{266} \mathrm{Ibid}, 40$.

${ }^{267}$ Harrington 309, 312.
} 


\subsection{Conclusion}

The concept of belonging and place is rarely associated with RSF and trauma, contrasting the symbolic centrality of loss of building, personal and spiritual home and land in the Canterbury earthquakes. Findings from the field uncovered similar contradictions. Protestant theology of Church as the people contrasted group values of place and building. Similarly, Pagan notions of connection to land challenged personal-emotional and spiritual attachment to man-made structures. On the other hand, loss in some cases resulted in spiritual reconnection and RSF enhancement or new experiences of belonging and acceptance, not always reflective of participant spiritual or cultural origins. The above examples demonstrate that, for those people for whom RSF matters, where individuals feel connected and experience a sense of belonging to a group or place, is equally as important in addressing the overwhelming and cumulative effects of trauma, as less tangible resources like prayer, ritual and making sense.

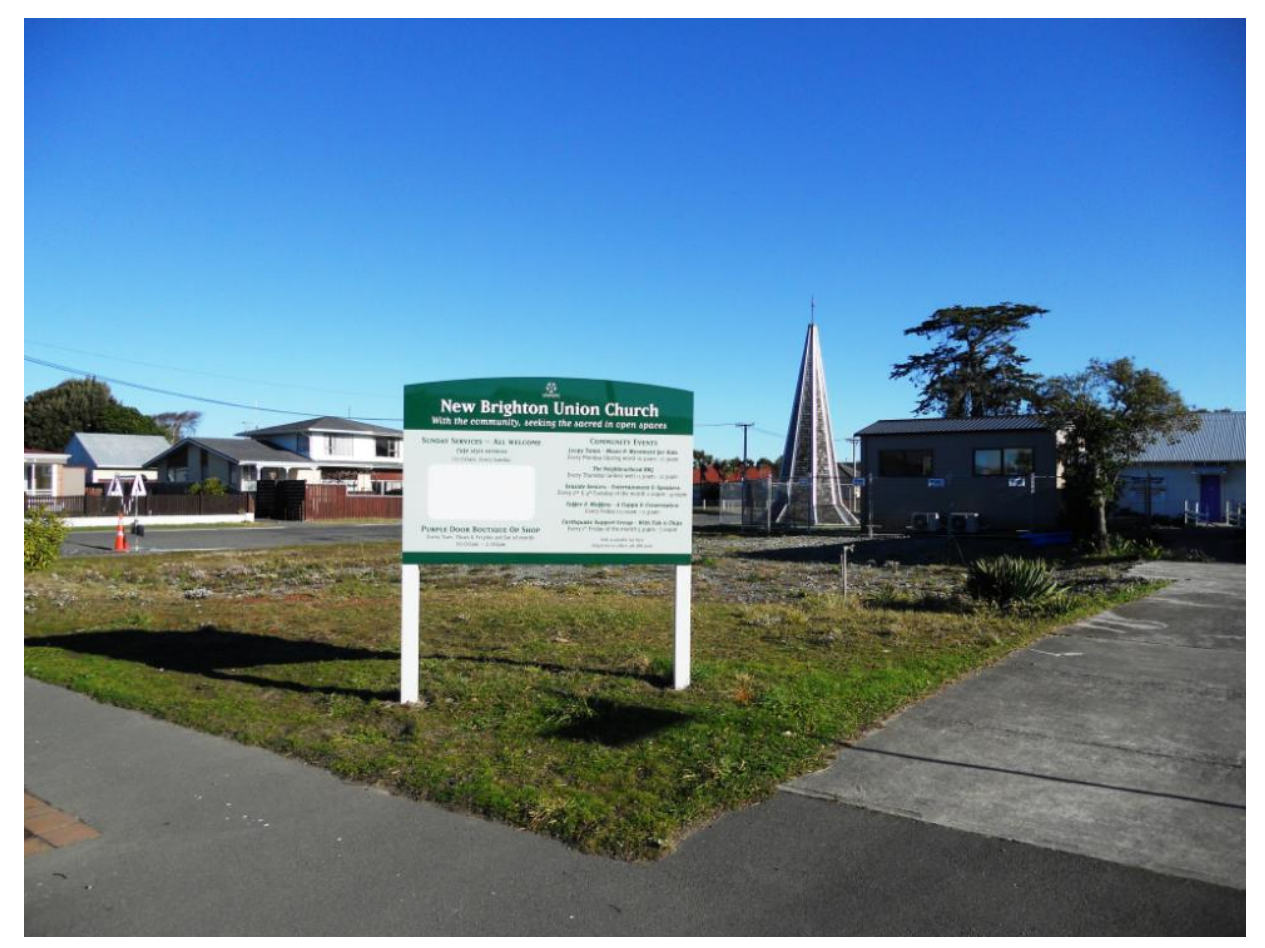

1.27: All that remains: church sign and steeple. 
P a g e | $\mathbf{1 2 8}$ 


\section{Section 3: Conclusion}

This thesis has argued that in times of crisis, some people draw on RSF to help them address difficult life challenges. This observation may appear somewhat simplistic. Yet by focusing on variant experiences of significant trauma, it has been possible to illuminate something of the breadth, diversity and significance of such resourcing, as well as the sometimes surprising, unanticipated forms that this engagement with RSF may take. My study is shaped by the hypotheses that religion is a lived experience, and that RSF is employed in ways that are often overlooked in discussions on religion and trauma. It demonstrates that in varying moments of crisis, people for whom RSF is important, may draw on diverse forms of RSF as a matter of priority to help them.

In the introduction to this thesis, I addressed Maslow's theory of needs, noting the way that it has influenced much subsequent thinking and scholarship in the study of trauma. In many ways, a key premise of this thesis was a challenge to the application of Maslow's theory of needs to the study of trauma in toto. Maslow's theory argued that in times of crisis, people abandon religion for more urgent concerns such as shelter, food, and safety. ${ }^{268}$ I have argued that application of Maslow's emphasis beyond the setting of crisis situations involving extreme human deprivation and hardship, the focus of his work, risks misreading the role of religion in trauma and high stress situations for those who experience it. In a sense, Maslow's hierarchy secularises need. This approach, however, may misunderstand both the identities and priorities of individuals for whom RSF matters, and matters deeply. To investigate this premise, I conducted fieldwork in post-earthquake Christchurch in 2012 and 2013. I chose respondent groups representing RSF formulations that have previously received limited attention in studies on religion and trauma, disaster and resilience, and on religion in New Zealand. My selection responded to calls in the literature on trauma for greater attention to religious forms other than those shaped by traditional Christian frameworks; as well as more New Zealand-specific enquiries. Trauma and religion researchers also wanted more studies that examined exactly how and in what ways people draw on religion during and following traumatic experience, from the perspective of the individuals themselves.

\footnotetext{
${ }^{268}$ Maslow, 373-4.
} 
Findings from the field highlighted that the way people employ RSF in crisis and recovery is wide-ranging, extensive and dynamic. Respondents deployed RSF in ways that were often unpredictable, surprising, and innovative. At times, their approaches were apparently inconsistent with their own professed beliefs or previous practises - or with those of their group or faith tradition. Moreover, RSF utilisation was often pragmatic and adaptable; changing according to the nature of participants' RSF or trauma, and to their perceived needs at any given time. This included forms of RSF that were useful for a limited period only, or that caused distress in some way.

In some situations the forms of RSF that respondents engaged with entrenched preexisting beliefs and practises; in others, those same practises or beliefs changed, occasionally quite dramatically. It was particularly noteworthy that during and in the wake of traumatic experience - and across the faith traditions - many people set aside old, scripted forms of RSF in favour of spontaneous, informal, intrinsic and experiential RSF practise models. Although widespread among participants, the shift to intrinsic RSF was more salient for those respondents suffering intense, overwhelming and cumulative significant trauma.

A significant and consistently-reported dimension of the intrinsic RSF experience was a respondent sense that they were not alone in their struggles; that the individual was supported by Deity or the Spiritworld to address their situations, leading to a positive outcome. Again, intrinsic RSF experience, practise and belief, did not always reflect respondents' faith traditions of origin.

In some situations, the way people drew on RSF to help them conflicted with established teachings, creating a tension between theology, tradition and experience. In others, evidence suggested that whether an individual or group enlisted specific RSF resources had more to do with personality than theological underpinnings. Nevertheless, the fact that certain respondents did not draw on their traditional RSF at certain times of need - despite their professed commitment - did partly uphold Maslow's assertion that people set aside RSF in moments of crisis. Yet even these participants were often found to draw spontaneously on other RSF types. 
It is important not to overstate the findings identified in this study. My thesis does not deal with Maslow-type situations. Many of the trauma experiences I addressed are either significantly less extreme, or drawn out over longer durations than those envisaged in Maslow's model. They are representative of the everyday extraordinary life stressors that Drescher and Foy point out will affect at least half of us during our lifetime. ${ }^{269}$ Moreover, this study is driven more by practise than theory, with experiences interpreted subjectively, rather than scientifically. The emphasis is on how RSF functions in people's everyday lives and shapes their experiences, according to respondent perspective - rather than the perspective of clinicians, religious scholars or mental health theorists. Annie-Bell demonstrates why RSF matters in trauma recovery experience and why the respondent voice needs to be included as evidence in such studies:

When you go through trauma with grief, it's kind of like survivor's grief and then you have to really focus each moment of each day on your own survival because when you go down that slippery slope, [it feels like] the only way that your grief is going to pass at that time, is if you're no longer living. Then you have to work on your spirituality to help you through. But to get there - we don't think about survival as an actual thing.

In some respects, the present thesis is merely a small beginning. There is more that can still be done. Respondents in this study are a micro-representation of the traditional and non-orthodox faith paths that are currently marginalised in discussions of New Zealand religion in general, and also on trauma, resilience and disaster. My study is shaped by notable constraints, and does not claim that its findings are necessarily generalisable to a wider group. My respondents were mainly women, and the experiences they describe reflect this weighting. It is also likely that my position as an insider-outsider researcher impacted how material was gathered, interpreted and presented. An increase in the number of male respondents, an enhanced etic or different theoretical analysis - for example, analysis grounded explicitly in feminist theory - could yield different or contrasting insights.

Nevertheless, this thesis presents fresh insights into the role of RSF in experiences of trauma, and makes a distinctive contribution to the study of religion in New Zealand more generally. It addresses the experiences of certain groups - including 
various forms of Pagan, Spiritualist and Progressive Christian RSF - that have received scant attention in the literature to date. The thesis provides new insights into these faith paths. Additionally, it highlights the porous boundaries that often exist between supposed 'traditions' in the context of 'lived religion', complicating understandings of the ways that RSF actually functions.

The faith paths and processes identified here need to be better understood. Despite being told that my field exploration in 2012 was 'too soon', one of my respondents, George thanked me for allowing people to share their RSF stories. 'No one ever wants to hear this stuff', he said. Clearly, more stories need to be told of ordinary people living ordinary lives, sometimes dealing with extraordinary situations, like significant trauma, and for whom RSF is important.

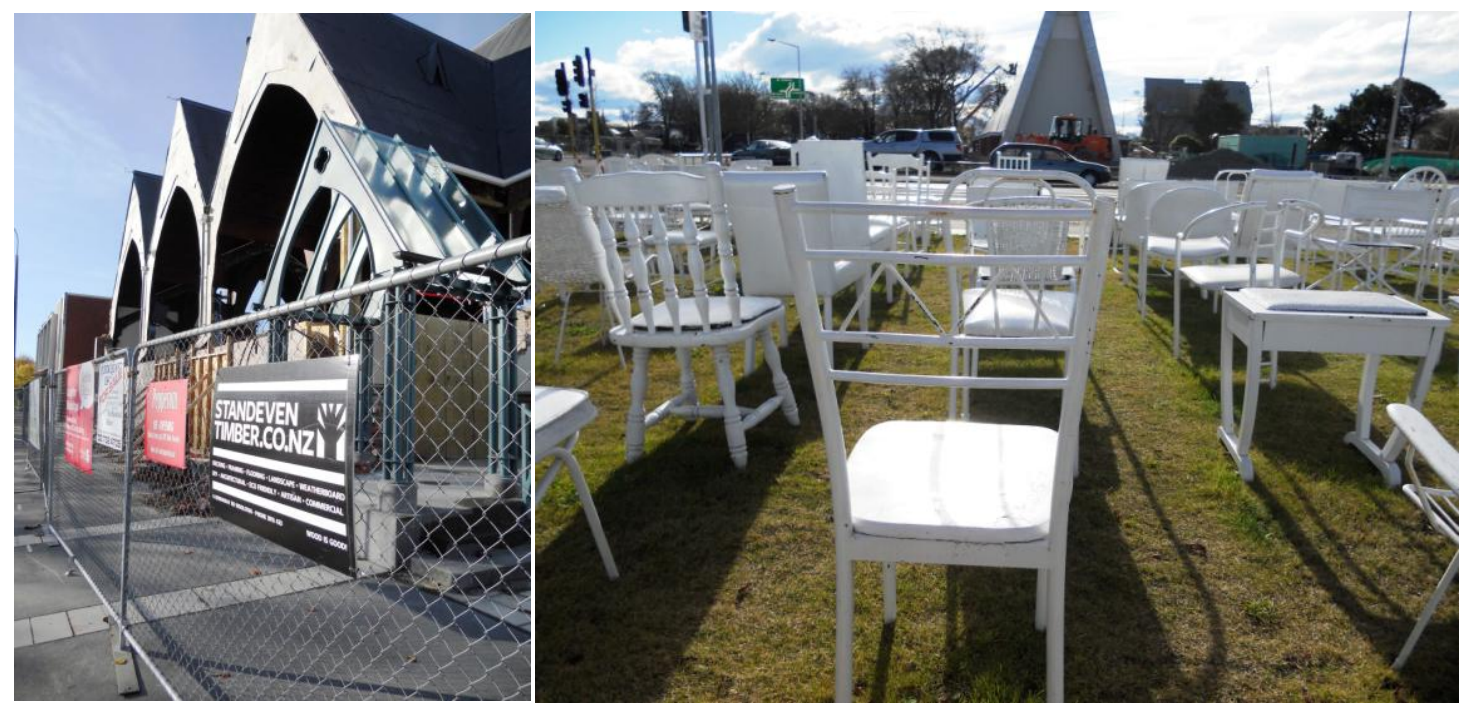

1.28: Left to Rt: Knox Presbyterian, 185 Chairs 


\section{Bibliography}

Abrahams, Hilary. Rebuilding Lives after Domestic Violence: Understanding LongTerm Outcomes. USA: Jessica Kingsley Publishers, 2010.

AddictionCenter "12-Step Programs" https://www.addictioncenter.com/treatment/12step-programs/

Allport, Gordon W. The Individual and His Religion: A Classic Study of the Function of Religious Sentiment in the Personality of the Individual. New York: The MacMillian Company, 1950.

Ammerman, Nancy Tatom. "Sacred Stories, Spiritual Tribes: Finding Religion in Everyday Life." Oxford Scholarship online (2013)

Aten, Jamie D, and Donald F. Walker. "Future Directions for the Study and Application of Religion, Spirituality and Trauma Research." Journal of Psychology and Theology 40, no. 4 (2012): 349-53.

Attridge, Harold W. The Harper Collins Study Bible: New Revised Standard Version. USA: HarperOne,1989.

Banziger, Sarah, Jacques Janssen, and Peer Scheepers. "Praying in a Secularized Society: An Empirical Study of Praying Practices and Varieties". The International Journal for the Psychology of Religion, 18 (2008): 256-265.

Bartowski, John P. Gabriel A. Acevedo and Harriet Van Loggerenberg. "Prayer, Meditation and Anxiety: Durkheim Revisited." Religions 8, no. 191 (2017) doi:10.3390/rel8090191

Bayer, Kurt. "Cantabrians still struggling to cope with quake effects - research." nzherald.co.nz. 17 June 2014 https://www.nzherald.co.nz/nz/news/article.cfm?c_id=1\&objectid=11275709

Bell, Catherine. Ritual: Perspectives and Dimensions. New York: Oxford University Press, 2009.

. Ritual Theory, Ritual Practise. New York: Oxford University Press, 1992.

Bennett, Julia Margaret. "Doing Belonging: a sociological study of belonging in place as the outcome of social practices." PhD. Diss.. University of Manchester, 2012.

Blum, Harold. "Psychic Trauma and Traumatic Object Loss". Journal of the American Psychoanalytic Association 51 (2003): 415-431.

Bowie, Fiona The Anthropology of Religion: An Introduction. Oxford, UK: Blackwell Publishing, 2006. 
Breen, Lauren J. "The Researcher 'In the Middle': Negotiating the Insider/Outsider Dichotomy". The Australian Community Psychologist. 19, no. 1 (2007): 163174.

Brown, Delwin. What Does a Progressive Christian Believe? A Guide for the Searching, the Open, and the Curious. New York, New York: Church Publishing Incorporated, 2008.

Thomas Kingsley Brown "Religious Seekers and Finding a Spiritual Home: An Ethnographic study of conversion to Christian Spiritualist Churches in Southern California" Phd Diss., University of California, San Diego, 2000.

Buehrens, John A. and Rebecca Ann Parker. A House for Hope: The promise of Progressive Religion for the Twenty-First Century. Boston: Beacon Press, 2010.

Butler, Jenny. "Remembrance of the Ancestors in Contemporary Paganism: Lineage, Identity, and Cultural Belonging in the Irish Context." Journal of the Irish Society for the Academic Study of Religions 1, no.2 (2015): 94-118.

Carville, Olivia. "Forgotten Victims: The Hidden Toll of the Christchurch Earthquakes." nzherald.co.nz 18 April 2016 http://www.nzherald.co.nz/nz/news/article.cfm?c id=1\&objectid=11622371

Castel, Bronwyn. "Missing Pieces: Understanding the Influence of Client's Religious and Spiritual Beliefs within the Frame of Cognitive Case Conceptualisation." Phd diss., Massey University, New Zealand, 2013.

Central PHO (Central Primary Health Organisation). "Hauora Maori: Maori Model of Health: Te Whare Tapa Wha." (2010). http://www.centralpho.org.nz/hauoramaori

Child, Louise. "Mantras and Spells: Durkheim and Mauss, Religious Speech and Tantric Buddhism". New Series, 9 (2003): 58-67

Culbertson, Philip. "The Shadow of the Transcendent: Valuing Spirituality in Psychotherapy". The Journal of the New Zealand Association of Psychotherapists, 4 (1998): 14-37.

Cunningham, Scott. Living Wicca: A Further Guide for the Solitary Practitioner. USA: Llewellyn Publications, 1999.

De Swarte, Rev Lyn Guest. The Spiritualists' Handbook: A Concise and Extensive Guide to Spiritualism and All It's Practises. USA: The New Spiritualist's Society, 2017. 
Drescher, Kent. and David W. Foy. "When Horror and Loss Intersect: Traumatic Experiences and Traumatic Bereavement". Pastoral Psychol, 59 (2010): 147158.

Ellwood, Robert S. Islands of the Dawn: The Story of Alternative Spirituality in New Zealand. Honolulu: University of Hawaii Pres, 1993.

Ferraro, Gary. Cultural Anthropology: An Applied Perspective. Belmont, CA: Thomson/Wadsworth, 2008.

Fox, Selena. "Pagan Rituals." Circle Sanctuary.

https://www.circlesanctuary.org/index.php/circle-magazine/samplearticles/pagan-rituals

Gall, Terry Lynn, Claire Charbonneau, Neil Henry Clarke, Karen Grant, Anjali Joseph, and Lisa Shouldice. "Understanding the Nature and Role of Spirituality in Relation to Coping and Health: A Conceptual Framework." Canadian Psychology 46, no. 2 (2005): 88-104.

GeoNet, "M7.1, Darfield (Canterbury), 4 September 2010", EQC and GNS Science, http://info.geonet.org.nz/display/quake/M+7.1,+Darfield+(Canterbury),+4+Sept ember+2010

Geertz, Clifford. The Interpretation of Cultures. New York, NY: Basic Books, 1973.

Gleig, Ann. "Researching New Religious Movements from the Inside Out and the Outside in: Methodological Reflections for Collaborative and Participatory Perspectives." Nov Religio: The Journal of Alternative and Emergent Religions 16, no. 1 (2012): 88-103

Gozdziak, Elzbieta M. "Spiritual Emergency Room: The Role of Spirituality and Religion in the Resettlement of Kosovar Albanians ". Journal of Refugee Studies 15, no. 2 (2002): 136-52.

Hampton, Linda E. Wise Women: New Zealand Women's Alternative Spirituality \& History. Leeston, Cant'y, NZ: Linda Hampton, 2013.

Harrington, Jane Therese. 'Being here': Heritage, Belonging and Place Making: A Study of Community and Identity Formation at Avebury (England), Magnetic Island (Australia) and Ayutthaya (Thailand). PhD thesis, James Cook University. (2004).

Harris, Adrian. "Sacred Ecology." In Pagan Pathways: A Guide to the Ancient Earth Traditions, by Harvey Graham and Charlotte Hardman, 149-156. London: Thorsons, 2000. 
Harris, David Alan. "The Paradox of Expressing Speechless Terror: Ritual Liminality in the Creative Arts Therapies' Treatment of Posttraumatic Distress." The Arts in Psychotherapy 36. No. 2 (2009): 94-104.

Harvey, Graham and Charlotte Hardman. Pagan Pathways: A Guide to Ancient Earth Traditions. London: Thorsons, 1996.

Herman, J. L Trauma and Recovery, Third Edition. New York: Pandora Press, 2001. ."Recovery from Psychological Trauma", Psychiatry and Clinical Neurosciences 52, no. S1 (1998) https://doi.org/10.1046/j.14401819.1998.0520s5S145.x

Herman, Helen; Donna E Stewart, Natalia Diaz-Grandos, Elena L Berger, Beth Jackson, and Tracey Yuen, "What is Resilience?", Canadian Journal of Psychiatry 56, no.5 (2011): 258-265.

Holl, Rita M. "What is Prayer?" Alternative Health Practitioner 4, No. 2 (1998): 109114.

Hume, Lynne. "Creating Sacred Space: Outer Expressions of Inner Worlds in Modern Wicca. Journal of Contemporary Religion 13, no.3 (1998): 309-319.

Hurst, Hollye. "A Narrative Study of Contemporary Ritual and the Revitalisation of the Spiritual Imagination." PhD diss., Institute of Integral Studies, San Francisco, California, 1995.

Kaldenberg, Wyatt. Perceived Heathenism \& Odinic Prayer: A Book of Heathen prayer and Direct Contact with Our Living Gods. USA, Wyatt Kaldenberg, 2011.

Knox Church. "History." Knox Church Presbyterian Church 2012-2014. http://www.knoxchurch.co.nz/history.html

Koenig, Harold G. and David B. Larson. "Religion and Mental Health: Evidence for an Association." International Review of Psychiatry 13 (2001): 67-78.

Korn, Leslie E. Rhythms of Recovery: Trauma, Nature and the Body. New York, Routledge, 2013.

Krause, Neal. "Lifetime Trauma, Prayer, and Psychological Distress In Late Life". The International Journal for the Psychology of Religion. 19, no.1 (2009): 5572

Kroeze, Jan H. "Postmodernism, Interpretivism and Formal Ontologies." In Research Methodologies, Innovations and Philosophies in Software Systems Engineering and Information Systems edited by Manuel Mora, Ovsei Gelman, 
Annette Steenkamp and Mahesh S. Raisingham. pp43-62. USA: IGI Global, 2012.

Kuiper, Nicholas A. "Humor and Resiliency: Towards a Process Model of Coping and Growth." Europe's Journal of Psychology 8, no. 3 (2012): 475-491.

Lawson, Erma J. and Cecelia Thomas. "Wading in the Waters: Spirituality and Older Black Katrina Survivors ." Journal of Health Care for the Poor and Underserved 18 (2007): 341-54.

Luhrmann, T.M. "Lord, Teach Us to Pray: Prayer Practice Affects Cognitive Processing." Journal of Cognition and Culture 13 (2013): 159-177.

Magliocco, Sabina. "Reclamation, Appropriation and the Ecstatic Imagination in Modern Pagan Ritual" In Handbook of Contemporary Paganism edited by Murphy Pizza and James R. Lewis. Leiden: Brill Academic, 2009: 223-240. Majendie, Pete. "Christchurch, 185 Chairs: In Remembrance". http://www.sidedoor.org.nz/files/03_Christchurch-185Chairs-Draft_R005.pdf: $1-11$

Malefijt, Annemarie de Waal. Religion and Culture: An Introduction to Anthropology of Religion. USA: Waveland Press Inc, 1968.

Maltby, John and Liza Day. "Religious Experience, Religious Orientation and Schizotypy." Mental Health, Religion and Culture 5, no.2. (2002): 163-174.

Marti, Gerardo. "Present and Future Scholarship in the Sociology of Religion." Sociology of Religion 75 no.4 (2014): 504-506

Maslow, Arthur H. "A Theory of Human Motivation." Psychological Review 50 (1943): 370-396.

Mattis, Jacqueline, S. "Religion and Spirituality in the Meaning-Making and Coping Experiences of African American Women: A Qualitative Analysis." Psychology of Women Quarterly 26 (2002): 309-321.

McCann, Lisa and Laurie Anne Pearlman. Psychological Trauma and the Adult Survivor: Theory, Therapy and Transformation. London \& New York: BrunnerRoutledge, 1990.

McDonald, Julie. "Contemporary Ritual-makers: A Study of Indepent Celebrants in New Zealand." PhD Doctor of Philosophy, Massey University, New Zealand, 2011.

McFarlane, Alexander C. "The Long-Term Costs of Traumatic Stress: Intertwined Physical and Pyschological Consequenes." World Psychiatry 2010, 9: 3-10. 
McGee, R. Jon and Richard L. Warms. Anthropological Theory: An Introductory History, Fourth Edition. New York: McGraw-Hill, 2008.

McGee, La Dorna. "Participation, Identity, and Social Support in a Spiritual Community." Master of Arts, Sociology, University of Texas, Arlington, 2005.

McGuire, Meredith B. Lived Religion: Faith and Practice in Everyday Life. Oxford, New York: Oxford University Press, 2008.

Melton, John Gordon. Encyclopaedia Britannica 2018

https://www.britannica.com/topic/spiritualism-religion

Miller, Linda Mayorga, Terry Lynn Gall and Lise Corbeil. "The Experience of Prayer Wit a Sacred Object Within the Context of Significant Life Stress". Journal of Spirituality in Mental Health, 13 (2011): 247-271.

New Zealand Herald. "Christchurch hit with more than 10,000 quakes since 2011."

https://www.nzherald.co.nz/nz/news/article.cfm?c id=1\&objectid=11593554

New Zealand History, Nga korero a ipurangi o Aotearoa, "Christchurch earthquake kills 185". (Ministry for Culture and Heritage)

http://www.nzhistory.net.nz/page/christchurch-earthquake-kills-185

Mitchell, Jerry T. "Prayer in Disaster: Case Study of Christian Clergy". Natural Hazards Review 4, No.1 (2003): 20-26.

Naidu, Maheshvari. "Displaced Sense: Displacement, Religion and Sense-making", Journal for the Study of Religion 29, No. 1 (2016): 104-126.

Natural Hazards Centre, University of Colorado, Boulder. "A Creative Rebirth: Public Art and Community Recovery in Christchurch." (2015). https://hazards.colorado.edu/article/a-creative-rebirth-public-art-andcommunity-recovery-in-christchurch

Oldani, Michael. "Postmodernism and Anthropology: Conflict or Cooperation?" Kroener Anthropological Society Papers 83 (1998): 83-101.

Otago Daily Times. "11,000 Aftershocks since Christchurch Quake." https://www.odt.co.nz/news/national/11000-aftershocks-christchurch-quake

Paintner, Christine Valters. "Radical Hospitality and Holy Disruption," Patheos (September 30 2012) http://www.patheos.com/progressive-christian/radicalhospitality-christine-valters-paintner-10-02-2012

Parappully, Jose, Robert Rosenbaum, Leland van den Daele and Esther Nzei. "Thriving after Trauma: The Experience of Parents of Murdered Children". Journal of Humanistic Psychology 42 (2002): 33-70. 
Park, Crystal L. and Susan Folkman. "Meaning in the Context of Stress and Coping". Review of General Psychology 1, No.2 (1997): 115-144.

Parsons, Melissa. Rubble to Resurrection: Churches Respond in the Canterbury Quakes. Mairangi Bay, Auckland: DayStar Books Ltd, 2014.

Pearson, Joanne. Belief Beyond Boundaries: Wicca, Celtic Spirituality and New Age. Burlington, USA: Ashgate Publishing Ltd, 2002.

Peres, Julio F.P, Alexander Moreira Almeida, Antonia Gladys Nasello, and Harold G. Keonig. "Spirituality and Resilience in Trauma Victims." Journal Religion and Health 46 (2007): 343-350.

Pickering, W.S.F, ed. Marcel Mauss On Prayer. New York, Oxford: Durkheim Press/Berghahn Books, 2003.

Potter S.H; J.S. Becker, D.M. Johnston, and K.P. Rossiter, "An overview of the impacts of the 2010-2011 Canterbury earthquakes", International Journal of Disaster Risk Reduction 14 (2015): 6-14.

Renn, Aaron M. "Erasing Distinctions: Eight Protestant Trends", The Institute for SacredArchitecture

http://www.sacredarchitecture.org/articles/erasing distinctions

Rountree, Kathryn. Embracing the Witch and the Goddess: Feminist Ritualmakers in New Zealand. London and New York: Routledge, 2004.

Rowney, Casey. Pantea Farrid, and Chris Sibley. "'I laugh and say I have 'Earthquake Brain!': Resident Responses to the September 2010 Christchurch Earthquake." New Zealand Journal of Psychology. 43, no.2 (2014): 4-13.

Schweitzer, Robert; Jaimi H.Greenslade and Ashraf Kagee. "Coping and Resilience in Refugees from the Sudan: A Narrative Account." Australian and New Zealand Journal of Psychiatry 41, no. 3 (2007): 282-88.

Sewell, Marilyn. "Radical Hospitality," Unitarian Universalist Association (1996-2018) https://www.uua.org/worship/words/sermon/radical-hospitality

Shumaker, Sally A. and Arlene Brownell. "Toward a Theory of Social Support: Closing Conceptual Gaps." Journal of Social Issues 40, no. 4 (1984): 11-36.

Sibley, Chris G, and Joseph Bulbulia. "Faith after an Earthquake: A Longitudinal Study of Religion and Perceived Health before and after the 2011 Christchurch New Zealand Earthquake." PLos ONE 7, no. 12 (2012): e49648. 
Silton, Nava R, Kevin J. Flannelly, Kathlessn Galek and David Fleenor. "Pray Tell: The Who, What, Why, and How of Prayer Across Multiple Faiths. Pastoral Psychol 62 (2013): 41-52.

Small, Jamie. "Artist calls for 185 white chairs to become permanent memorial to Canterbury earthquake." The Press. Stuff.co.nz https://www.stuff.co.nz/thepress/business/the-rebuild/88687177/call-for-185-white-chairs-to-become-

\section{permanent-memorial-to-canterbury-earthquake}

Stringer, M.D. Contemporary Western Ethnography and the Definition of Religion. London \& New York: Continuum International Publishing Group, 2008.

Taussig, Hal. A New Spiritual Home: Progressive Christianity at the Grass Roots. USA: Polebridge Press, 2006.

Tamasese, Kiwi; Carmel Peteru, Charles Waldegrave, and Allister Bush. "Ole Taeao Afua, The New Morning: A Qualitative Investigation into Samoan Perspectives on Mental Heath and Culturally Appropriate Services." Australian and New Zealand Journal of Psychiatry 39 (2005): 300-309.

Thornley, Louise, Jude Ball, Louise Signal, Keri Lawson-Te Aho, Emma Rawson. "Building Community Resilience: Learning from the Canterbury earthquakes." Final Report to Health Research Council and Canterbury Medical Research Foundation. (2013):1-153

Tudor, Raewyn, Jane Maidment, Ada Campbell, and Karen Whittaker. "Examining the Role of Craft in Post-Earthquake Recovery: Implications for Social Work Practise." British Journal of Social Work 45, No.1 (2015).

Tse, Samson; Chris Lloyd, Leon Petchkovsky and Wiremu Manaia. "Exploration of Australian and New Zealand Indigenous People's Spirituality and Mental Health." Australian Occupational Therapy Journal 52 (2005): 181-187.

Turner, Victor. The Ritual Process: Structure and Anti-Structure. Ithaca, New York: Cornell Paperbacks, Cornell University Press, 1991.

Vandermark, Lisa M. "Promoting the Sense of Self, Place, and Belonging in Displaced Persons: The Example of Homelessness. Archives of Psychiatric Nursing 21, no.5 (2007): 241-248.

Viccarino, Franco. Heather Kavan and Philip Gendall. "Spirituality and Religion in the Lives of New Zealanders." The International Journal of Religion and Spirituality 1, no.2 (2011): 85-96.

Walker, Courtouis, and Aten. Spiritually Oriented Psychotherapy for Trauma. Washington: American Psychological Association, 2015. 
Wallace, Dale. "Pagans at the Parliament." Agenda, No.61, Religion and Spirituality, 2004: 80-84.

Wallace, William L. Progressive Christianity.Org: Spiritual Networking and Resources for an Evolving Faith. Worship Materials: Eurcharistic Resources From the Celebrating Mystery Collection (11 September 2015). https://progressivechristianity.org/resources/worship-materials-eucharisticresources/

Walsh, M. Violent Trauma, Culture, and Power. Palgrave Studies in Lived Religion and Societal Challenges. Cham: Palgrave Macmillian, 2017.

Washington, Olivia G. M., David P. Moxley, Lois Garriott, and Jennifer P. Weinberger. "Five Dimensions of Faith and Spiritually of Older African American Women Transitioning out of Homelessness." Journal of Religion and Health 48, no. 4 (2009): 431-44.

Wilson, Julie T and Boden, Joseph M. "The Effects of Personality, Social Support and Religiosity of Posttraumatic Growth." The Australasian Journal of Disaster and Trauma Studies 1 (2008)

https://www.massey.ac.nz/ trauma/issues/2008-1/wilson.htm

York, Michael. 2003. Pagan Theology: Paganism as a World Religion New York and London: New York University.

Yuen, Angel. "Less Pain, More Gain: Explorations of Responses versus Effects when Working with the Consequences of Trauma." Explorations: An E-Journal of Narrative Practice 1 (2009): 6-16.

Zwissler, Laurel. "Second Nature: Contemprary Pagan Ritual Borrowing in Progressive Christian Communities." Canadian Woman Studies 29, no. 1/2: 16-23. 